\title{
Hybrid Alkyds, the glowing route to reach cutting-edge properties?
}

Fabien Chardon, Maxinne Denis, Claire Negrell, Sylvain Caillol*

\section{Abstract}

This review highlights both the various polymers grafted to alkyd resins reported in the literature and the different routes to synthesize these alkyd hybrids. Alkyd resins were discovered in the mid-1920s. Then, they quickly found a prominent place among coatings and paint binders thanks to their numerous advantages such as good heat resistance, excellent gloss, and low cost. Nevertheless, in the 50s, the emergence of new synthetic polymers with better properties (chemical resistance, mechanical and thermal properties) such as epoxy, acrylic or polyurethane, weakened the position of the alkyd resins among coating industry. Nowadays, due to global issues such as health and environmental concerns, research focuses on biobased polymers. Since, alkyd resins are mainly biobased, they have gained increasing attention in the last decade. Nevertheless, the issue of using volatile organic compounds (VOC) and the urge of replacing them, have led to the development of new synthetic routes. Moreover, in order to enhance alkyd properties and bridge the gap with new materials, other polymers such as epoxy, acrylates, polyurethanes or siloxanes were used to form alkyd hybrids. Hence, the different strategies to perform alkyd hybrids are detailed and discussed in this review. Furthermore, composites made with alkyd hybrid matrix are presented. Finally, the perspectives about the future developments of alkyd hybrids and the most promising hybrids are discussed.

\section{Keywords}

Alkyd; acrylate; epoxy; polyurethane; hybrid; coating; emulsion

\section{Abbreviations}

AA: Acrylic acid

AAPTMS: Aminosilane, [3-(2-aminoethylamino)propyl]trimethoxysilane

AIBN: 2,2'-Azobis(2-methylpropionitrile) 
APTMS : 3-amino propyltrimethoxysilane

ATBS: Acrylamido tertiary-butyl sulfonic acid

ATRP: Atom Transfer Radical Polymerization

BA: Butyl acrylate

BMA: Butyl methacrylate

BPA: Bisphenol A

BPO: Benzoyl peroxide

CC-AR: Cyclic carbonate alkyd resin

CHDA: 1,4-cyclohexanedicarboxaldehyde

CuO: Copper oxide

CMR: Carcinogenic, mutagenic and reprotoxic

DFF: 2,5-diformylfuran

DGEBA: Diglycidyl ether of bisphenol A

EG: Expanded graphite

EHA: 2-Ethylhexyl acrylate

FA: Fumaric acid

FMA: Dodecafluoroheptyl methacrylate

GMA: Glycidyl methacrylate

GO: Graphene oxide

G-POSS: 3-Glycidyloxypropyl-POSS

$\mathrm{H}_{2} \mathrm{O}_{2}$ : Hydrogen peroxide

$\mathrm{HCl}$ : Hydrogen chloride

HEMA: Hydroxyl ethyl methacrylate

HMDI: Hexamethylene diisocyanate

HMMM: Hexamethoxymethyl melamine

IPDA: Isophorone diamine

IPDI: Isophorone diisocyanate

IPNs: Interpenetrating polymer networks

JCO: Jatropha curcas oil

$\mathrm{KOH}$ : Potassium hydroxide

MA : Methyl acrylate

MAA: Methacrylic acid

MDI: 4,4-methylenediphenyl diisocyanate

MEKP: Methyl-ethyl ketone peroxide

MMA: Methyl methacrylate

MPS: -methacryloxypropyltrimethoxysilane

$\mathrm{NaCl}$ : Sodium chloride

NiO: Nickel oxide

NIPU: Non-Isocyanate PolyUrethane

NMR: Nuclear magnetic resonance

PAU: Poly(alkyd-urethane)

PBMA: Poly(butyl methacrylate)

PET: Poly(ethylene terephthalate)

RAFT: Reversible addition-fragmentation chain transfer polymerization 
REACH: Registration, Evaluation, Authorization and Restriction of Chemicals

SA: Stearyl acrylate

SAM: Silicone acrylate monomer

SARS-CoV-2: Severe acute respiratory syndrome coronavirus 2

SDS: Sodium dodecyl sulfate

SEM: Scanning electron microscopy

$\mathrm{SiO}_{2}$ : Silicon dioxide

SOFA: Soybean oil fatty acid

$\mathrm{T}_{\mathrm{g}}$ : Glass transition temperature

TDI: Toluene diisocyanate

$\mathrm{TiO}_{2}$ : Titanium dioxide

TMP: Trimethylolpropane

TOFA: Tall oil fatty acid

UV: Ultraviolet

VOC: Volatile organic compound

ZnO: Zinc oxide

\section{Introduction}

In the mid-1920s, polyesters modified with unsaturated fatty acids, named alkyd resins, were polymerized for the first time by Kienle. ${ }^{1-4}$ Alkyd resins have been used mainly as coatings or binders in paints since the 1930s thanks to their numerous advantages over other resins, such as good heat resistance, excellent gloss, and low cost. ${ }^{1,5-7}$ The commercial production began in 1933 at General Electric and then, was followed by other companies. ${ }^{1,4,8}$ Indeed, commercial success of the alkyd resins has been supported by their great properties which can be modified by changing the oil length, and their compatibility with a number of polymers which makes them very versatile polymers to produce a broad range of coating materials for numerous applications. ${ }^{1}$ However, in the 1950s, the emergence of emulsion polymerization technology driven by acrylic and vinyl polymers made it possible to produce water-based paints which captured the majority of the coatings market. ${ }^{9}$ Indeed, waterbased coatings are easier to clean and more economic to produce. Moreover, the introduction and development of synthetic polymers and resins, especially acrylic, for the coating industry considerably weakened the position of the alkyd resins. ${ }^{1,4}$ Nevertheless, in the 1980s, due to environmental concerns, a new push in research on alkyd resins started. Indeed alkyd resins are mainly composed of biobased raw materials. However, alkyd resins have traditionally been diluted in organic solvents such as xylene or white spirit, derived from petroleum resources. ${ }^{3,10}$ Those organic solvents used in paint or ink formulations are 
volatile and can be released in the atmosphere. Hence they are defined as volatile organic compounds (VOC). ${ }^{11,12}$ Their use is limited by European regulations to avoid harmful environmental impact, such as air pollution. ${ }^{1,8,13}$ Therefore many research studies have been focused on the development of water-based alkyd coatings, in order to formulate zero VOC paints. $^{1}$

Unfortunately, these water-based alkyd coatings have not achieved the same performances as solvent-based alkyd coatings. ${ }^{1,9}$ Indeed, the resulting coatings provided undesirable yellowing effect and the drying time was too long. Moreover, alkyd resins suffer from poor chemical resistance and low hardness. ${ }^{7,14}$ In fact, alkyd coatings are no longer sufficient on their own to meet both environmental challenges and property requirements. Thus, alkyd resins are blended or chemically modified with other polymers in order to obtain hybrid polymers that combine the best properties of both polymers. Hence, a hybrid polymer is composed at least of two kinds of polymers which can be bonded by chemical covalent bonds or strong physical intermolecular interactions. ${ }^{15}$ Depending on their applications, coatings require different properties, thus alkyd resins can be mixed with numerous polymers in order to cover a broad range of coatings. Indeed, for interior applications a low amount of VOC is needed whereas for exterior applications water and ultraviolet (UV) light resistances are mostly required. ${ }^{7}$ Common examples of hybrid alkyds include acrylic-alkyd, urethane-alkyd, epoxy-alkyd, silicone-alkyd, and amide-alkyd. ${ }^{1,4}$ One of the first alkyd hybrid system was the synthesis of silicone-alkyd resin reported in $1947 .{ }^{16}$ Modifying alkyd resins with polyamide resins affect viscosity and yield thixotropic alkyd resins. ${ }^{2}$ To improve drying time of alkyd resins, exhibit better abrasion resistance, toughness, chemical and UV resistance, hybridization with urethane has been developed. ${ }^{10,17}$ Blends between alkyds and epoxy resins enhanced properties in terms of morphology, viscosity, adhesion, pendulum hardness and impact strength. ${ }^{10}$ The drying time for alkyd emulsion is long but it could be improved by adding acrylic latexes. ${ }^{18,19}$ Acrylic-alkyd hybrid systems represented a promising approach for combining the best properties of both alkyds and acrylics in a low VOC waterbased system. ${ }^{20}$ Silicone compounds conferred hydrophobicity to silicone-alkyd coatings, providing anticorrosion properties, useful for metal surfaces.

More and more researchers and industrial companies are focusing on alkyd hybrid polymers but to our knowledge there is not yet any review on the alkyd hybrid polymers used for coatings and their various properties owing to different kinds of polymers. Hence, the aim of 
this original review is to present various hybrid-alkyds coatings, their synthesis conditions and the relationships between additional polymers and final properties of the coatings. In the first section, the synthesis of traditional alkyd resins and their performance is reported. The following section is devoted to the formation of epoxy-alkyd resins and the coatings properties. The third section is dedicated to the study of acrylic-alkyd coatings, and then in the next section urethane-alkyd are described. The following section presents the formation and properties of silicone-alkyd coatings. The next section provide information about thixotropic properties brought by amide-alkyd resins. Then, the influence on the properties of introducing particles into alkyd hybrids to form composite is discussed in the following part. Finally, the last part is devoted to the presentation of the perspectives. This review is mainly focused on covalent alkyd-hybrids, hence alkyds blended with other polymers without covalent bonds will not be discussed.

\section{Alkyd resins}

Alkyd resins are polymerized from three different kinds of monomers: polyols, polyacids and vegetable oils or fatty acids. ${ }^{2,4,5,21}$ Those starting materials are mainly based on renewable resources. ${ }^{4}$ Moreover, the categorizing of alkyd resins is centered on the oil length (short, medium or long oil length) which provides different properties. ${ }^{8,22}$ Long oil alkyd resins contain more than $60 \%$ fatty acids by weight, whereas medium oil alkyd resins contain from $40 \%$ to $60 \%$ fatty acids by weight and short oil alkyd resins contain less than $40 \%$ fatty acids by weight. $^{5}$

\section{1) Alkyd resins synthesis}

Three common methods, the alcoholysis process, the acidolysis process and the fatty acid process are used and described in literature for alkyd resin synthesis. ${ }^{4}$ Those processes depend on the starting materials selected to form the alkyd resin.

Alcoholysis process, generally called monoglyceride process, was the first method used by Kienle to form alkyd resin and it is still the most commonly used process. ${ }^{23,24}$ This two-stage process firstly occurs with a transesterification reaction between a polyol and triglycerides which are the main constituents of vegetable oils. Glycerol is the most used polyol in alkyd 
resins synthesis. This polyol has three hydroxyl groups including two primary and one secondary. Trimethylolpropane is also a molecule with three alcohol functions but all the hydroxyl groups are primary which confers a higher reactivity to trimethylolpropane compare to glycerol. ${ }^{25}$ However, its high cost makes its use rare in the synthesis of alkyd resins. Pentaerythritol, with four primary hydroxyl functions, is widely used because it allows the construction of highly branched polymers. ${ }^{21}$ Its high functionality allows faster chain growth, leading to a fast increase in molecular weight as well as viscosity. This first step allows to form a monoglyceride conferring miscibility between the reactants (Scheme 1)..$^{2,4,5,8,26-28}$ This reaction is carried out at $240{ }^{\circ} \mathrm{C}$ in the presence of basic catalyst, typically lithium hydroxide and yields to a mixture mainly containing monoglycerides whose formation is confirmed by solubility test in methanol. ${ }^{29}$ The reaction mixture is dissolved in methanol with a ratio of $1: 3$ and complete dissolution leads to a clear liquid solution, indicating the formation and the majority presence of monoglyceride. ${ }^{26,27,29,30}$ Nevertheless, unreacted glycerol, diglycerides and unconverted triglycerides are also present in the mixture. $^{4}$<smiles>[R]C(=O)OCC(COC([R])=O)OC([R])=O</smiles>

Scheme 1: Transesterification reaction of glycerol and triglyceride to form monoglyceride

Then, a (protected) polyacid such as phthalic anhydride, of petrochemical origin, is added to the reaction mixture containing monoglyceride and the second step, the polycondensation, occurs (Scheme 2). ${ }^{2,4,5,8,26-28,30}$

$\mathrm{n}$<smiles>[R]C(=O)OC(CO)CO</smiles>

Monoglyceride $\mathrm{n}$<smiles>CC(C)OC1C(=O)c2ccccc2C1=O</smiles>

Phtalic anhydride<smiles>[R]C(=O)OC(CO)COC(=O)c1ccccc1C(=O)OCC</smiles>

Alkyd resin 
The acidolysis process is also a two-step reaction but triglycerides are firstly reacted with polyacids at elevated temperature, around $280-300{ }^{\circ} \mathrm{C}$, to form fatty acids and an acidolysis product (Scheme 3)..$^{2,4,31}$ The completion of acidolysis can be measured by analysis of the fatty acid content through titration. Usually, the reaction is complete in about one hour, when the mixture is clear. ${ }^{32}$
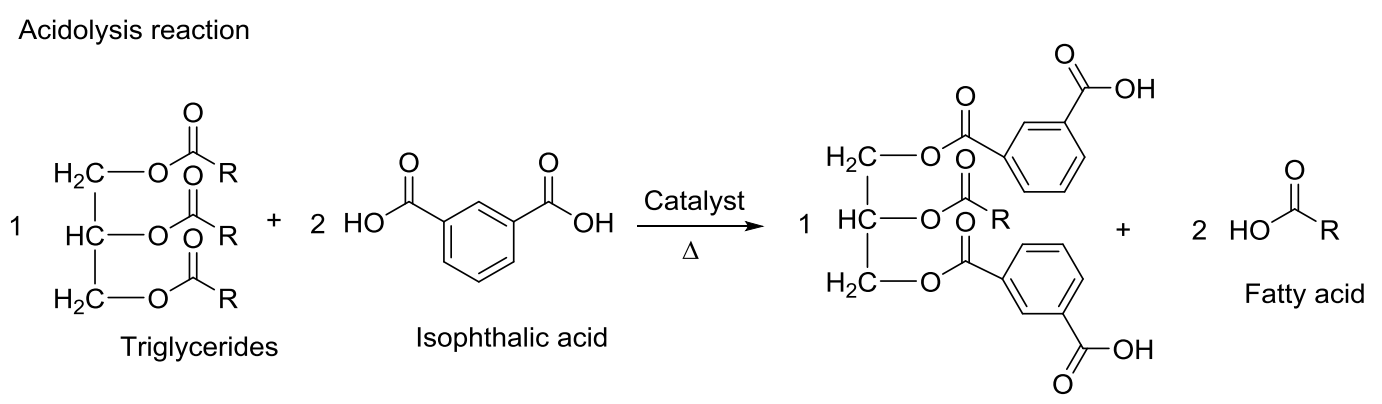

Acidolysis main product

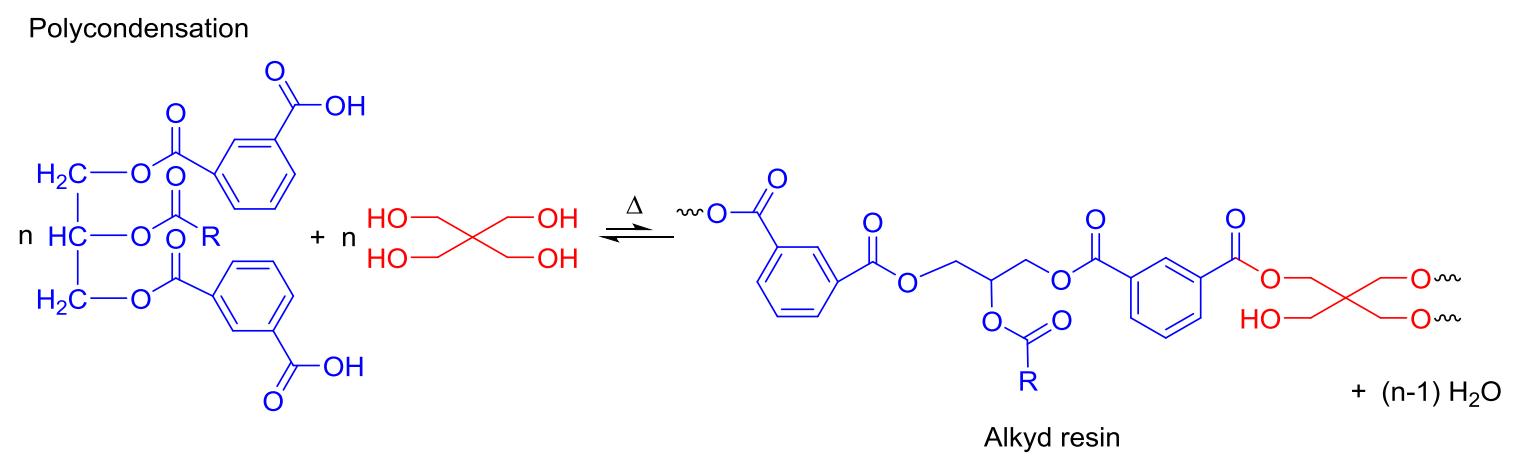

Scheme 3: Acidolysis reaction to modify triglyceride oil with isophthalic acid and then polycondensation

The acidolysis process only occurs when problems of reactivity or solubility of polyacids are encountered. That is why this process is generally used with isophthalic or terephthalic acids. ${ }^{33}$ Moreover, this process takes much longer time than monoglyceride process even with the presence of catalyst and requires higher temperature. Therefore, the acidolysis process is the least used and described in the literature. The second step is the polycondensation reaction between a polyol and the carboxylic groups of the acidolysis product which allows to obtain an alkyd resin. ${ }^{2,4}$

The third process uses fatty acid instead of triglycerides which allows the formation of alkyds in only one step. ${ }^{4}$ Indeed, since fatty acids contain carboxylic group, they can easily react with polyol and it is therefore not necessary to carry out a first miscibility step as for 
monoglyceride or acidolysis process. Thereby, fatty acids, polyols and polyacids are added together and react through esterification reaction (Scheme 4). ${ }^{4,8,34}$

$\mathrm{n}$

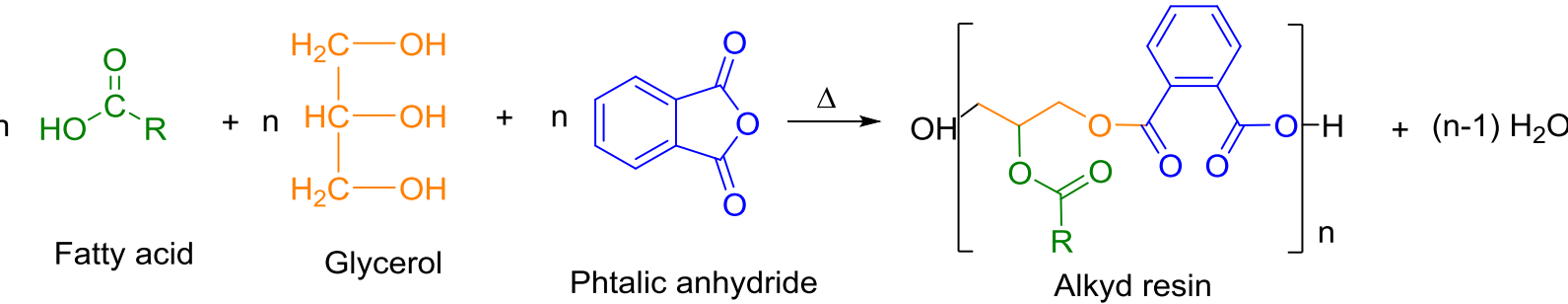

Scheme 4: Polymerization of alkyd resin using fatty acids

Nevertheless, fatty acids are more expensive than oils but they allow shorter process time and better products. In order to make final product cost effective, a mixture of fatty acids and oil is frequently used.

In all those processes, the polycondensation reaction occurs between an alcohol and a carboxylic acid. Moreover, this reaction is based on a thermodynamic equilibrium which can be shifted by removing water from the reaction mixture thanks to two different techniques. ${ }^{2,21}$ First, the fusion process involves mixing of the components at an elevated temperature, generally around $240{ }^{\circ} \mathrm{C} .{ }^{2}$. Moreover the inert gas is passed through the reaction mixture to remove water, an essential step for advancement of polycondensation and prevent harmful oxygen action. ${ }^{21}$ Since this process occurs at higher temperature, there is a considerable loss of volatile reactants. This process is generally used to form long oil alkyd resins where loss of volatile reactants has not much effect on process control parameters. To overcome these issues, a second technique, called solvent process or azeotrope process, is widely used. It involves the addition of small quantities of hydrocarbon solvent such as xylene into the reaction mixture. In this process, reactants are heated together at temperatures between $200{ }^{\circ} \mathrm{C}$ and $240{ }^{\circ} \mathrm{C}$, in order to form a water/solvent azeotrope Water is removed and solvent (with some volatile reactants lost) is recycled and reinjected into the reactor thus allowing much better control of the process parameters. ${ }^{2,21}$ Anhydride acid compounds release only one water molecule in the mixture during polycondensation instead of two when diacids are used. ${ }^{25}$ Thereby phthalic anhydride is preferred in alkyd resins polymerization.

The polymerization reaction is monitored by measuring the acid value and the viscosity and stopped when these parameters reach the previously defined values. The acid value 
corresponds to the number of free acid groups in the alkyd resin. ${ }^{30}$ During the polymerization, the acid value decreases because acid groups are consumed to extend the polymer chains leading to an increase in both molar mass and viscosity.

\section{2) Drying process}

The main compounds used are vegetable oils which mainly contain triglycerides, themselves made up of saturated and unsaturated fatty acids. ${ }^{35}$ Depending on the amount of unsaturated fatty acids in alkyd resins, they can be divided into two main groups: drying alkyds which contain enough unsaturated fatty acids to allow oxygen-curing in air and nondrying alkyds which contain lower contents of unsaturated fatty acids and cannot be cured under air atmosphere only. ${ }^{21}$

Polyunsaturated fatty acids such as linoleic acid and linolenic acid contain respectively two and three $\mathrm{C}=\mathrm{C}$ double bonds which easily react with oxygen and allow air-drying by an autooxidative reaction at room temperature..$^{8,21,29,36-39}$ Nevertheless, this process is relatively slow and it can be accelerated by transition metal-based driers, such as cobalt, zinc, calcium and zirconium salts. ${ }^{4,21,39}$ Autoxidation of alkyds is a three-stage process including peroxidation, peroxide decomposition, and cross-linking reaction that occurs by a freeradical mechanism. ${ }^{37}$ The initial phase of autoxidation involves peroxidation of unsaturated hydrocarbons with the penetration of oxygen into the films allowing the oxidation of fatty acids and promoting the formation of hydroperoxides. ${ }^{21,39}$ As soon as they are formed, the hydroperoxides dissociate into free radicals $\left(\mathrm{ROO}^{\bullet}\right.$ et $\mathrm{RO}^{\bullet}$ ) (Scheme 5)..$^{36,37,39,40}$
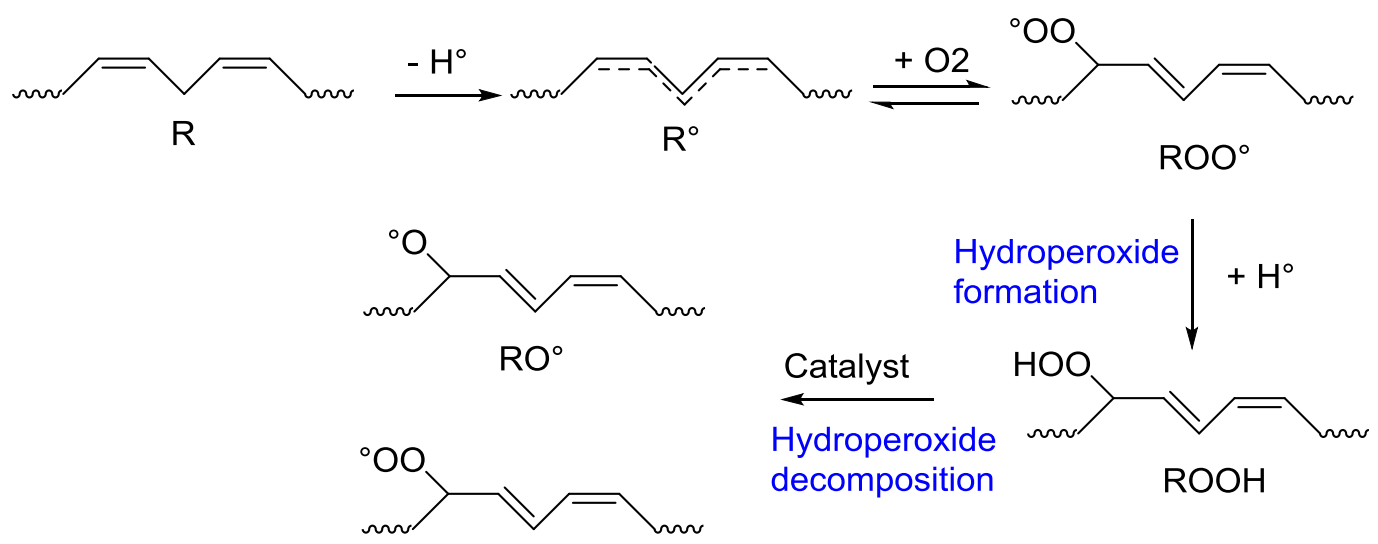

Hydroperoxide

$\mathrm{ROO}^{\circ}$

Scheme 5: Oxidative drying alkyd mechanism 
The free radicals react through radical-radical combinations to form cross-links at carboncarbon (1), ether (2), and peroxide (3)(4) bonds (Figure 1). ${ }^{4,40}$

\begin{tabular}{|ll|}
\hline $2 R^{\bullet} \rightarrow R-R$ & $(1)$ \\
$R O^{\bullet}+R^{\bullet} \rightarrow R-O-R$ & $(2)$ \\
$2 R^{\bullet} \rightarrow R-O-O-R$ & $(3)$ \\
$R^{\bullet}+R O O^{\bullet} \rightarrow R-O-O-R$ & $(4)$ \\
\hline
\end{tabular}

Figure 1: Radical combinations to form cross-linking

Oils containing two conjugated double bonds dry faster than those containing similar levels of non-conjugated double bonds. ${ }^{21}$ Short-oil alkyd resins have less unsaturations than medium or long-oil alkyds, so they dry more slowly. Nevertheless, unsaturations are responsible for the yellowing over time of the coatings. ${ }^{5}$ That is why, depending on the final application, it is crucial to find a good equilibrium between fast drying and low yellowing.

Non-oxidizing alkyds contain non-drying oil composed of saturated or mono-saturated fatty acids, which cannot be cured by auto-oxidation due to the low quantity of $\mathrm{C}=\mathrm{C}$ double bonds. ${ }^{21}$ Non-oxidizing alkyds, generally have oil lengths below $40 \%$ and the films can be cured by reacting free hydroxyl groups of alkyds with other polymers having reactive groups such as amino groups. ${ }^{21}$ 


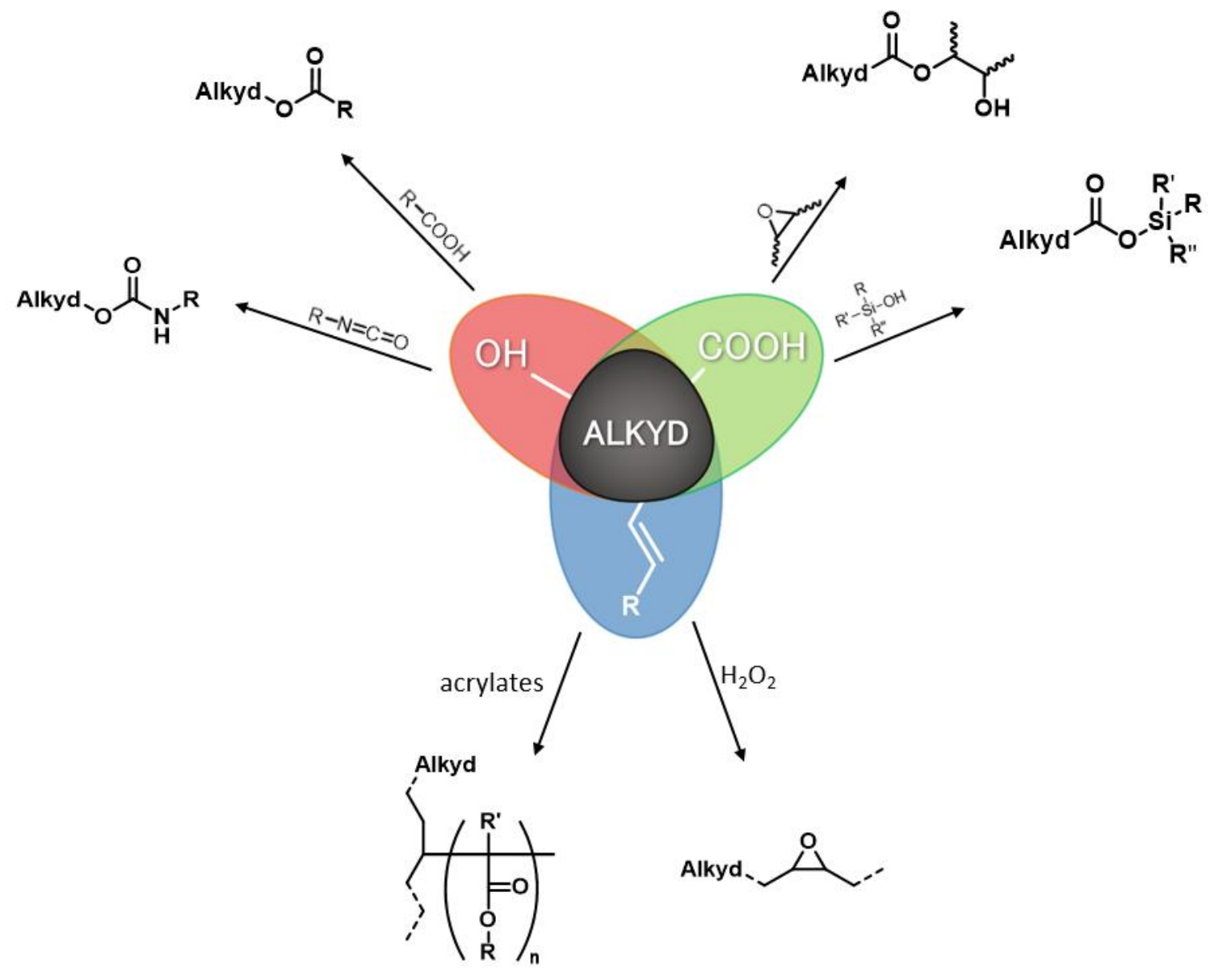

Figure 2: General scheme of grafting sites to form alkyd-hybrids

\section{Epoxy-Alkyd resins}

Epoxy resins are highly cross-linked thermoset materials. The term epoxy refers to the oxirane ring that is the precursor function of these resins. Oxiranes may be opened via anionic ring opening polymerization (ROP) leading to the formation of polyethers. ${ }^{41}$ However, in order to obtain epoxy resins, oxirane monomers are reacted, usually, with amines or carboxylic acids leading to secondary or tertiary amines or ester functions via polyaddition. The most used resins in industry are obtained by using diglycidyl ether of biphenol A (DGEBA) synthesized by epoxidation of bisphenol A (BPA) with epichlorohydrin (Figure 3). ${ }^{42}$ Epoxidation of double bonds is also used to achieve epoxide monomers: it is mainly used on vegetable oils, as they naturally have many unsaturations in their alkyl chains. The reaction is easily performed with hydrogen peroxide $\left(\mathrm{H}_{2} \mathrm{O}_{2}\right)$ and acetic acid in 
presence of ion exchange resin or other catalysts. ${ }^{43}$ As alkyd resins are mainly constituted of oils, this method can be applied to yield hybrid alkyds. The curing with amine hardeners is the most used route to cross-link epoxy resins. This reaction can be performed at room temperature thanks to the high reactivity between aliphatic amines and oxirane rings. ${ }^{44}$ However it is possible to use tertiary amines as catalyst in order to speed up the reaction. ${ }^{45}$ The reaction between oxirane rings and carboxylic acids is another way to cure epoxy resins (Scheme 6). The reaction with acids or anhydrides exhibits a lower reactivity than with amines therefore heat and catalysts are often needed. ${ }^{46}$ Thanks to the high amine functionality of curing agents, three dimensional network polymers are obtained inducing the following properties : they can feature many attributes such as excellent chemical resistance to alkali environment, outstanding adhesion to a variety of substrates, very high tensile, compressive and flexural strengths, remarkable resistance to corrosion, or fatigue. ${ }^{47}$ Epoxy resins have found a broad range of applications thanks to their versatility, from water pipes to automotive coatings or flooring applications. However they are brittle, hygroscopic ${ }^{48}$ and may shrink on curing. ${ }^{49}$ Alkyd resins can be modified with epoxy resins in order to improve the properties of both resins.

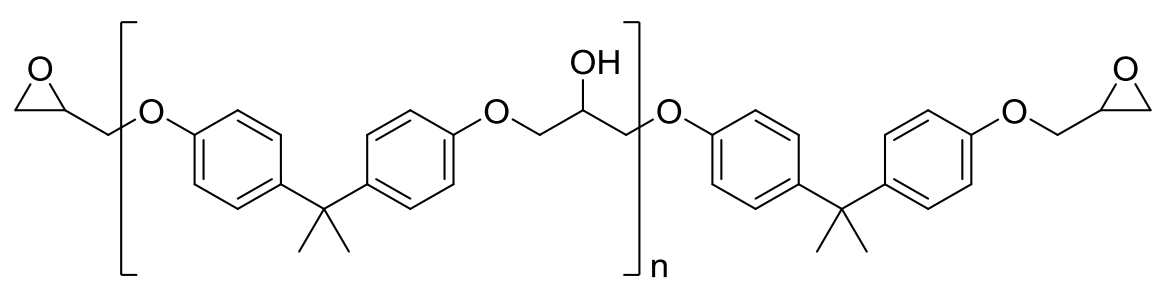

Figure 3: Typical Bisphenol A Epoxy Resin

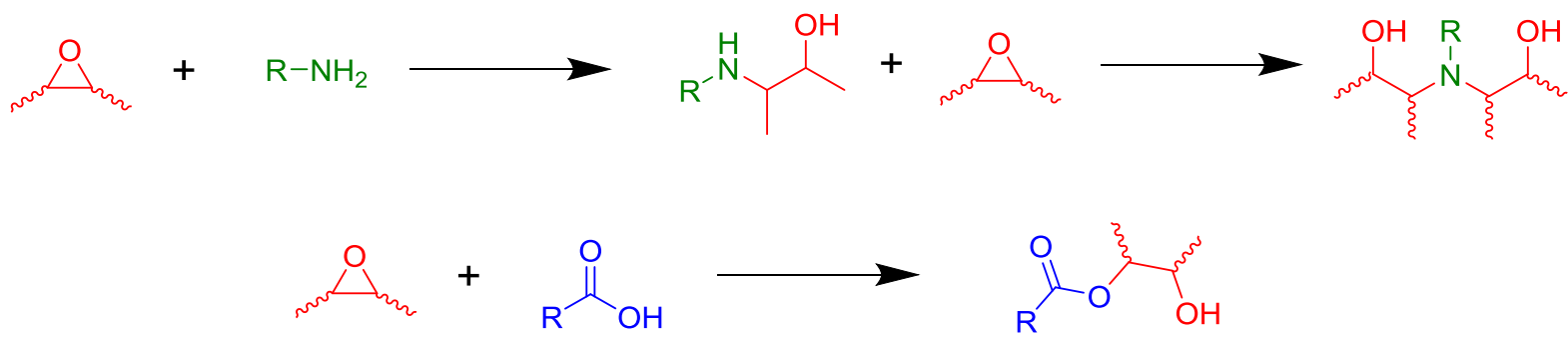

Scheme 6: Oxirane ring opening with amines and carboxylic acids 


\section{1) Alkyd epoxy hybrids made by blend curing}

As seen previously, many epoxy resins are obtained by curing epoxide monomers with amine hardeners. Hence alkyd epoxy hybrids can be made by blending the alkyd with unreacted epoxy resin precursors before curing. In 2015, Assanvo et al. synthesized conventional alkyd resins using Ricinodendron heudelotii oil, phthalic anhydride and glycerol in different amounts. ${ }^{50}$ These resins were blended with commercial epoxy resin at 50:50 $(\mathrm{w} / \mathrm{w})$ ratio and then cured at $50^{\circ} \mathrm{C}$ with poly(amidoamine) as hardener in presence of methyl-ethyl ketone peroxide (MEKP) and Co-octoate. Indeed, MEKP and with cobaltoctoate have been described as catalysts for epoxy-amine system and cobaltoctoate also showed efficiency as autoxidation catalyst for alkyd resins. ${ }^{40}$ This catalyst system helped in this case both oxirane ring opening and alkyd autoxidation, inducing a faster cross-linking. The obtained coatings showed good thermal stability. ${ }^{51}$ Alkyd resins were also synthetized from neem oil with maleic anhydride, phthalic anhydride and glycerol by Das et al.. ${ }^{52}$ These alkyds were then cured using epoxy resin, poly(amidoamine) and Co-octoate catalyst. The coatings showed good anticorrosive properties, good chemical resistance towards hydrogen chloride $(\mathrm{HCl})$ and sodium chloride $(\mathrm{NaCl})$ dilute solutions and excellent hardness. However, the composition of the used commercial epoxy resin was not given in these two articles, therefore results should be taken carefully.

Additionally, Patel et al. investigated the curing of castor oil with BPA based epoxy resin at $80{ }^{\circ} \mathrm{C}$ in presence of trimethylamine as catalyst. ${ }^{53}$ It was then blended with cyclohexanoneformaldehyde resin and alkyd resin and cured with $\mathrm{Pb}$-octoate, Co-octoate and Mn-octoate dryers in small quantities. Alkyd resin represented more than $70 \%$ of the total in weight of this formulation. These blends showed good chemical resistance to water, xylene and alkali solutions after curing. Scratch hardness and impact resistance showed good results, pencil hardness reached up to $5 \mathrm{H}$. Bajpaj et al. investigated the blend of conventional alkyd resins with epoxy esters made from tobacco seed oil before curing with diethylamino propylamine. ${ }^{54}$ Better properties against corrosion were obtained for the blends containing more epoxy groups. In all these studies, alkyd resin was blended with epoxide monomer and amine hardener before curing. We have seen that oxirane rings are more reactive towards amines; however carboxylic acids and anhydrides are present in alkyds and may also react with oxirane rings. The competition between amines and acids or anhydrides could have been discussed, as it may be the key factor for a suitable bonding of the two different resins. 
Issam et al. investigated the utilization of bisphenol A based epoxy resin with alkyd resins obtained via a two-step synthesis. ${ }^{55}$ First the alcoholysis of palm oil with glycerol is performed, then phthalic anhydride is added with xylene as solvent. Both resins were blended with alkyd/epoxy ratios ranging from 20:80 to 50:50 then cured in presence of trimethylamine as a catalyst. In that case, no amine hardener was used, the free carboxylic and anhydride groups of the alkyd opened the oxirane ring and cross-linked the network. Triethylamine allowed the reaction to occur at $33{ }^{\circ} \mathrm{C}$ in less than $30 \mathrm{~min}$, leading to coatings with 60 and $120 \mu \mathrm{m}$ thickness. Scanning electron microscopy (SEM) images showed a good compatibility between resins. Properties of the hybrids such as chemical resistance to solvents, thermal stability or hardness were comprised between those of respective epoxy and alkyd alone. The ratio alkyd:epoxy 30:70 is given as optimum based on hardness and surface smoothness of the coating. The crosshatch adhesion of the hybrids reached $100 \%$ whereas alkyd alone had only $80 \%$ adhesion.

\section{2) Melamine-alkyd-epoxy resins}

Various studies have been done on the alkyd-epoxy systems in order to improve properties, including addition of melamine. Hence, conventional alkyd resin was synthesized by Ma et al. form Zanthoxylum bungezanum oil using phthalic anhydride and trimethylolpropane. ${ }^{56}$ Then commercial epoxy resin was added for curing. The resulting resin was then blended with hexamethoxymethyl melamine (HMMM) (Figure 4) in order to make $0.3 \mathrm{~mm}$ thick films. These alkyd-epoxy resins showed better chemical resistance and stability, in accordance with the previous reported studies. Moreover, due to higher crosslinking, the blend with HMMM further improved the thermal stability, chemical resistance and hardness properties. Indeed hardness of the blends went up to $4 \mathrm{H}$ whereas alkyd alone was only at B. Cakić et al. also blended alkyd resin with epoxy resin and melamine with deeper considerations on curing kinetics. ${ }^{57}$ Hence, they obtained good mechanical properties with improved hardness and the maximum score for crosscut adhesion test showing that the coating fully adhered to the substrate. 


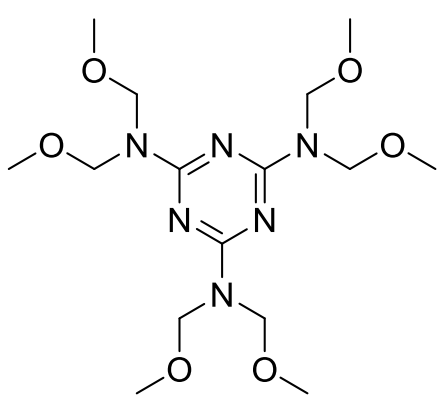

Figure 4: Structure of hexamethoxymethyl melamine (HHHM)

\section{3) Epoxidation of alkyd resins}

Another way to obtain alkyd/epoxy hybrid is to functionalize the alkyd with oxirane ring. Patil et al. made alkyd resin from linseed oil, and itaconic acid. ${ }^{58}$ The resin was then epoxidized with $\mathrm{H}_{2} \mathrm{O}_{2}$ in presence of acid acetic and Amberlite IR-12OH (Figure 5). Nuclear magnetic resonance (NMR) analyses showed that double bonds of both oil and itaconic acid have been converted into oxirane rings. 3-amino propyltrimethoxysilane (APTMS) was then grafted by epoxide ring addition reaction. The obtained coatings ranged from 50 to $60 \mu \mathrm{m}$ and showed great solvent and chemical resistances, and good barrier properties suitable for anticorrosion system. In this case, it is very likely that surface properties are induced by the trimethoxysilane group, and the alkyd-epoxy hybrid is only used to allow its grafting. Li et al. made alkyd resin from poly(limonene-8,9-oxide carbonate) bearing an oxirane group. ${ }^{59} \mathrm{lt}$ led to faster drying alkyds with high glass transition temperature $\left(T_{\mathrm{g}}\right)$ and König hardness, but showed higher yellowing. This is an interesting way to obtain alkyd/epoxy hybrids, since the functions were directly grafted on the alkyd backbone and allowed good compatibility avoiding phase separation. Although this route requires more chemical steps than blend curing, the homogeneity of these coatings can be an asset for applications such as corrosion protection. Hydroxyl groups resulting from oxirane opening with amines allow the formation of hydrogen bonds. These hydrogen bonds have been proved to impact properties of materials such as $\mathrm{Tg}$, Young modulus, adhesion and elasticity. ${ }^{60}$

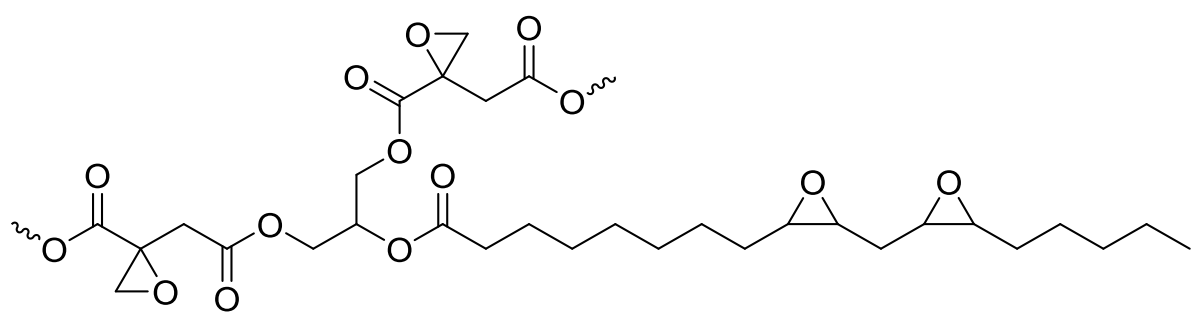


Hence, alkyd-epoxy hydrids led to the formation of coatings combining the properties of both polymers. Indeed epoxy improve thermal stability, chemical resistance and mechanical properties thanks to dense crosslinking networks and the presence of amide groups. However, even though this phenomenon is not discussed in the presented studies above, the presence of fatty acids and amines may also lead to unwanted amidation side-reactions.

\section{Acrylate}

Many coatings use acrylic resins as binders, mainly dispersed in water. Acrylic resins are characterized by fast physical drying, yellowing and chemical resistances. However, these coatings generally need co-solvents for applications and use harmful or toxic acrylate monomers. ${ }^{61}$ Utilization of acrylic-alkyd hybrids can make the most of each polymer in order to improve coatings properties.

\section{1) Acrylate-alkyd hybrids via solution polymerization}

\section{1.a) Grafting of polyacrylate to the alkyd resin}

In 2009, Akbarinezhad et al. made acrylic-alkyd resins by free radical solution polymerization. $^{62}$ Polyacrylate copolymers were prepared by free radical solution copolymerization of methacrylic acid (MAA), acrylic acid (AA), butyl methacrylate (BMA) and methyl methacrylate (MMA) (Figure 6A). Monoglyceride was prepared with trimethylolpropane (TMP) and soybean oil fatty acid (SOFA). Then the acrylic-alkyd hybrid was synthesized by mixing the monoglyceride and acrylic copolymer and heating at $210^{\circ} \mathrm{C}$. The acrylic copolymer played the role of polyacid thanks to the presence of acrylic and methacrylic acids in its backbone, allowing the condensation to occur. Acid value impact of the acrylic copolymer on the hybrid resin was investigated. The higher is the acid value, the more $\mathrm{COOH}$ groups are available for crosslinking. Values under $128 \mathrm{mg} / \mathrm{g} \mathrm{KOH}$ led to soft materials whereas gelation occurred for higher values $(178 \mathrm{mg} / \mathrm{g} \mathrm{KOH})$ due to higher crosslinking density. However, the intermediate formulation comprised between 135 and $145 \mathrm{mg} / \mathrm{g} \mathrm{KOH}$ exhibited good properties. The formed hybrids were then neutralized by amines prior emulsification in water and used in an air-drying, water-reducible lacquer formulation to make films. Physical and mechanical properties of the films were acceptable. 
Akgün et al. also made acrylic-alkyd hybrids by mixing alkyds and acrylic copolymer. ${ }^{63}$ The acrylic copolymer was synthesized by free radical copolymerization of MAA and fumaric acid (FA) with (benzoyl peroxide) BPO as radical initiator (Figure 6B). The alkyd part was synthesized using conventional polycondensation of TOFA, phthalic anhydride, TMP and 1,3propanediol. Then alkyd and acrylic copolymers were mixed and free hydroxyl groups of the alkyd reacted with carboxylic groups of the polymerized fumaric acid. Once the acrylic-alkyd hybrid is formed, it was neutralized by diethanolamine and emulsified in water. Different ratios of acrylic/alkyd segments were used to form $50 \mu \mathrm{m}$ films. The incorporation of acrylates into alkyd led to softer and flexible materials, with higher abrasion and alkaline resistance compared to alkyd part alone. No negative influence was observed on drying or adhesion properties. Büyükyonga et al. grafted MAA-co-MA acrylates to alkyd resins made from recycled PET using the same method. ${ }^{64}$ Using the same principle, Saravari et al. made acrylic-alkyd hybrids by mixing alkyd with anhydride-based acrylate copolymer. ${ }^{14}$ Maleic anhydride was copolymerized with n-butyl methacrylate using BPO as radical initiator. The copolymer was then mixed with monoglyceride of palm and tung oils. Maleic anhydride reacted with hydroxyl groups of monoglycerides to form the acrylic-alkyd hybrid. Then hybrid was neutralized with diethanolamine and emulsified in water. $30 \mu \mathrm{m}$ films were formed with different alkyd/acrylic ratios. Water and acid resistances were excellent, and the higher rates of acrylic into the alkyd showed the better alkali resistance.

(A)

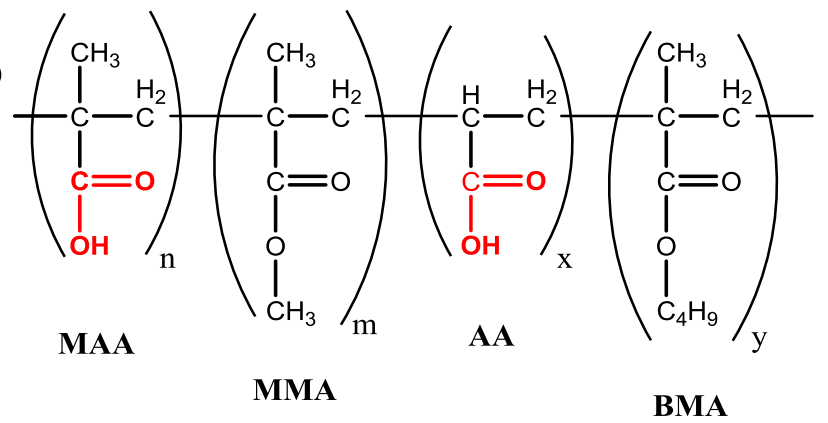

(B)

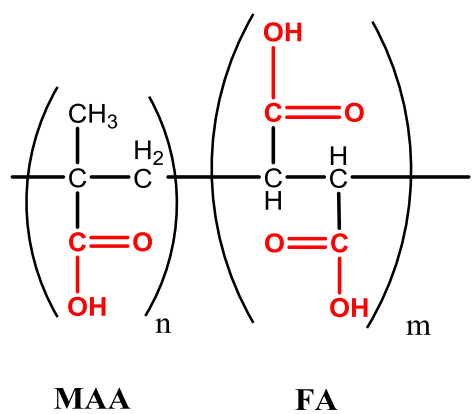

MAA
FA

Figure 6: Structure of different acrylate copolymers

\section{1.b) Copolymerization of acrylate from the alkyd}

Furthermore, some works studied the direct polymerization of acrylates from the alkyd double bonds. Hence, Wang et al. polymerized butyl acrylate onto different types of alkyds. ${ }^{65}$ The alkyd was charged with $n$-butanol, and a mixture of BA containing BPO or AIBN 
as radical initiator solubilized in $n$-butanol was added dropwise under mechanical stirring. This process involved a competition between the polymerization of acrylates on the alkyd chain, and the formation of homopolymers in the reaction medium. This competition could depend on the type of oil used in the alkyd resin, the number of double bonds and their conjugation. Several options are available for grafting butyl acrylate (BA) to the alkyd (Figure 7). At $80^{\circ} \mathrm{C} \mathrm{BPO}$ and AIBN dissociate into primary radicals; these radicals can either initiate polymerization or undergo hydrogen abstraction. This study concluded that BPO allowed higher hydrogen abstraction than AIBN, so the hydrogen based on polyol backbone is easier to graft to. It explained the fact that BPO led to higher degree of grafting than AIBN for alkyds with the same oil composition. However poorly unsaturated alkyds made from stearic acid could not achieve degrees of grafting higher than $10 \%$ where linolenic based alkyds were grafted up to $95 \%$ with only very few homopolymerization of BA. Different mechanisms of grafting were described depending on the type of oil.

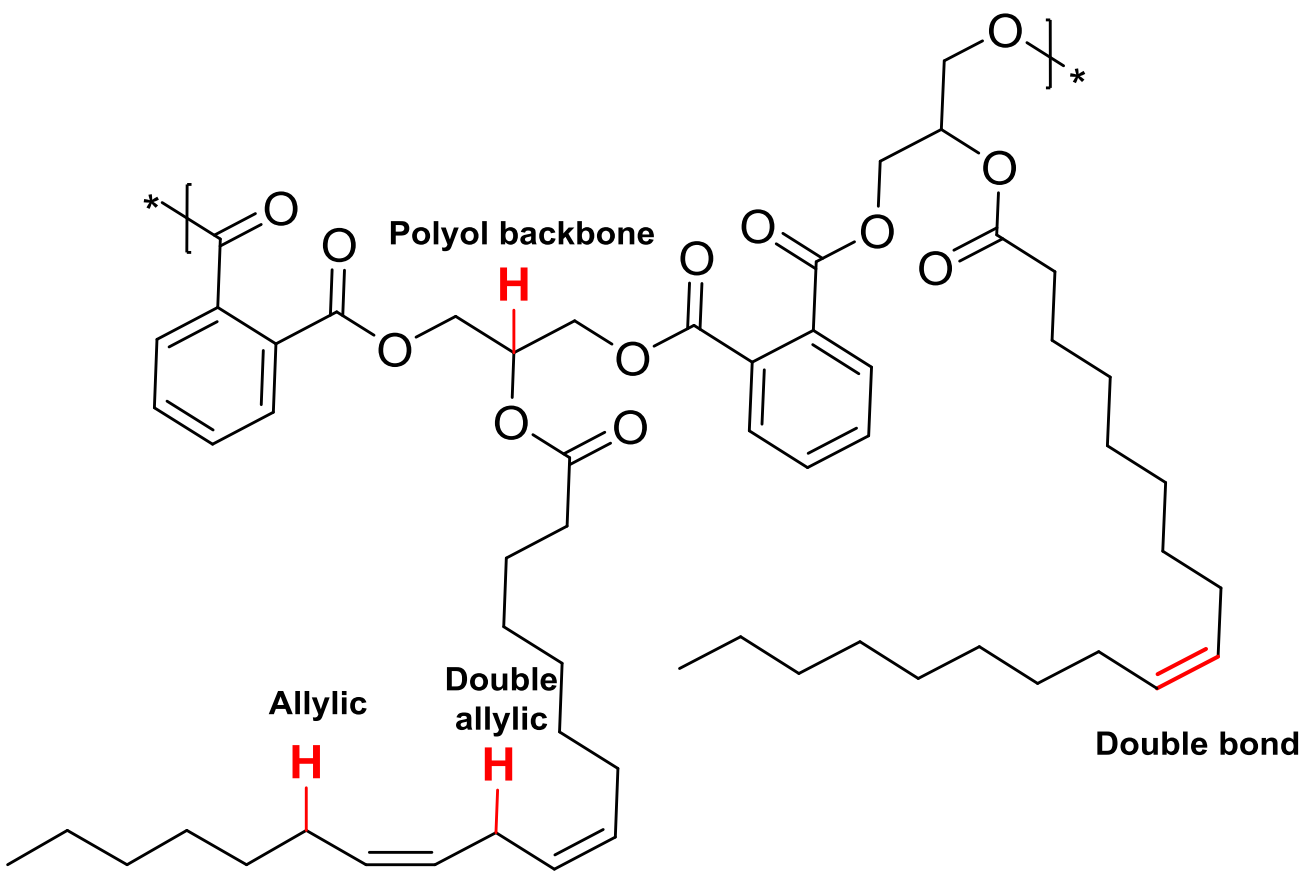

Figure 7: Grafting sites on alkyd resin for butyl acrylate (BA)

Ataei et al. investigated the grafting of MMA onto alkyd resin via radical polymerization. ${ }^{66}$ The alkyd and MMA were dissolved in toluene and the BPO as radical initiator was added dropwise. NMR analyses confirmed that copolymer was formed and that the polymerization 
rate increased when the MMA content was higher. $50 \mu \mathrm{m}$ coatings were made with different ratios of MMA. The increase of MMA content led to faster drying and better alkali resistance or hardness. Acrylic-alkyd hybrids made with different acrylate monomers were synthesized by Dziczkowski et al. by free radical polymerization. ${ }^{67}$ Influence of different parameters such as oil length, degree of unsaturation in the alkyd backbone and acrylic to alkyd ratio were studied for their impact on final film properties. Oil length showed the most impact on film properties such as pencil hardness, impact resistance, solvent resistance, crosslink density, and dry time. However, acrylic/alkyd ratio had the most effect on resin characteristics like molecular weight or hydrolytic stability. Alkyd-acrylic hybrid resins were made by Elrebii et al. using MMA, MAA, MA (methyl acrylate) and EHA (2-ethylhexyl acrylate), as acrylate monomers. ${ }^{68,69}$ Alkyd resin was synthesized apart, then acrylate monomers and radical initiator were added to perform free radical polymerization. The hybrid was then neutralized and emulsified in water (Figure 8). The most stable dispersions were obtained for 50/50 acrylate alkyd, with the presence of maleic anhydride in the acrylic prepolymer backbone. 


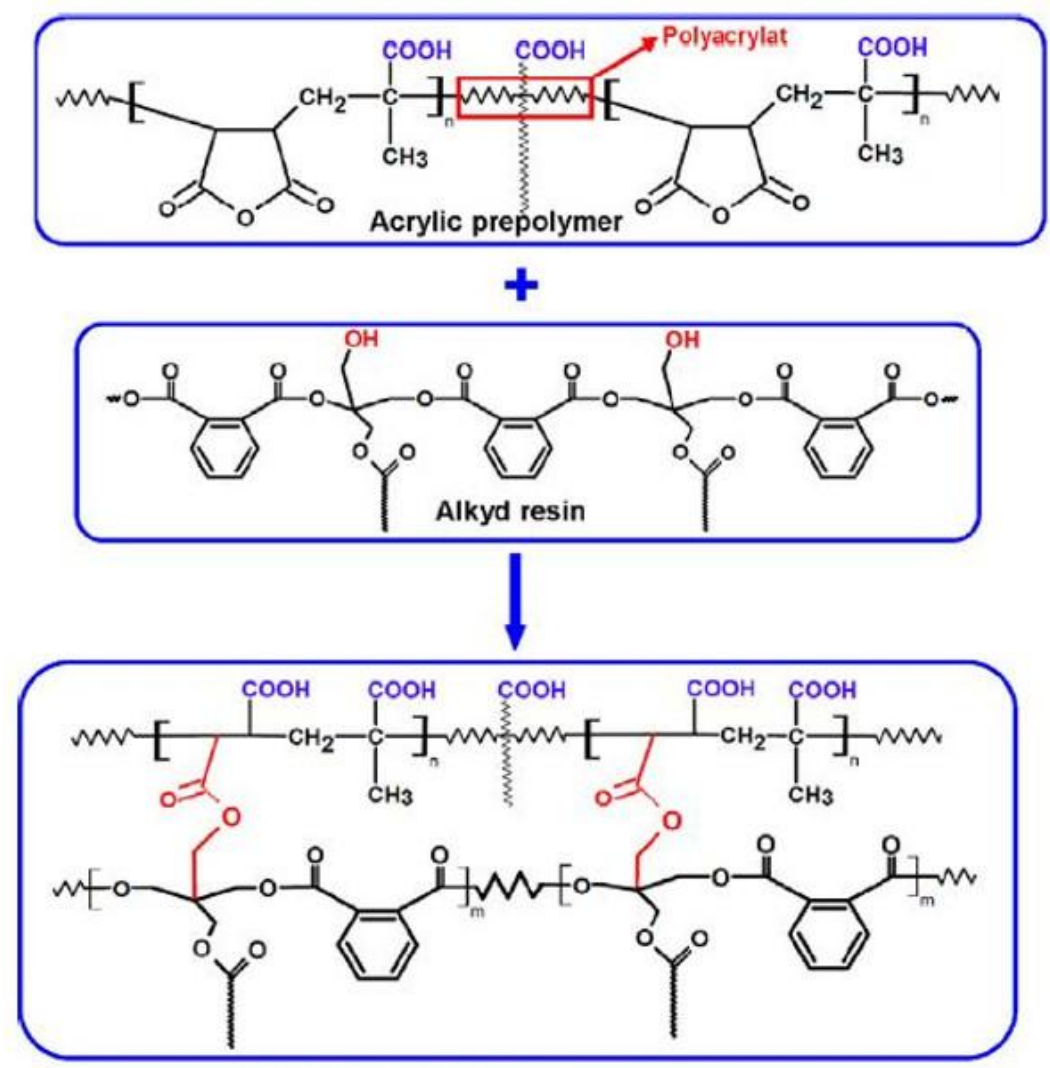

Hybrid Alkyd/acrylic resin
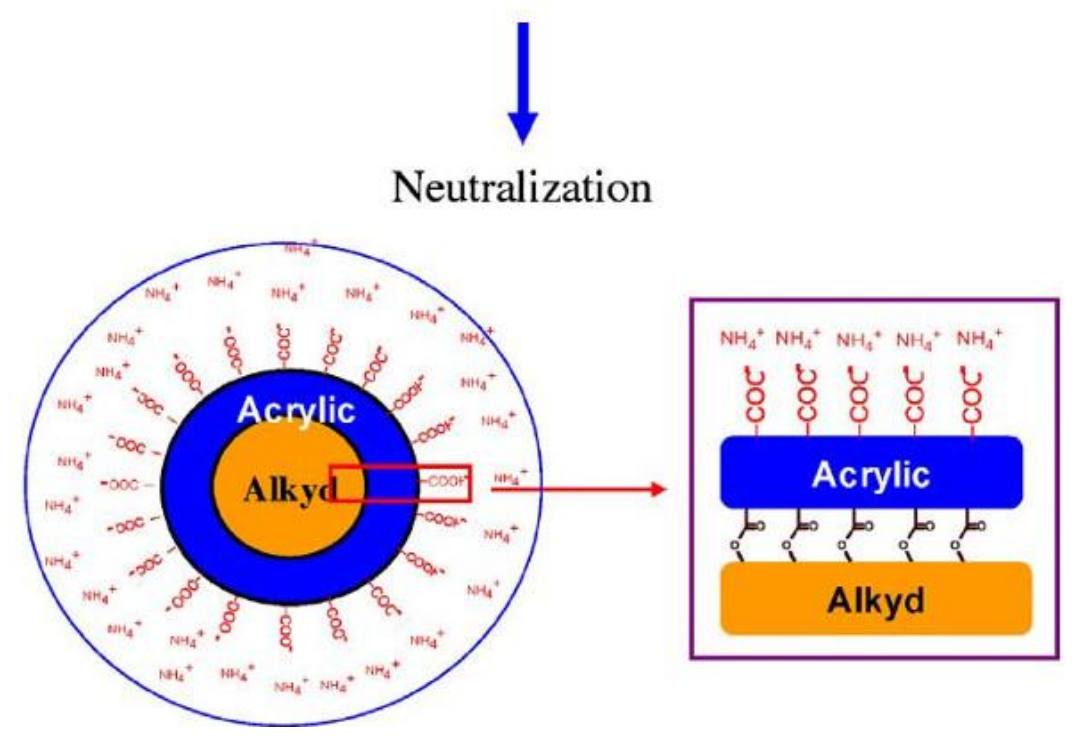

Figure 8: Illustrative strategy adopted in the synthesis of the alkyd/acrylic resin

Nalawade et al. investigated the synthesis of acrylic-alkyd hybrids via quasi-living polymerization. ${ }^{70}$ Medium and long oil alkyd resins were synthesized, and then transformed into macroinitiator for ATRP or macro-RAFT agent for RAFT polymerization. MMA and BA monomers were used for the synthesis (Scheme 7 and Scheme 8). These polymerization techniques let the alkyd backbone of the alkyd and its double bonds intact. Autoxidation was 
able to occur with ATRP-polymerized acrylated alkyds, however RAFT agents showed antioxidant activity and no drying was observed for the RAFT-polymerized acrylated alkyds. Properties of the films depended on the fatty acid content without any correlation with the synthesis method.

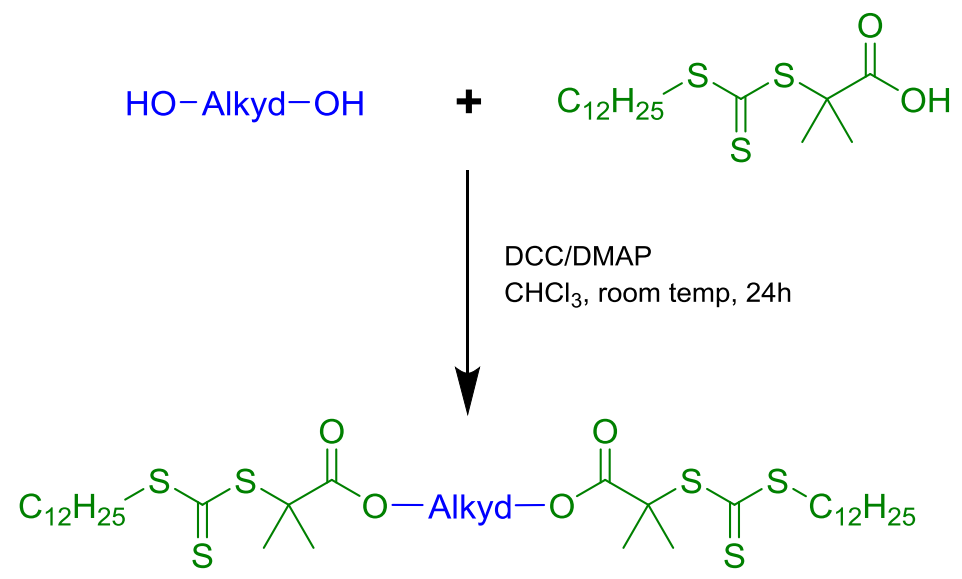

Alkyd macro-RAFT agent

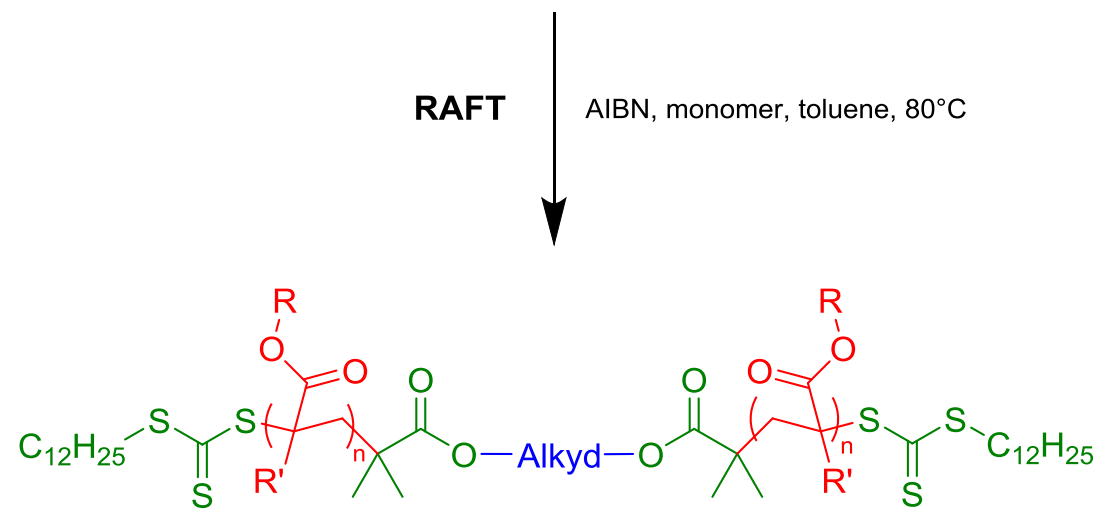

$\mathrm{R}=\mathrm{CH}_{3}$ or $\mathrm{C}_{6} \mathrm{H}_{3}$ $\mathrm{R}^{\prime}=\mathrm{H}$ or $\mathrm{CH}_{3}$

Acrylated alkyd

Scheme 7: Synthesis of alkyd-acrylic copolymer via RAFT polymerization 


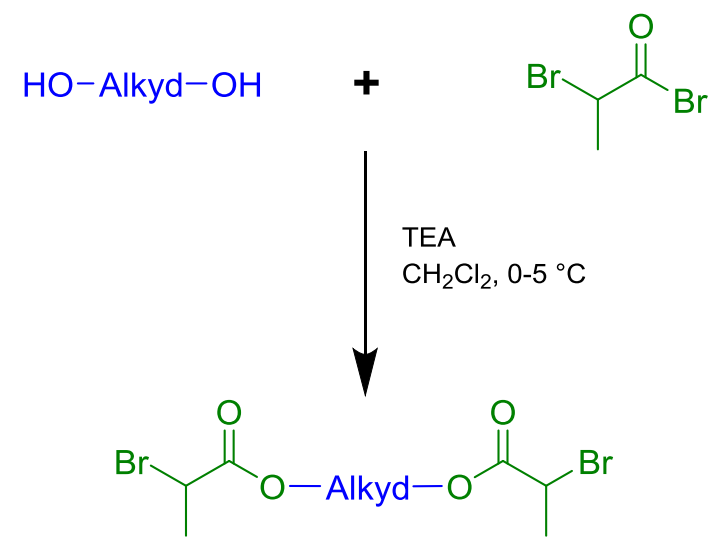

Alkyd macro initiator

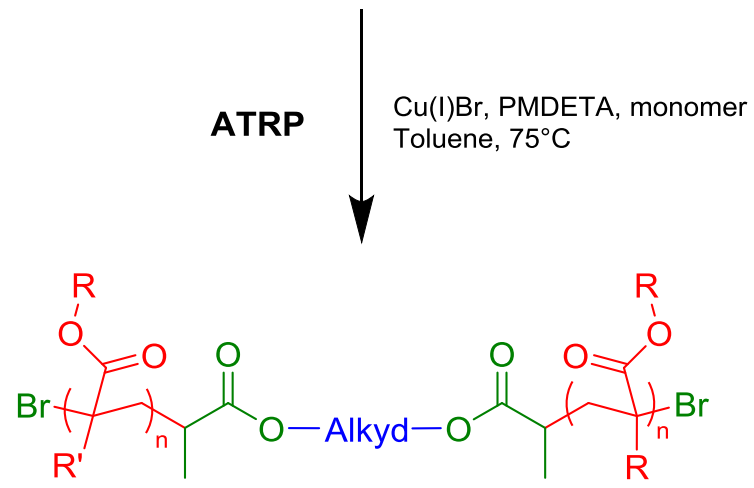

$\mathrm{R}=\mathrm{CH}_{3}$ or $\mathrm{C}_{6} \mathrm{H}_{3}$ $\mathrm{R}^{\prime}=\mathrm{H}_{\text {or } \mathrm{CH}_{3}}$ Alkyd-acrylic copolymer

Scheme 8: Synthesis of alkyd-acrylic copolymer via ATRP polymerization

Another way to graft acrylates onto alkyds is to use Diels-Alder reaction. However, it is little used because Diels-Alder reaction requires the presence of conjugated double bonds, and alkyds are classically made with oils containing mainly oleic and stearic acids that are not suitable for this reaction. Nonetheless, Thanamongkollit et al. grafted different dienophile acrylates onto alkyds by the reaction at $150{ }^{\circ} \mathrm{C}$ of the acrylate function on the conjugated double bonds present in the alkyd part. ${ }^{71}$ Xu et al. also used this method, to graft isobornyl acrylate. $^{72}$

\section{2) Acrylate-alkyd hybrids via emulsion polymerization}

Emulsion polymerization is one of the most important techniques for the polymerization of acrylates. It offers many advantages compared to other techniques, as it is quicker than bulk and solution polymerization, requires no VOC and easily reaches up to $100 \%$ conversion. 
Emulsion polymerization consists of dispersed monomers in aqueous phase, in the presence of surfactant and radical initiator. Radicals are generated in aqueous phase and then migrate into micelles or particles where polymerization occurs. Many descriptions of emulsion polymerization can be found in literature ${ }^{73-76}$ including biobased systems. ${ }^{77-81}$

In 1996, Nabuurs et al. synthesized alkyd-acrylic hybrid systems. ${ }^{82}$ Conventional alkyd resins were made using tall oil fatty acid, glycerol and isophtahlic acid. Alkyd was dissolved in the acrylic monomers then surfactants and water were added. Alkyd/acrylic ratios were used from 25:75 to 50:50, using different combinations of monomers such as styrene, BA, MMA, $B M A, E H A$ or vinyl acetate. MMA appeared to be the monomer that led to the most finely dispersed pre-emulsions. The presence of more unsaturations on the alkyd backbone decreased the polymerization rates. Good grafting rates were observed, up to $99 \%$. However free unreacted acrylate monomers can present an acute toxicity and must be removed. The hybrids were used into paint formulation in order to compare their properties to acrylic-alkyd blends. Properties were quite similar; but hybrids combined the best properties of each component: fast drying time and no need for a co-solvent. Such a synergetic behavior make alky-acrylic hybrids an asset for VOC-free fast drying paints. Many studies investigated the properties of acrylic-alkyd hybrids made by emulsion with the same monomers. The stability of the emulsion, the fast drying of the coatings and the flexibility granted by the acrylate part were often observed. ${ }^{19,83-89}$ Athawale et al. used hydroxyl ethyl methacrylate (HEMA) among other acrylate monomers to make acrylic-alkyd hybrids. ${ }^{90}$ The reaction was performed via emulsion polymerization, then films were coated on mild steel and cured at $150^{\circ} \mathrm{C}$ for $2 \mathrm{~h}$. The higher was the acrylate ratio in the polymer, the harder were the films. This was due to the presence of HEMA containing hydroxyl group. The free $-\mathrm{OH}$ from HEMA reacted with free carboxylic groups of the alkyd while curing, explaining the stiffness observed. The utilization of surfactant during the emulsion polymerization can affect its final properties, such as adhesion gloss or water sensitivity. Thus, Faucheu et al. studied the migration of surfactant in alkyd-acrylic hybrid system. ${ }^{91}$ Surfactant particles preferentially interacted with the acrylate phase, and partially clustered throughout the polymer film. Recently, Limousin et al. highlighted that acrylic-alkyd hybrids dried faster than alkyds alone thanks to oxygen diffusion. ${ }^{92}$ Indeed acrylate parts allowed oxygen to diffuse in the interior of the film allowing autoxidation to occur simultaneously in the whole material. 
Goikoetxea et al. made acrylic-alkyd hybrids via miniemulsion polymerization using glycidyl methacrylate (GMA). ${ }^{93}$ Commercial alkyd resins were functionalized with GMA in order to obtain methacrylate-functionalized alkyd resins. Oxirane groups were opened by carboxylic or hydroxyl groups of the alkyd, and hydroquinone was used to prevent homopolymerization. After emulsification of the functionalized alkyd resin, the latexes were synthesized with MMA, BA, AA and stearyl acrylate (SA). Unsaturations present on the alkyd backbone were not reacted during the radical polymerization, only the acrylic part of the GMA grafted on alkyd copolymerized. Better compatibility between alkyd and acrylate was observed for the GMA functionalized hybrids compared to hybrids made with unmodified alkyd. However, some gelation have been observed because functionalized resin contained both methacrylic double bonds and unsaturations on the alkyd backbone. The same team used the same principle to make acrylic-alkyd hybrid protective coatings. ${ }^{94}$ Drying was faster, thanks to the presence of many double bonds still active on the alkyd backbone that could undergo autoxidation. Better grafting was observed thanks to the GMA compared to unmodified alkyd.

Murillo et al. used hyperbranched alkyds to make hybrids. ${ }^{15,95}$ Star-shaped resins were mixed with acrylic monomers and BPO as a radical initiator in order to obtain an homogeneous hydrophobic solution, then an aqueous solution containing SDS as surfactant was added in order to obtain miniemulsion. Conversion degree ranged between $95 \%$ and 99 \%. Films were made with the help of metal-based dryers. Higher drying rates were observed with acrylic-alkyd resins compared to alkyd resin only. Adhesion and flexibility were also improved by the presence of acrylates.

Zhong et al. used surfactant-free miniemulsion polymerization in order to obtain fluorinated acrylic-silicone modified-alkyd hybrid resins with good anticorrosion properties. ${ }^{96}$ Silicone modified alkyd resin was functionalized with maleic anhydride prior to emulsification, to create $\mathrm{COOH}$-terminated resin. Dodecafluoroheptyl methacrylate (FMA), BA, MMA and AIBN asradical initiator were mixed with this modified resin. Latex films were then made by using crosslinking agent. The utilization of very hydrophobic elements such as FMA combined with cross-linking led to better thermal and anticorrosion properties compared to uncured resins. Jowkar-Deriss et al. made acrylic-alkyd hybrid via emulsion using already formed latexes. ${ }^{18,97}$ Hence, BA-co-MMA latex was charged into a reactor and the alkyd was added slowly to the mixture in order to achieve stable hybrid resins having either oil/water emulsions or 
water/oil/water multi-emulsions with a solids content above 80 wt.\% Different parameters such as $\mathrm{pH}$, surfactant or solid content of the emulsion were studied for their impact on droplet size. A pH of 8 led to the formation of the smallest droplets, more solid content and more surfactant also induced smaller droplets. This decrease of the droplet size allows a better ageing stability of the latexes.

Acrylates were combined with alkyds in order to confer properties such as fast drying and chemical resistance, weak point of alkyds. These two polymers showed good compatibility and hybrid thereof can be synthesized via emulsion polymerization, overcoming the main drawback of the acrylate that is the utilization of solvent. These solvent free alkyd-acrylic hybrids are attracting great interest due to their wide range of applications.

\section{Polyurethane}

Polyurethane (PU) is one of the most versatile polymer and it is also the $5^{\text {th }}$ most produced in the world. $^{98}$ Polyurethanes result from the polyaddition reaction of a polyol and a diisocyanate compound. Thereby, polyurethanes contain hard and soft segments which confer structuration and interesting mechanical properties to them. ${ }^{99}$ Hence, PU exhibit flexibility as well as hardness, which makes them favored polymers for coating applications. In the late 1970s, poly(alkyd-urethane) resins (PAU) also named uralkyds were developed. ${ }^{100}$ These polyurethane-alkyd resins were studied in order to combine the properties of both polymers, such as drying properties for alkyds and resistance against various external aggressions for $\mathrm{PU} .{ }^{101}$ Thanks to the incorporation of polyurethane, abrasion resistance, as well as UV and chemical resistance of the alkyd resins were improved. ${ }^{10}$ Moreover, urethane conferred better hydrolysis resistance to alkyds, allowing the formation of waterborne PAU. $^{102}$

\section{1) Isocyanate compounds grafted to alkyd resins}

The addition of urethane link into alkyd resins allowed the formation of PAU that provided higher chemical and solvent resistances to films than coatings formed only with alkyd resins. $^{102}$

The first way to develop urethane-alkyd hybrid appeared in the late 1970s with the reaction between various isocyanates and alkyd resins with a high content of residual hydroxyl 
groups. ${ }^{101,103}$ This method easily led to the formation of poly(alkyd-urethane) with a low level of residual isocyanate. ${ }^{102}$ This procedure was reported by Athawale et al. with the use of isophorone diisocyanate (IPDI) (Scheme 9). The synthetized PAU showed better chemical resistance compare to regular alkyd resins. ${ }^{104}$

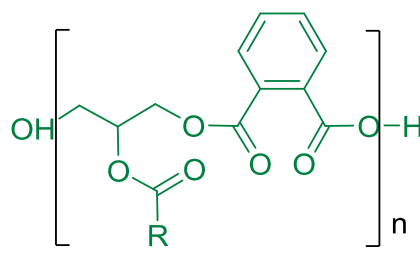

Alkyd resin

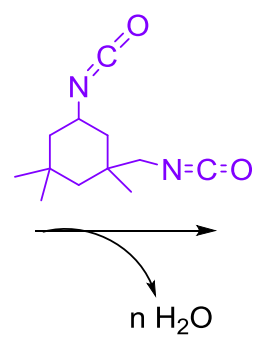

$\mathrm{H}_{2} \mathrm{O}$

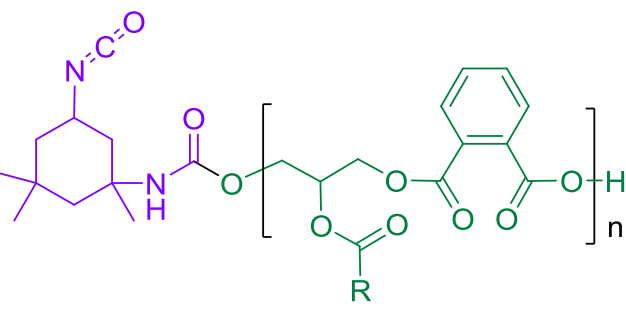

Alkyd urethane resin

Scheme 9: Synthesis route of alkyd urethane resin

In order to exhibit excellent film properties, the authors reported the formation of interpenetrating polymer networks (IPNs) with poly(alkyd-urethane) and polybutyl methacrylate (PBMA) which made IPNs potentially useful in coatings and rubber industries. Adding PBMA to poly(alkyd-urethane) allowed to combine the coating properties of alkydurethane resins and elastomeric nature of PBMA.

\section{2) Copolymerization of poly(alkyd-urethane)}

However, in order to obtain a higher content of urethane functions, polyalkyd-urethane resins can be formed by a two-step procedure where polyacid (e.g. phthalic anhydride) is fully or partially replaced by diisocyanate. ${ }^{17,104}$ The first step corresponds to the formation of monoglyceride by reacting triglyceride oil with polyol. ${ }^{8,105}$ Then, the second step is carried out by adding a diisocyanate compound in the mixture. The hydroxyl groups react with isocyanate groups to form urethane linkages. ${ }^{8,105}$ Güner et al. also reported the formation of poly(alkyd-urethane) following the same procedure (Scheme 10). ${ }^{17}$

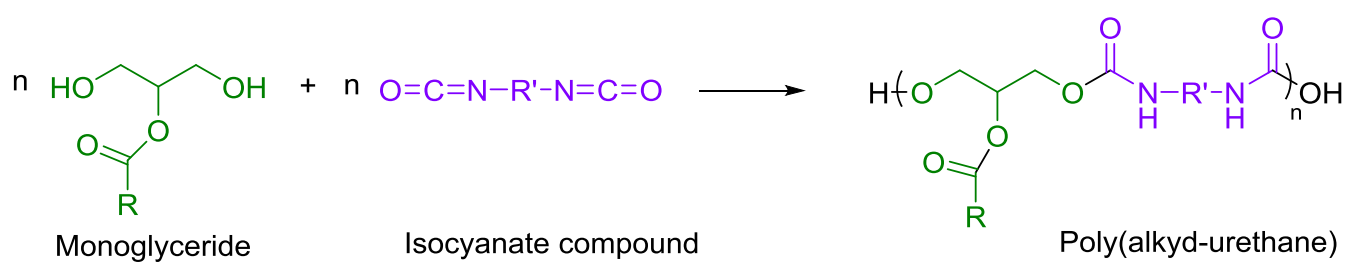


Hence, different isocyanate compounds were used in order to study their impact on the properties of the film. Indeed, diisocyanate compounds can be either aromatic such as toluene diisocyanate (TDI) or aliphatic such as hexamethylene diisocyanate (HMDI). According to the expected properties, the choice of aliphatic or aromatic form is crucial. The obtained films exhibited a thickness of $40 \mu \mathrm{m}$. Those made of aromatic diisocyanates-based polyurethane-alkyd resins exhibited good abrasion and chemical resistances. Furthermore, aromatic isocyanates exhibited hardness properties thanks to the benzene ring. However, their surface degraded upon sunlight exposure and they had inferior color retention. ${ }^{105}$ Moreover, with aliphatic diisocyanates-based polyurethane-alkyd resins, films had excellent resistance to UV light and better color retention but exhibited lower glass transition temperature values. ${ }^{105}$

Nevertheless, some authors have developed slightly different syntheses in order to develop new polyalkyd-urethane design. Hence, Saravari et al. have mixed castor oil which contains hydroxyl groups with jatropha oil to lead to transesterification and rearrange the fatty acid chains on glycerol backbone. ${ }^{105}$ The reaction was completed when all triglyceride molecules contained at least one hydroxyl group. Then the second step occurred by adding TDI which reacted with hydroxyl groups, leading to the formation of PAU (Scheme 11). 

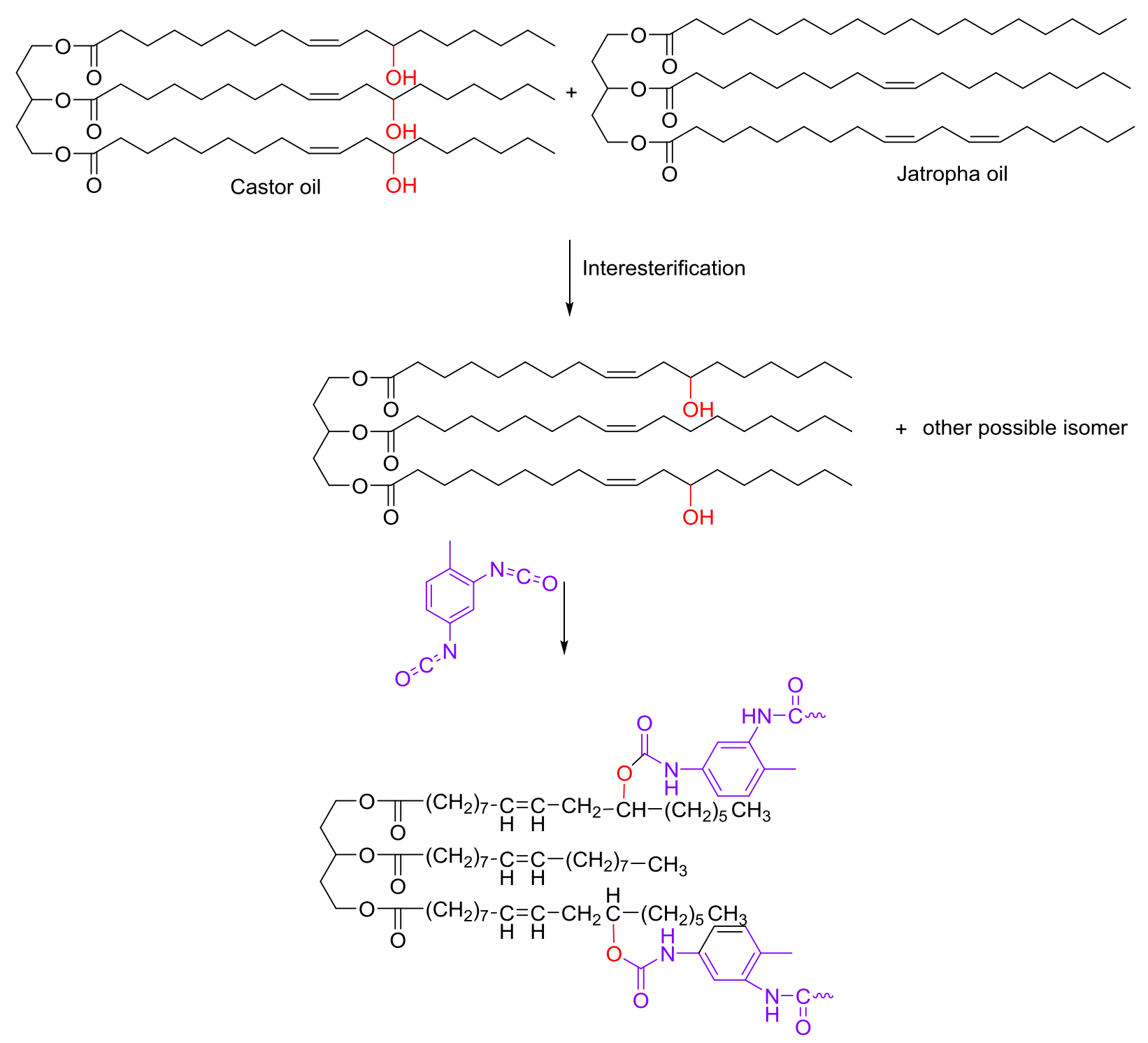

Scheme 11: Synthesis of PAU from interesterified castor oil/jatropha oil by Saravari et al. ${ }^{105}$

PAU films with a thickness of $60 \mu \mathrm{m}$ were very flexible and exhibited excellent adhesion with a result of $5 \mathrm{~B}$ which is the maximum rate of adhesion, as well as high impact resistance. The use of castor oil is an alternative raw material to glycerol for alkyd-urethane resins formation. Nevertheless, PAU films containing a high level of non-drying castor oil exhibited long drying times. Furthermore, alkali resistance of castor oil/jatropha oil-based urethane alkyd films was lower than urethane alkyd films formed with glycerol and jatropha oil. This is due to the high amount of oil in the resin, which led to a high content of ester groups that were hydrolyzed under alkaline conditions. Moreover, depending on the nature of vegetable oils used, fatty acids chains are different, as well as the structure of fatty acids and the number of unsaturations. ${ }^{106}$ Triglycerides based polyols are formed by functionalizing $\mathrm{C}=\mathrm{C}$ 
double bonds with a polyol. The more numerous are the double bonds, the higher is the hydroxyl number of the resulting polyols, leading to more urethane linkages when diisocyanates are added. Thereby, the increasing content of urethane groups improved mechanical resistance such as tensile strength.

Ling et al. have developed a novel chemical design of poly(alkyd-urethane) by a three-step copolymerization. $^{10}$ In the first step, monoglycerides were formed thanks to a transesterification between triglyceride and glycerol. Then a novel diol compound was synthetized with monoglycerides and phthalic anhydride, called alkyd diol. The authors added MDI able to polycondensate with the hydroxyl groups on the alkyd diol compounds to form urethane bonding, leading to the copolymerization of PAU (Scheme 12).

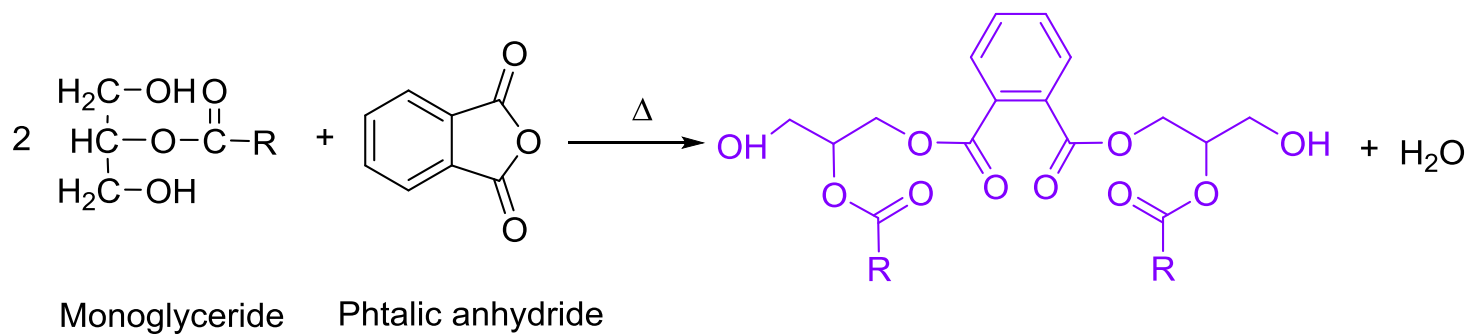

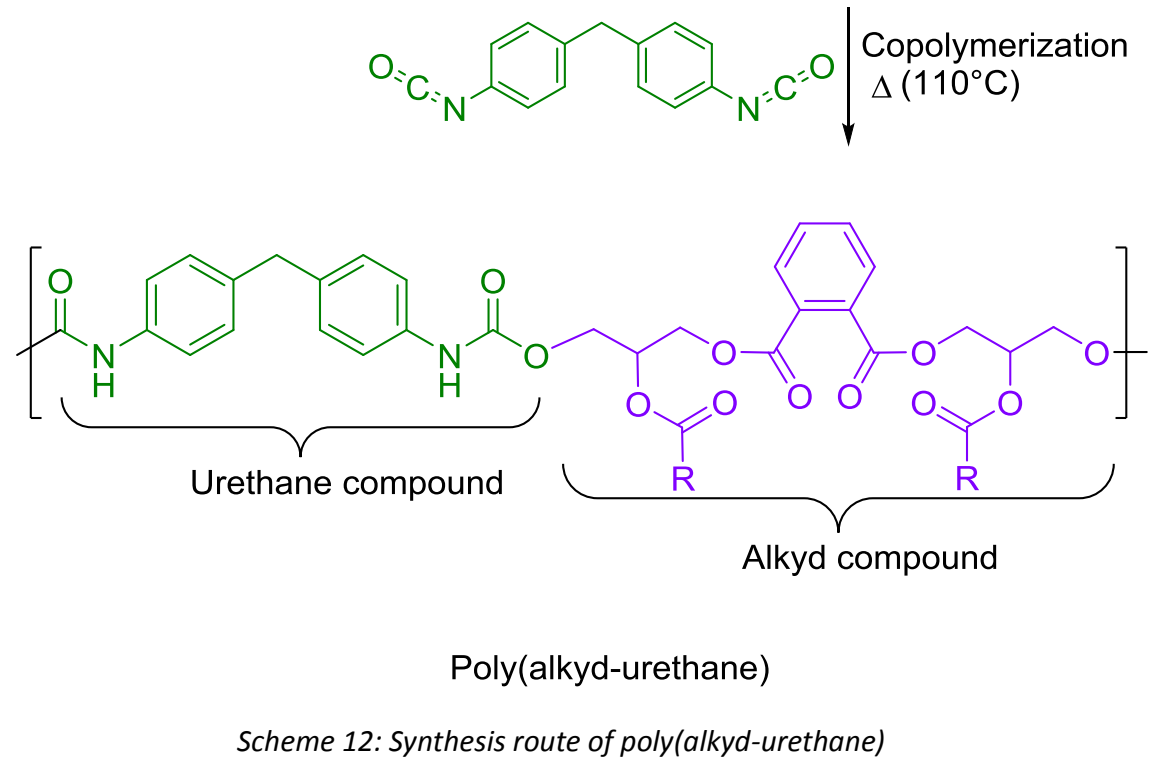

In the study, three different PAU were synthetized depending on the type of oil used: palm oil, soy oil and sunflower oil. All PAU films with thickness of $120 \mu \mathrm{m}$ exhibited good mechanical performance and chemical resistance conferred by urethane groups. Indeed, those coatings obtained $4 \mathrm{~B}$ at the cross-cut adhesion test meaning that less than $5 \%$ of area is removed. In order to have a good adhesion to substrate, the coating should exhibit hardness and flexibility which are respectively attributed to the aromatic structure of the 
polymer and to the urethane as well as the ester linkages. However, sunflower based PAU displayed superior drying properties, followed by soy oil and then palm oil based PAU. Indeed drying properties were affected by the number of unsaturations present in fatty acids. $^{10}$

Poly(alkyd-urethane) exhibited coatings with best properties of both polymers. Alkyd resin confers excellent flexibility and urethane part allows to improve chemical resistance as well as mechanical properties such as hardness and tensile strength thanks to the urethane linkage, considered as hard segment.

\section{Polysiloxane}

One of the limitation of the alkyd is their poor outdoor weatherability that could be improved by adding silicones which possess excellent moisture and UV-degradation resistance. ${ }^{16,107}$ Indeed, silicones, also called polysiloxanes, are a popular group of synthetic polymers providing hydrophobicity to coatings thanks to their siloxane groups (Si-O-Si). ${ }^{108}$ Moreover, silicone containing polymers are attractive because they exhibit low surface tension, excellent electrical properties, good weatherability, non-flammability, high gas permeability, good thermal and chemistry stability, as well as corrosion protection. ${ }^{109-111}$ Since the $\mathrm{Si}-\mathrm{O}$ bonds have higher bond strength compared to $\mathrm{C}-\mathrm{C}$ bonds, the barrier protection effect of matrices modified with Si-O is strongly enhanced. ${ }^{110,112}$ However, siloxanes exhibit poor miscibility with alkyds. Hence, the first silicone-alkyd hybrid systems were blends with microphase separations which exhibited multiple glass transition temperatures. In order to overcome this drawback, siloxanes were grafted to alkyds, thus the microphase separation was reduced, leading to better overall properties. ${ }^{16}$ Several routes were investigated to create covalent bonds between constituents. Alkyd resins can be post-functionalized by silicon compounds thanks to their remaining hydroxyl groups or by chemically modified unsaturations present in their long aliphatic chains in order to obtain silicone-modified alkyd resins. ${ }^{111}$ Another way to confer silicone properties to alkyd resins is through the development of silicone alkyd copolymers. ${ }^{113,114}$ 


\section{1) Post-functionalization of alkyd resins with silicone compounds}

Hence, Patil et al. reported the synthesis of a bio-based silicone-modified alkyd resin. Alkyd resin was obtained by reacting linseed oil with glycerol and then itaconic acid. ${ }^{58}$ The unsaturations of the fatty acids were completely converted into oxirane rings through epoxidation reaction in the presence of hydrogen peroxide and acetic acid. Finally, the epoxidized alkyd resin was modified with different amounts of 3-amino propyltrimethoxysilane (APTMS), between 10 and 40 mol\% to form a silicone-modified alkyd resin (Scheme 13). 

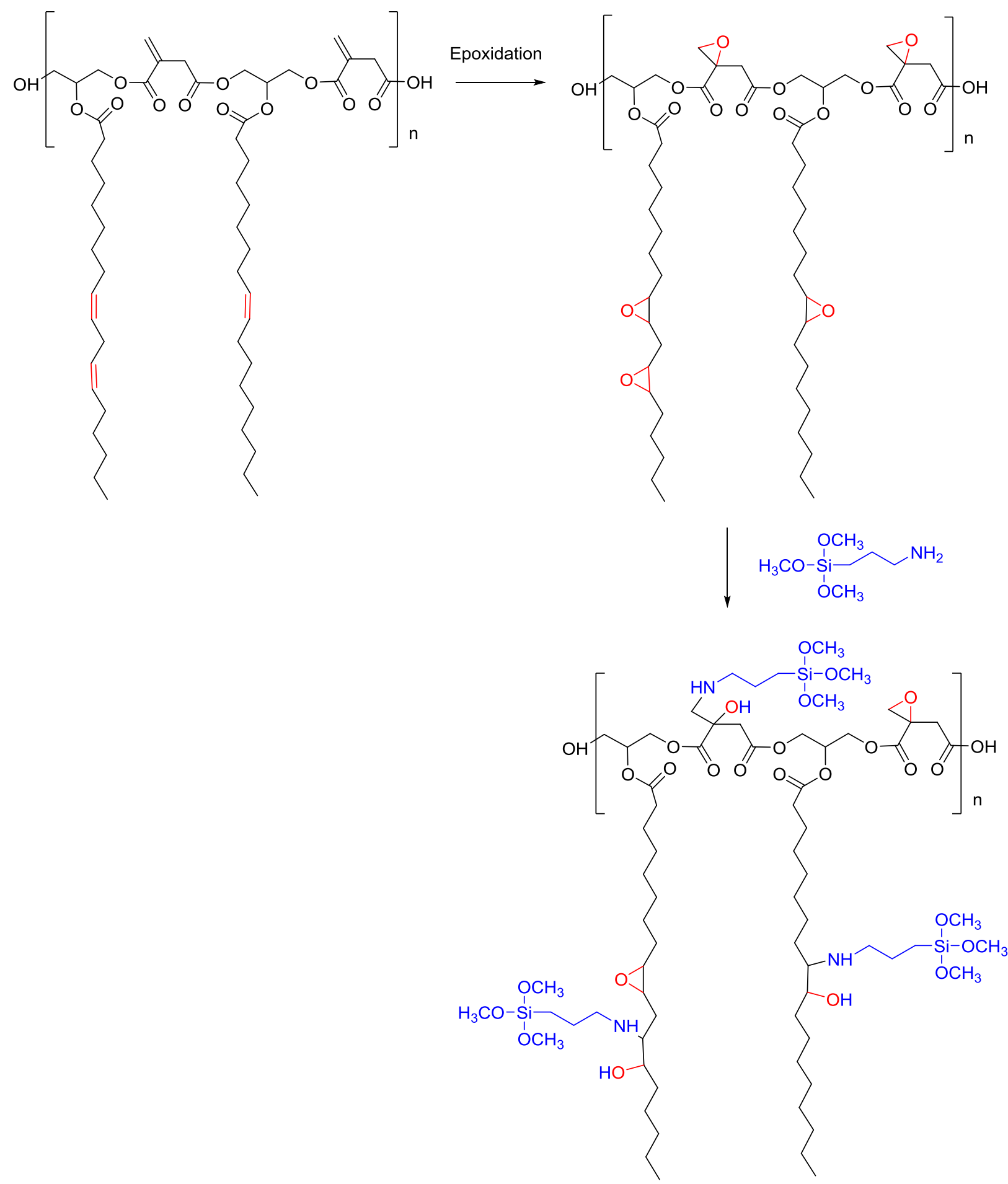

Scheme 13: : Patil et al. ${ }^{58}$ synthetic route for silicone-modified alkyd resin

Resin was solubilized in xylene in order to cast films with a thickness between 50 and $60 \mu \mathrm{m}$ which were thermally cured by reaction leading to siloxane ( $\mathrm{Si}-\mathrm{O}-\mathrm{Si}$ ) linkages. The APTMS allowed a three dimensional cross-linked structure of coatings. Moreover, the hydroxyl groups present in the backbone of silicone-modified alkyd resin formed hydrogen bonds with each other and with the metal substrate, which enhanced mechanical properties such 
as adhesion, hardness as well as resistance against solvent, acid and alkali solutions. All the coatings had a highly cross-linking density, providing chemical resistance. However, the mechanical and anticorrosion properties of the coatings were improved with increasing amounts of APTMS.

Moreover, Nalawade et al. reported the functionalization of soybean oil with 3(trimethoxysilyl)propyl methacrylate, an alkoxysilane monomer, by Diels-Alder reactions. Then, this siloxane-functionalized soybean oil was used as reactive diluent in the coating formulation with long oil alkyd resin and metal drier. ${ }^{11}$ Reactive diluents are useful to replace organic solvents and reduce VOC content. The $50 \mu \mathrm{m}$ films exhibited excellent coating performances with a formulation containing from 10 to 20 wt\% of reactive diluent. Tensile strength and tensile modulus were improved by $24 \%$ and $21 \%$ respectively, compare to alkyd coating.

Post functionalized alkyd resins by grafting siloxane compounds onto double bonds of fatty acids did not allow a drying process by autoxidation. ${ }^{11}$ In fact, curing occurred via sol-gel reaction, which needed longer drying time. In order to keep double bonds for film drying, siloxane compounds can be grafted onto the main chain through copolymerization reaction.

\section{2) Copolymerization of silicone-modified alkyd resins}

Silicone copolymers are widely used in the paint industry. ${ }^{114}$ Indeed polysiloxanes confer heat resistance, anticorrosion and hydrophobic properties to coatings. ${ }^{114}$ Silicone monomers can be copolymerized with alkyd resins by step growth polymerization. Moreover, alkyd resins are most commonly encountered in two forms: in solution for use in industrial finishes, and in emulsion in decorative waterborne finishes. ${ }^{16}$

\section{2.a. Solvent borne coatings: traditional method to formulate coatings}

Ratajczak et al. studied the effect of an alkyd resin in a grafting process of an aminosilane, [3-(2-aminoethylamino)propyl]trimethoxysilane (AAPTMS) to the wood matrix formed of sawdust with grains size equal to $0.5 \mathrm{~mm} .{ }^{108}$ Aminosilanes are interesting for wood treatment thanks to the presence of the amino group that exhibits antifungal properties and the silicone function that increases hydrophobicity of the coating. Nevertheless, wood treated with AAPTMS without alkyd resin exhibited leaching of silicon coming from the $\mathrm{Si}\left(\mathrm{OCH}_{3}\right)$ groups. Thus, to overcome this limitation, the wood sawdust was mixed with 
different amounts of AAPTMS, $20 \mathrm{wt} \%$ of alkyd resin and white spirit as solvent before being dried. Infra-red and NMR analyses of the formulation based on $2.5 \mathrm{wt} \%$ of AAPTMS showed chemical permanent bonding between aminosilane-alkyd resin and the wood matrix thanks to the hydroxyl groups of the cellulose. Moreover, alkyd resin grafted with AAPTMS limited leaching of this organosilane and improved its bonding with the wood matrix, providing lasting antifungal and hydrophobicity properties.

Different studies reported the use of a commercial hydroxyl-terminated silicone compound to modify an alkyd resin and confer hydrophobic properties. Mejia et al. demonstrated improvement of gloss value as well as chemical resistance properties and hydrophobic characteristics thanks to an alcoholysis reaction between silanol and hydroxyl groups of the alkyd resin. ${ }^{109}$ Kanai et al. synthesized a silicone acrylic methacrylate monomer by reaction between hydroxyl-terminated silicone compound and 2-hydroxyethyl methacrylate. ${ }^{113}$ Tetraisopropoxide titanate was incorporated in order to avoid self-condensation of silicone. The silicone acrylate monomer was then copolymerized with a soybean alkyd resin (Scheme 14). The incorporation of silicone acrylate monomer into alkyd resin was limited to $30 \mathrm{wt} \%$ to avoid any phase separation. 
<smiles>[R]C(=O)OCC(COC([R])=O)(COC(C)=O)COC(=O)c1ccccc1C(=O)OCC(CC)OC([R])=O</smiles>

Alkyd resin

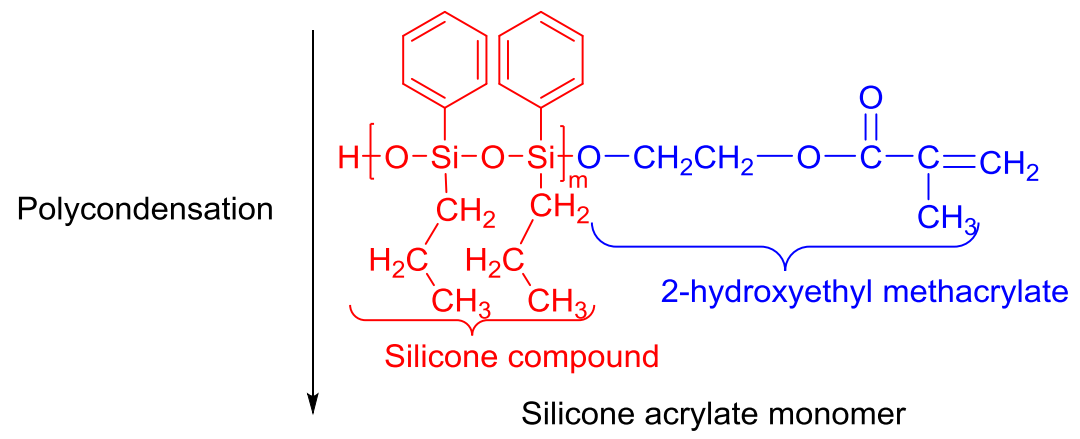

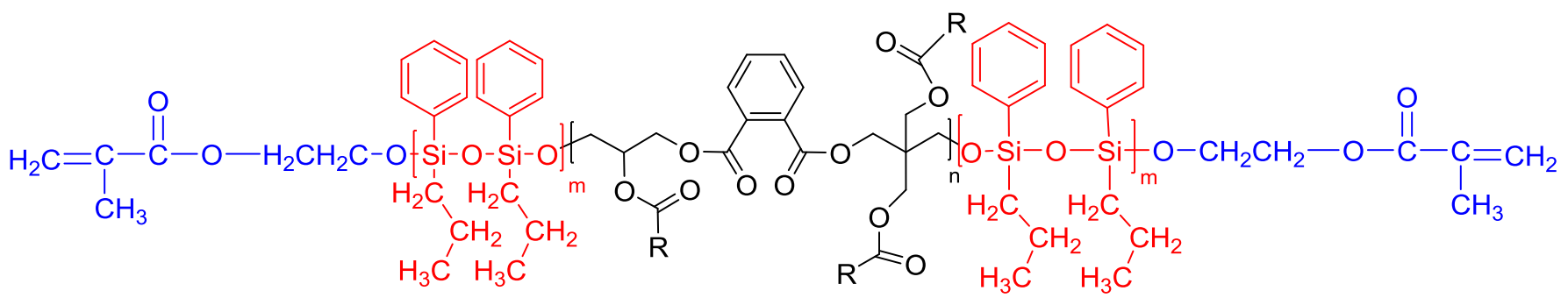

Silicone acrylate modified alkyd resin

Scheme 14: Synthesis of silicone acrylate modified alkyd resin

Coatings were formulated with xylene as solvent and films thickness was $300 \mu \mathrm{m}$. Coatings were dried by auto oxidation process and the reaction withvinylic double bond of acrylate end-chain leading to a highly cross-linked resin.Indeed, incorporation of $30 \mathrm{wt} \%$ of silicone acrylate monomer (SAM) into alkyd resin has led to coatings with superior weathering and mechanical properties compared to resin with less SAM or silicone-alkyd resin without acrylate. These results showed a synergic effect between acrylate and silicone.

Hiles et al. copolymerized alkyd resin with a polysiloxane by polycondensation onto the remaining hydroxyl groups. ${ }^{115}$ The obtained coatings exhibited a thickness of $50 \mu \mathrm{m}$ and showed better color and gloss retention as well as heat resistance than neat alkyd resin. The authors used these coatings for varnish formulation. 


\section{2.b. Limited solvent coatings: new methods to formulate coatings}

Due to the restriction about volatile compounds, some routes have been developed to avoid and limit the use of VOCs into formulations such as high solids coatings. High solid coating are needed in order to reach high concentration of solid compound (at least $65 \mathrm{wt} \%$ ). They have been developed to reduce the VOCs emitted by coatings formulated with volatile solvents. ${ }^{116}$ Murillo et al. reported high solid coatings based on hyperbranched alkydsilicone resins. ${ }^{7}$ The authors previously studied and synthetized hyperbranched alkyds by esterification of dendritic polyols with fatty acids. ${ }^{117}$ The results of the study showed higher elasticity, lower viscosity and faster drying times of hyperbranched alkyd resins compare to conventional alkyd resins. Moreover, hyperbranched alkyd resin was mixed with a silicone compound which reacted with terminal hydroxyl groups of hyperbranched alkyd resin through alcoholysis reaction (Scheme 15)

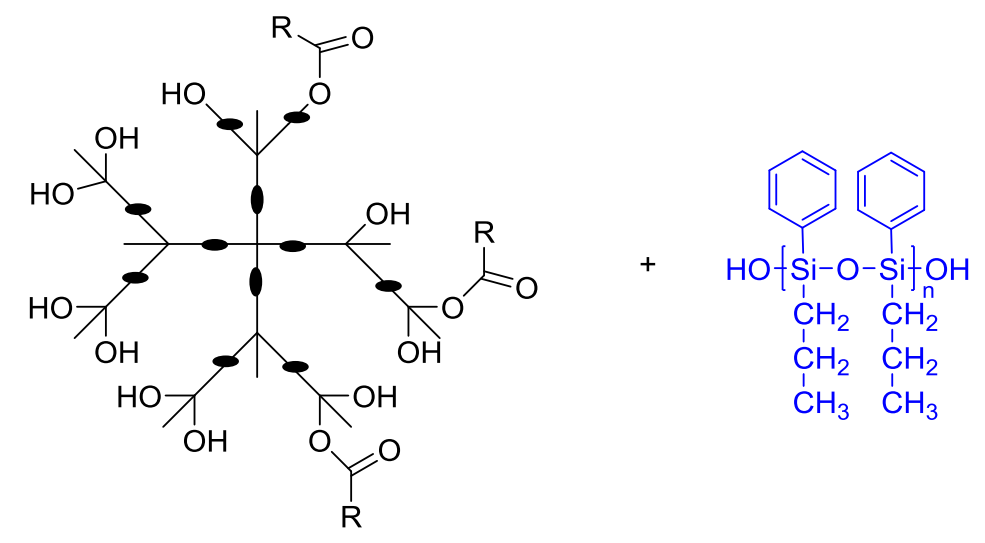

Hyperbranched alkyd resin

Z-6018 Silicone

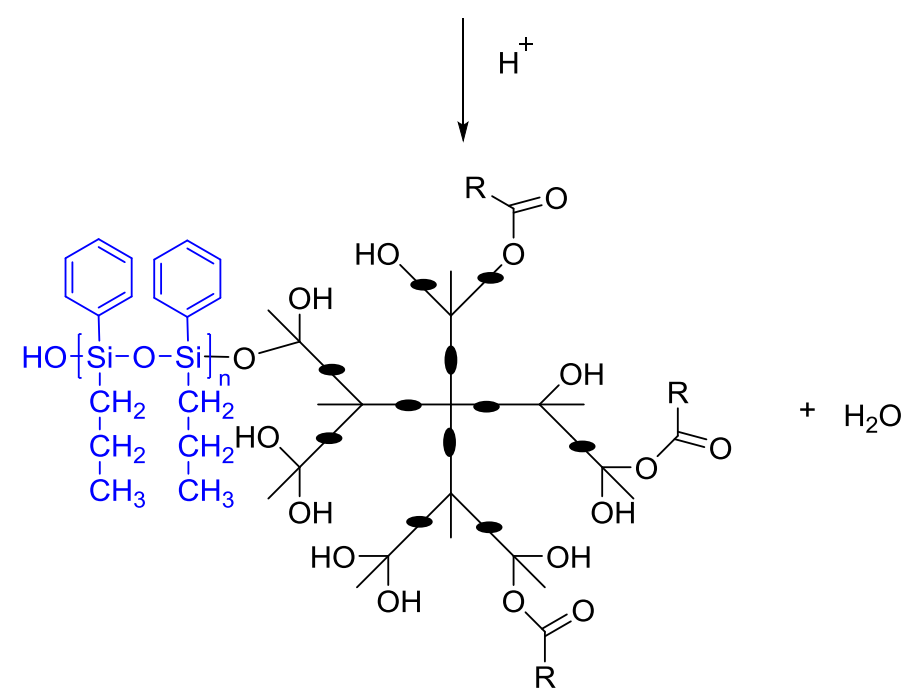

Hyperbranched alkyd-silicone resins

Scheme 15: Structural representation of synthesis of hyperbranched alkyd-silicone resins ${ }^{7}$ 
Then xylene was added to obtain hyperbranched alkyd-silicone resins with a solid content of $70 \mathrm{wt} \%$. The results for hyperbranched alkyd-silicone resins showed better film properties, including higher adhesion, shorter drying times, higher hardness and higher gloss compare to net hyperbranched alkyd resins. Moreover, hyperbranched alkyd-silicone resins exhibited higher hydrolysis resistance than net hyperbranched alkyd resins. Indeed, silyl ether groups are more stable than the ester groups toward acid and base hydrolysis. ${ }^{116}$

Furthermore, depending on the structure of the silicone or the alkyd compounds, final properties of the coatings can be impacted. The influence of oil length and silicone backbone substituents have been studied by Chakraborty et al. thanks to a coating formulation with a silicone-alkyd resin and a cobalt, zirconium and calcium drier package without using any solvent. ${ }^{16}$ Siliconized-alkyd resin was obtained by a hydrocoupling reaction allowing to mix the telechelic siloxane with the hydroxyl functions of the alkyd resin using Wilkinson's catalyst (Scheme 16). 
<smiles>[R]C(=O)OCC(CO)(COC([R])=O)COC(=O)c1ccccc1C(=O)OCC(CO)(C(C)C)C(C)O</smiles>

Alkyd resin<smiles>[Y][Si]([Y])(O[Si](C)(C)C)O[Si](C)(C)C</smiles>

Silicone monomer

Wilkinson's catalyst<smiles>[R]C(=O)OCC(COC([R])=O)(COC(=O)c1ccccc1C(=O)OCC(CO[Si]([Y])(C)O[Si]([Y])([Y])O[Si](C)(C)C)(O[SiH]([Y])C)C(C)O)CO[Si](C)(C)O[Si]([Y])(C)O[Si](C)(C)C</smiles>

Silicone modified alkyd resin

Scheme 16: Siliconized-alkyd resin by a hydrocoupling reaction using Wilkinson's catalyst

Different silicone-alkyd hybrids were prepared with three different oil lengths and three silicones with different backbone substituents. Films were formed with a thickness of 200 $\mu \mathrm{m}$ and exhibited good weatherability and chalking resistance. Nevertheless, the results showed that physical coatings properties depended on both oil length and silicone substitution. The results showed that crosslink density, flexibility, and reverse impact resistance were directly proportional to oil length. On the other hand, tensile modulus, hardness, elongation at break, glass transition temperature, drying time, and fracture toughness were inversely proportional to oil length. Moreover, the cycloaliphatic substituents such as cyclopentyl and cyclohexyl groups on the silicone backbone improved all the mechanical and coatings properties of the hybrids better than methyl groups on the silicone backbone. Nevertheless, those cycloaliphatic substituents decreased the crosslink 
density compared to methyl group substituents because the distance between reactive sites increased with the bulkiness.

Silicone compounds were combined with alkyd resins in order to provide coatings with various properties such as gloss value or hydrophobic properties. Indeed, silicone-modified alkyd resins have a weatherproofing ability that is really useful to avoid corrosion of metal. Hence, coatings formulated with silicone-modified alkyd resins find applications to protect metallic or wood surfaces.

\section{Polyamide}

Polyamide are characterized by -CONH groups that lead to hydrogen bonds between them, conferring high strength and mechanical properties to the polymer, despite low molecular weight. ${ }^{118-120}$ Polyamides have been introduced into alkyds in order to improve the thixotropy, a rheological property of the resin. Thixotropy is defined as the continuous decrease of viscosity with time when flow is applied to a sample that has been previously at rest and the subsequent recovery of viscosity in time when the flow is discontinued. ${ }^{121}$ This phenomenon is generally used for protective or decorative coatings such as paints. Thixotropy also improves the transfer of the paint to the brush or roller and reduces the tendency of the paint to drip and splatter when being applied. ${ }^{122}$ Moreover, thixotropy helps to reduce separation, flooding and settlement. ${ }^{123}$ Thixotropes can be divided into two categories: thixotropic additives and thixotropic resins. ${ }^{122}$ Thixotropic additives including fumed silica, organo-modified clays, organic wax paste, sulfonated castor oil, are added to the paint formulation during the pigment dispersion phase, leading to higher solid systems. ${ }^{122,124}$ Those systems are more sensitive to dye systems based on water, surfactants and other solvents. That is why, incorporation of the rheological properties directly into resin instead of paint formulation is more efficient. ${ }^{124}$ Usually, blends between polyamide and alkyd resin give thixotropic resins due to the hydrogen bonds between the respective $-\mathrm{NH}$ and $-\mathrm{OH}$ groups. ${ }^{121}$

\section{1) Polyamide crosslinked with alkyd resins}

A US patent reported new thixotropic paints containing short oil alkyd resin and a polyamide. ${ }^{123}$ Firstly, the alkyd resin was synthetized by a two-step procedure with glycerol 
and soybean oil and then phthalic anhydride. Polyamide was obtained by reacting polymeric fatty acids with diacids such as sebacic acid, and a diamine. The resulting polyamide modified alkyds exhibited thixotropic properties. Moreover, another US patent reported thixotropic resins prepared by reacting an oil soluble dimer acid based polyamide resin with an alkyd resin. ${ }^{122}$ The authors have synthetized low molecular weight polyamides with three reagents. One of the starting materials is a polycarboxylic acid, preferably an oligomer of fatty acids. The second one is an active hydrogen compound having the formula $X_{m}-R-Y_{n}$ where $R$ represents a group containing from 2 to 12 carbon atoms, $X$ and $Y$ are independently selected from primary amino, secondary amino and hydroxyl. Preferably compound is a diamine such as 1,6-diaminohexane. The last component is a capping agent composed of an unsaturated or hydroxyl functional monocarboxylic acid having from 8 to 22 carbon atoms.

Furthermore, modification of alkyd resin with fatty polyamides having aromatic diamine moiety have been reported by Anamika et al. and exhibited superior rheological performance and gel forming properties compared to the previously known thixotropic agents. ${ }^{122,124}$ Several authors studied the use of fatty polyamides with aromatic diamine moiety. Anyaogu et al. synthetized fatty polyamides by reacting 1,2-phenylene diamine with a soybean oil based dimer acid. ${ }^{125}$ Then, the $-\mathrm{NH}_{2}$ terminal groups of fatty polyamides reacted with the terminal $-\mathrm{COOH}$ groups of the alkyd resins to form amide linkages. The $-\mathrm{NH}$ groups in the chain of the polyamide-modified alkyd resins led to an increase of hydrogen bonds in the macromolecule, leading to thixotropic properties. Indeed the hydrogen bonds may be broken down by shearing forces like stirring and brushing thus leading to a drop in the viscosity of the resin. The bonds gradually reforms as soon as shearing ceases leading back to high viscosity. Moreover, films formed with fatty polyamides alkyd resin exhibited faster drying time, better storage stability and greater films hardness.

Ikyenge et al. also reported the modification of alkyd resin with fatty polyamide prepared by the reaction of dimer acids from Jatropha curcas oil and 1,2-phenylenediamine. ${ }^{126}$ The formed films showed shorter drying time, adhesion and hardness resistance. Solvent resistance was also exhibited except for alkali. Indeed, the ester groups were sensitive to hydrolysis in presence of alkali. 


\section{2) Polycondensation of polyesteramide}

Shende et al. have reported the polymerization of polyesteramide resin based on the condensation of hydroxyethylamide derivatives of fatty acids of soybean and various dibasic acid and anhydride. ${ }^{127}$ The first step consisted of reacting vegetable oil such as soybean oil and methanol with a catalyst to form a methyl ester of vegetable oil. Then diethanolamine was added to obtain diethanolamide-based vegetable oil which finally reacted with a dibasic acid compound to form polyesteramide (Scheme 17).

First step : formation of methyl esters based fatty acids

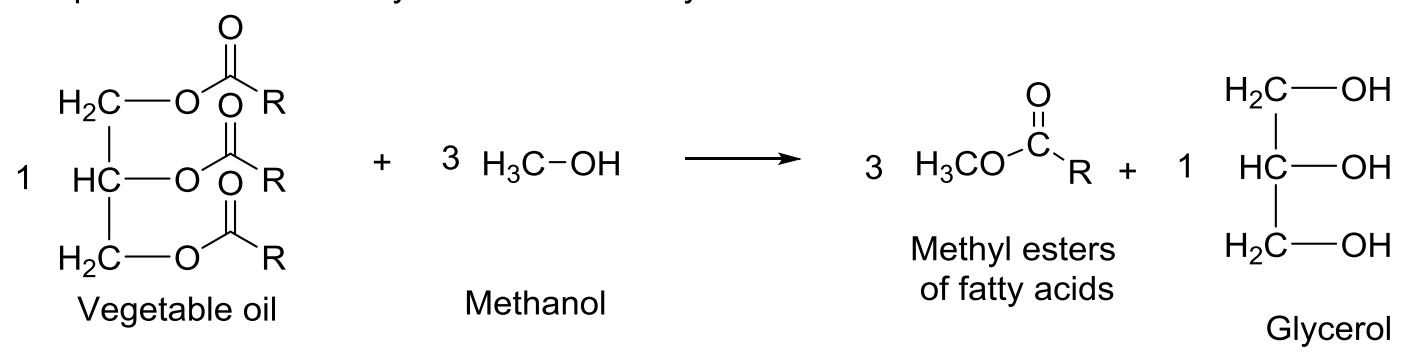

Second step : formation of diethanolamide

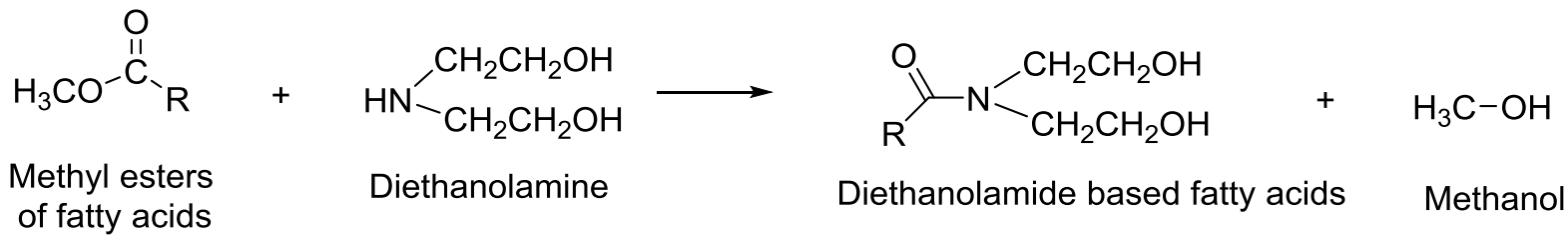

Third step : formation of polyesteramide<smiles>[R]C(=O)N(CCO)CCCO</smiles>

Diethanolamide based fatty acids<smiles>O=[R](O)C(=O)O</smiles>

Dibasic acid<smiles>[R]C(=O)N(CCOCC)CCOC(=O)[R]([H])([H])O</smiles>

Polyesteramide

$$
\mathrm{R}^{\prime}=\begin{aligned}
& \left(\mathrm{CH}_{2}\right)_{2} \\
& \left(-\mathrm{CH}_{2}\right)_{4} \\
& \left(-\mathrm{CH}_{2}\right)_{8}
\end{aligned}
$$<smiles>Cc1ccccc1C</smiles>

Scheme 17: Synthetic routes for polyesteramide formation

Coatings exhibited thixotropic properties as well as better drying time, hardness properties, solvents and water vapor resistance over conventional alkyd resins. Nevertheless, alkali resistance was not improved in those films. ${ }^{127}$ 
Most of the time, polyamides were added to alkyd resin in order to develop thixotropic properties, which are useful for the application of paints. Different synthesis routes have been reported in the literature allowing the formation of polyamide, which could enhance other properties such as chemical resistance, drying time or hardness. Moreover polyamide having aromatic diamine moiety exhibited better rheological properties.

\section{Alkyd composites}

In order to further improve alkyd-hybrids, it is possible to make composites. Hence, different inorganic particles or fillers can be introduced in order to obtain composites with desired properties. Several examples from the literature are summarized in Table 1.

\begin{tabular}{|c|c|}
\hline Filler & Properties \\
\hline Graphene oxide $^{128,129}$ & Tensile strength, elastic modulus, thermal stability \\
\hline Expanded graphite $^{130}$ & Thermal stability, mechanical properties, flame retardancy \\
\hline NiO $^{131}$ & Mechanical properties, $\mathrm{T}_{\mathrm{g}}$ increase, flame retardancy \\
\hline $\mathbf{C u O}^{132}$ & Thermal stability \\
\hline Glass Cloth $^{133}$ & Mechanical properties, hardness, $\mathrm{T}_{\mathrm{g}}$ increase \\
\hline $\mathbf{S i O}_{2}{ }^{96,110,134}$ & Thermal stability, anticorrosion properties \\
\hline $\mathrm{ZnO}^{112}$ & Thermal stability, scratch and abrasion resistance \\
\hline $\mathrm{TiO}_{2}{ }^{135}$ & Self-cleaning \\
\hline
\end{tabular}

Table 1: Main properties of alkyd hybrid composites in function of filler nature

\section{1) Composites from alkyd-epoxy systems}

Many particles can be used in order to improve alkyd-epoxy hybrids and further increase already existing properties, or confer new ones such as flame retardancy.

Hence, Gogoi et al. made composites using alkyd epoxy as matrix and graphene oxide (GO) as filler, in order to improve thermal and mechanical properties. ${ }^{128}$ Tensile strength, elastic modulus and thermal stability showed good results, the major degradation temperature increased from $251{ }^{\circ} \mathrm{C}$ without $\mathrm{GO}$ up to $290{ }^{\circ} \mathrm{C}$ with $5 \% \mathrm{GO}$. The filler was well dispersed and led to the formation of a homogeneous material. The addition of $5 \mathrm{wt} \% \mathrm{GO}$ has also reduced 
the curing time of the alkyd/epoxy system. Zhu et al. also incorporated graphene into alkydacrylic emulsions. The resulting coatings shown good barrier and anticorrosion properties. ${ }^{129}$ Using nearly the same protocol, Gogoi et al. investigated the incorporation of expanded graphite (EG) in alkyd-epoxy resins. Alkyd and epoxy resins were blended with EG using MEKP and Co-octoate for curing in presence of amine hardener at $70^{\circ} \mathrm{C}$. The incorporation of EG was homogeneous and showed improvements of thermal, mechanical as well as flame retardant properties. ${ }^{130}$ The same team highlighted that the use of $\mathrm{NiO}$ particles into alkydepoxy blends enhanced mechanical properties such as elastic modulus and tensile strength, and raised $\mathrm{T}_{\mathrm{g}}$ value by $20^{\circ} \mathrm{C}$. It also improved the flame retardancy of the materials. ${ }^{131} \mathrm{Ong}$ et al. incorporated $\mathrm{CuO}$ nanoparticles into alkyd-epoxy blends through sol-gel method in glycerol. Although the reduction of epoxy/alkyd ratio led to a decrease of both tensile and flexural strengths, the incorporation of $\mathrm{CuO}$ has recovered this loss and even improved these properties. A higher thermal stability was also observed. ${ }^{132}$ Huo et al. used glass cloth as reinforcement for an alkyd/epoxy resin matrix. 3-Glycidylpoxypropyl-POSS (G-POSS) was also added to the resin. The results showed an increase of the $T_{g}$ and the mechanical properties such as impact and tensile strengths. ${ }^{133}$

\section{2) Silicone-modified alkyd composites}

In the literature, numerous studied reported the introduction of particles into siliconemodified alkyd resins in order to enhance some properties and provide new ones. Usually those particles are metal oxide nanoparticles which are inorganic.

Dhoke et al. reported the formation of a waterborne silicone-modified alkyd resin and then the addition of zinc oxide ( $\mathrm{ZnO}$ ) nanoparticles in order to improve thermal stability, enhance scratch and abrasion resistance. ${ }^{112}$ The influence on coatings properties of different amounts of $\mathrm{ZnO}$ nanoparticles between $0.05 \mathrm{wt} \%$ and $0.3 \mathrm{wt} \%$ were studied. The coating thickness obtained was 9-10 $\mu \mathrm{m}$. The SEM results showed a uniform distribution of $\mathrm{ZnO}$ nanoparticles into the coating whatever the $\mathrm{ZnO}$ concentration. The coating with higher loading of $\mathrm{ZnO}$ nanoparticles $(0.3 \mathrm{wt} \%)$ exhibited better performances such as heat stability and mechanical properties. An optimization perspective to further improve these properties could consist in adding other nano-oxide in order to have a synergic effect with $\mathrm{ZnO}$. Thus coatings could exhibit good scratch, abrasion and heat-resistant properties and find applications in various 
industries where the metal is subjected to high temperature such as automotive industries or heaters.

Other nanoparticles such as titanium dioxide can be added to silicone-modified alkyd resins to bring novel properties. The dispersion of titanium dioxide $\left(\mathrm{TiO}_{2}\right)$ nanoparticles into polymeric coatings has been widely studied for the self-cleaning properties of coatings with superhydrophobic surfaces. Superhydrophobic surfaces are characterized by a water contact angle superior to $150^{\circ}$. On such surfaces, self-cleaning effect occurs by rolling water droplets off, which is also called "lotus effect ". Nevertheless, one of the major limitation of superhydrophobic coatings is the lack of long-term stability of polymeric coatings with nanodispersed particles. In order to overcome this drawback, Pawar et al. formulated a paint with $\mathrm{TiO}_{2}$ nanoparticles introduced into a silicone-modified alkyd resin where $\mathrm{TiO}_{2}$ exhibited superhydrophilic properties. ${ }^{135}$ Indeed titanium dioxide became hydrophilic after exposure to UV radiation which can be reversed by visible light radiation. Superhydrophilic surfaces are characterized by a water contact angle lower than $5^{\circ}$. Self-cleaning effect on such surfaces occurred by photocatalytic degradation of surface contaminants and then by water spreading and forming a thin film on surfaces. Synthesis of silicone-modified alkyd resin/ $/ \mathrm{TiO}_{2}$ was carried out in situ in three steps (Scheme 18). In the first step, $\mathrm{TiO}_{2}$ nanoparticles were dispersed into soybean oil, followed by the formation of monoglycerides and diglycerides with pentaerythritol. Then, alkyd resin was obtained by polycondensation prior modification of the remaining hydroxyl groups with a silicone intermediate. 
<smiles>[R]C(=O)OCC1COC([R])C([R])OC(=O)O1</smiles>$$
\text { . }
$$

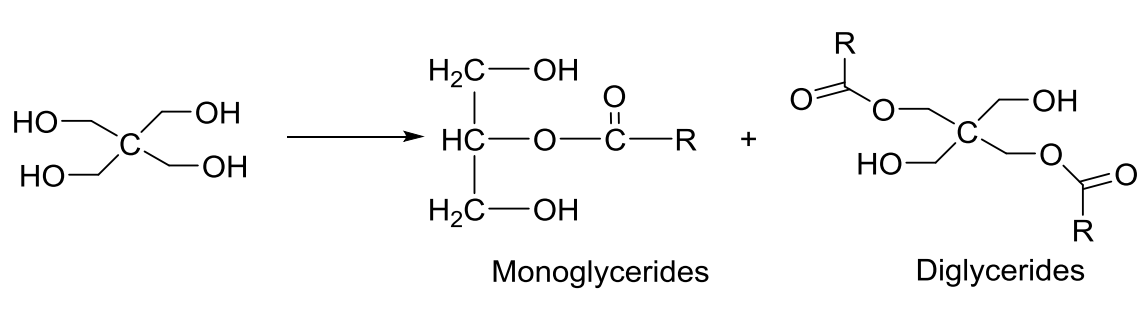

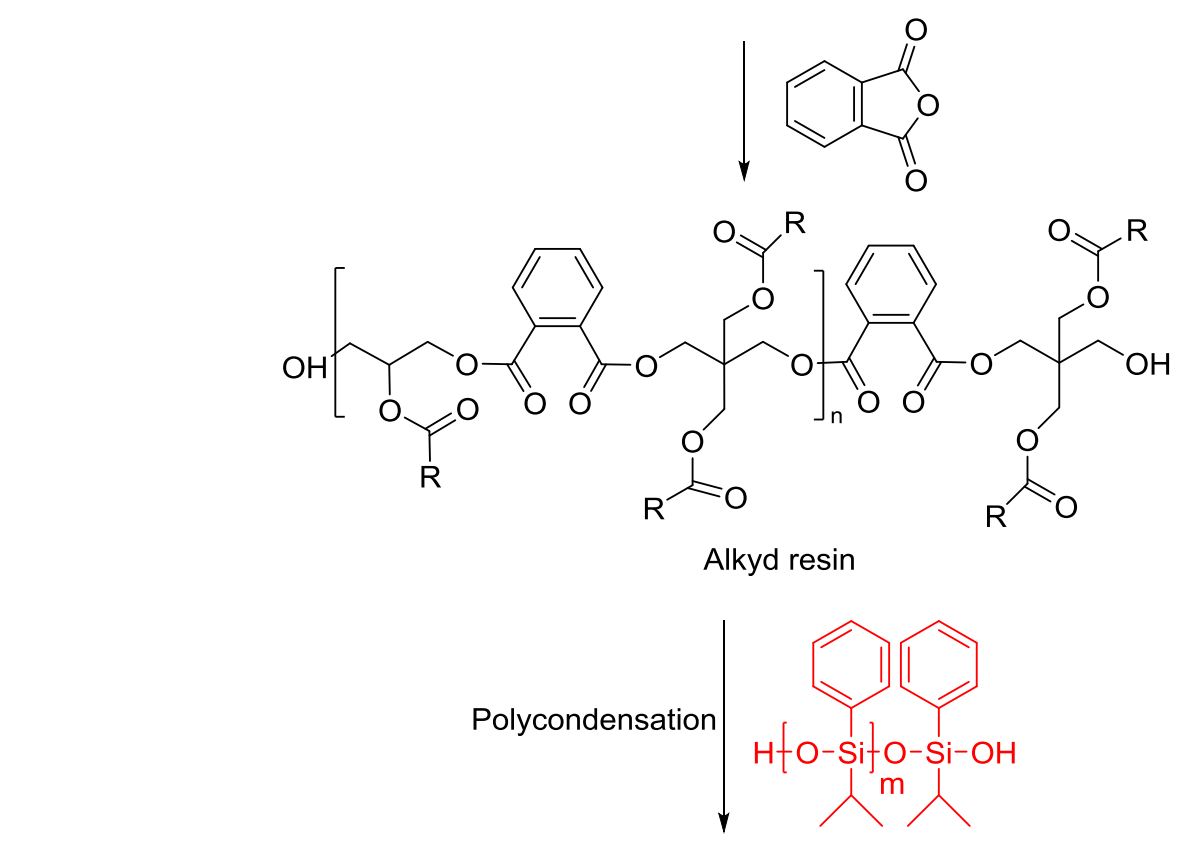

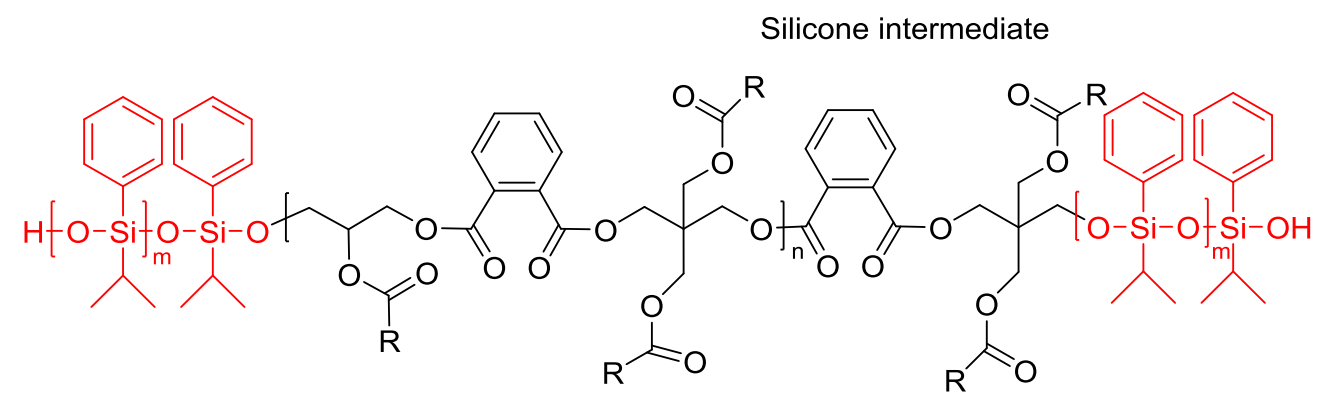

Silicone modified alkyd resin

Scheme 18: Synthesis of silicone-modified alkyd resin/TiO2

Paint coating formulation was prepared by adding $30 \mathrm{w}_{\mathrm{t}} \%$ of pigment, solvent and several additives to the silicone-alkyd resin/ $/ \mathrm{TiO}_{2}$. The coating thickness was $100 \mu \mathrm{m}$ and the best performances were obtained with the formulation containing $2 \mathrm{w}_{\mathrm{t}} \% \mathrm{TiO}_{2}$ into alkyd resin. Indeed, this formulation exhibited optimal hydrophilic characteristics with a water contact angle less than $10^{\circ}$.

In order to improve both mechanical and anti-corrosion properties of silicone modified alkyd resins, some authors reported the introduction of $\mathrm{SiO}_{2}$ nanoparticles. The influence of $\mathrm{SiO}_{2}$ 
into a waterborne acrylic-silicone modified alkyd resin have been reported by Zhong et al. ${ }^{110}$ and exhibited improvement of thermal stability, mechanical and anti-corrosion properties. A commercial silicon-modified alkyd resin was modified with maleic anhydride to provide unsaturated double bonds suitable for grafting acrylate monomer. Then methyl methacrylate (MMA) and butyl acrylate (BA) were added and reacted with the silicone alkyd resin at $70^{\circ} \mathrm{C}$. $\mathrm{Y}$-Methacryloxypropyltrimethoxysilane (MPS)-modified $\mathrm{SiO}_{2}$ nanoparticles were previously obtained by reacting hydroxyl groups of $\mathrm{SiO}_{2}$ nanoparticles with MPS and were also added to the reaction mixture with deionized water to form coarse emulsion which was ultrasonicated to obtain miniemulsion. It was found that $\mathrm{SiO}_{2}$ nanoparticles were uniformly introduced into the acrylic-silicone modified alkyd coatings by SEM analysis. Results indicated that better dispersed silicone nanoparticles improved the properties of the coatings. Moreover, increasing the amount of silicone nanoparticles also enhanced the properties. Thanks to anti-corrosion properties, those coatings found applications in the field of the waterborne, eco-friendly and VOC-free coatings for metal surfaces. Cakic et al. ${ }^{134}$ reported the influence of nanoparticles such as $\mathrm{SiO}_{2}$ into a waterborne poly(alkyd-urethane). Nanosilica particles with a diameter of $40 \mathrm{~nm}$, improved weatherability, increased hardness and thermal resistance of the films with a thickness of $100 \mu \mathrm{m}$. Nevertheless, nanoparticles are very expensive, therefore they were only used for specific applications. Zhong et al. further investigated the acrylic-alkyd hybrids applied to anticorrosion systems by developing novel surfactant-free waterborne acrylic-silicone modified alkyd hybrid resin coatings containing nano-silica. ${ }^{110}$

Alkyd hybrid resins could be additivated with nanoparticles in order to improve their thermal and mechanical properties or induce new ones such as flame retardancy and anticorrosion properties. Both a good dispersion and a well-balanced proportion of these particles were the keys to make these composites effective. Nevertheless, since those particles are expensive, therefore their use remained limited to specific applications.

\section{Further perspectives on sustainable alkyd hybrids}


In the last decade, environmental issues have become a major concern. Therefore, current researches have recently focused on the development of new alternatives more respectful of the environment. The substitution of carcinogenic, mutagenic and reprotoxic (CMR) compounds, the reduction of VOC emissions and the study of novel properties, provided eco-friendly alternatives which are described in this part.

\section{1) Development of non-isocyanate poly(alkyd-urethane)}

Poly(alkyd-urethane) used to be formed by combining isocyanates and alkyds. Nevertheless, due to the toxicity of some isocyanates (some of them are CMR substances) and the commitment to replace them due to regulations (annex XVII of the European regulation 1907/2006 Registration, Evaluation, Authorization and Restriction of Chemicals, REACH), alternatives to isocyanate are gaining increasing interest. ${ }^{139}$ That is why new routes have been developed to form Non-Isocyanate PolyUrethane (NIPU), following green chemistry principles. ${ }^{140}$ These NIPUs can be formed by different approaches, such as transurethanization, ${ }^{141-143}$ ring opening polymerization, ${ }^{144,145}$ or various rearrangements, ${ }^{146}$ but the most promising route seems the polyaddition between diamines and cyclic carbonates, ${ }^{147}$ including biobased resources. ${ }^{148}$ Haniffa et al. have synthetized a Jatropha curcas oil (JCO) based NIPU which mostly contains oleic and linoleic acids. ${ }^{140}$ Foremost monoglycerides were obtained by reacting JCO with glycerol and then succinic anhydride was added for polycondensation with monoglycerides. Double bonds $\mathrm{C}=\mathrm{C}$ of the fatty acids were epoxidized prior carbonation to led to cyclic carbonate alkyd resin (CC-AR). JCO based NIPU was obtained by reacting CC-AR with diamines such as isophorone diamine (IPDA) (Scheme 19). Films obtained with JCO based NIPU exhibited good chemical resistance to water, acid and alkali solutions. 


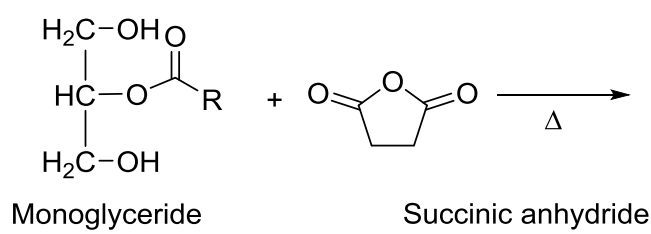

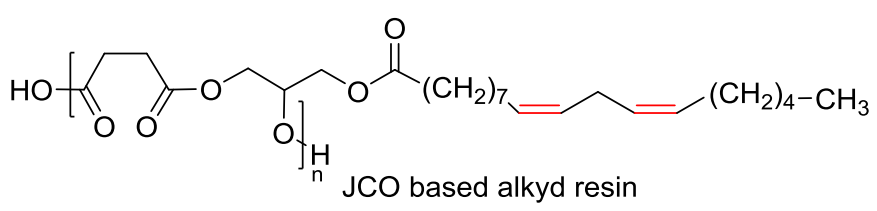
jatropha curcas oil

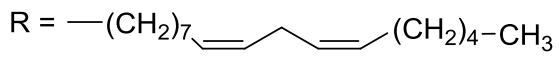

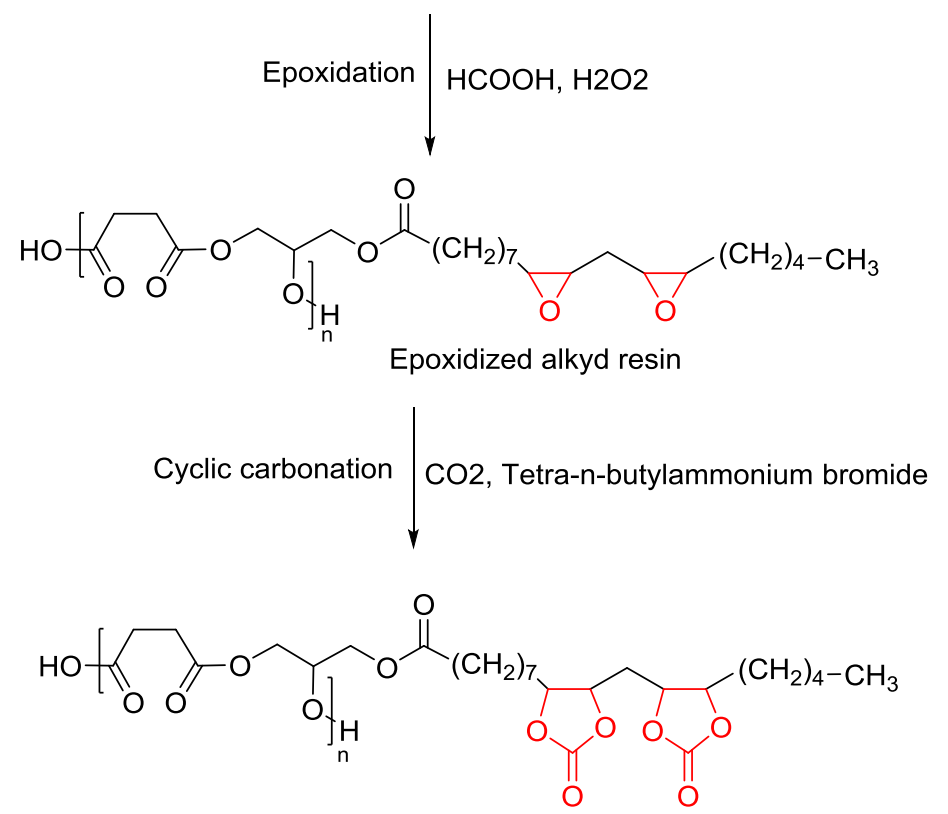

Cyclic carbonated alkyd resin
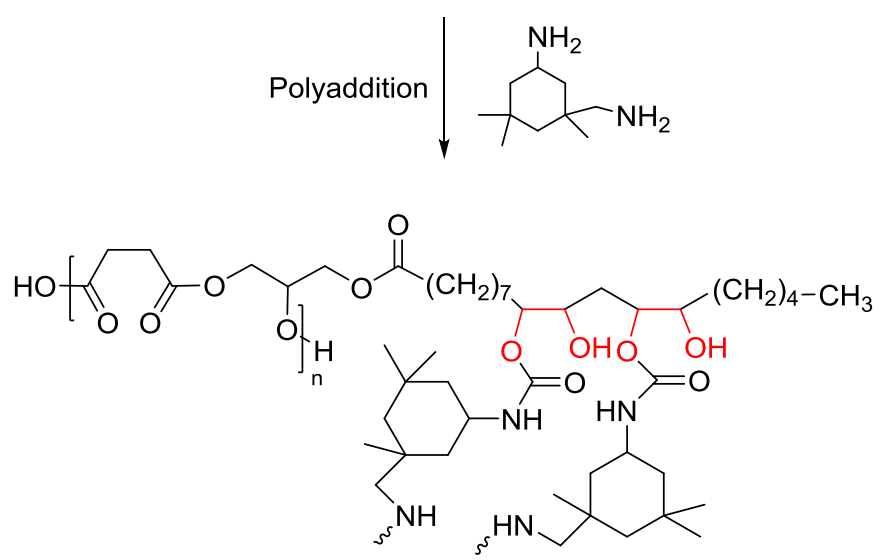

JCO based NIPU

Scheme 19: Reaction scheme of JCO based NIPUs

Additionally, the cross-linking of polycarbamates with dialdehydes has been reported in a US patent as a fast ambient cure NIPU route. ${ }^{149,150}$ Silbert et al. have investigated this novel route to synthetize NIPU with biobased reactants and obtained coatings with a thickness around $30 \mu \mathrm{m}$, which exhibited strong hardness and good solvent resistance. Hence, biobased polycarbamates were formed with methyl carbonate modified alkyds. Soybean oil based alkyds have been polymerized following the two-step procedure with pentaerythritol and two polyacids: isophthalic acid and phthalic anhydride. Then methyl carbamate was 
added to form polycarbamate which reacted with a dialdehyde such as 2,5-diformylfuran (DFF) or 1,4-cyclohexanedicarboxaldehyde (CHDA) leading to a poly(alkyd-urethane) without isocyanate (Scheme 20).<smiles>[R]C(=O)OCC(CO)(COC(=O)c1cccc(C(=O)OC)c1)COC(=O)c1ccccc1C(=O)OC</smiles>

Soybean oil based alkyd resin

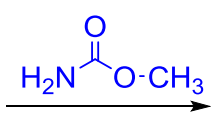<smiles>[R]C(=O)OCC(COC(N)=O)(COC(=O)c1cccc(C(=O)OC)c1)COC(=O)c1ccccc1C(=O)OC</smiles>

Polycarbamate
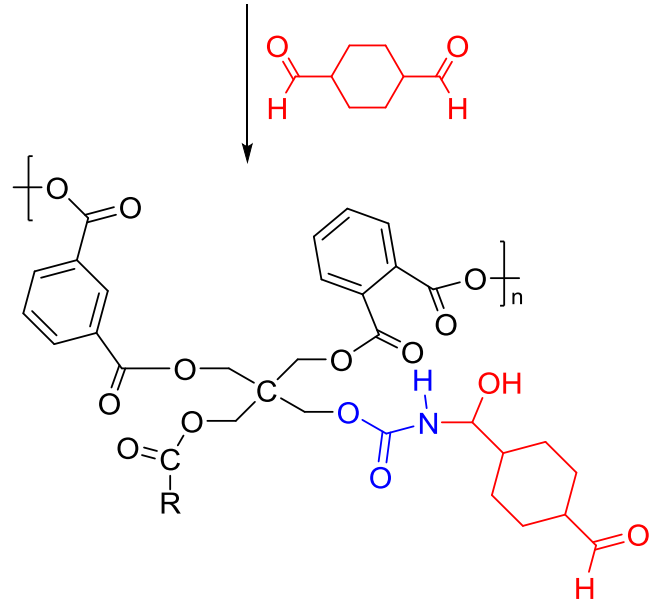

Poly(alkyd-urethane)

Scheme 20: Formation of poly(alkyd-urethane) with bioderived polycarbamate and biomass derived dialdehyde (CHDA)

Poly(alkyd-urethane) synthetized from DFF showed better hardness, adhesion and chemical resistance than those formed with CHDA. This was attributed to higher cross-linking with DFF than CHDA.

\section{2) Development of waterborne systems}

To reduce VOC emissions the major emphasis has been put on waterborne resins ${ }^{102}$ that are an eco-friendly alternative to solvent-borne resins since they are non-toxic and nonflammable. ${ }^{99}$ Nevertheless, the use of waterborne alkyd resin coatings are restricted to general applications due to their poor acid, water and alkali resistances. ${ }^{96}$ In order to tackle 
those limitations, researchers had tried to enhance the performances of coatings by introducing functional compounds other than acrylates.

\section{2.a Waterborne styrene-alkyd hybrid resins}

Similarly to alkyd resin modified with acrylic monomers by miniemulsion polymerization, Murillo investigated, recently, the utilization of hyperbranched alkyds and styrene for the synthesis of styrene-alkyd hybrids. ${ }^{151}$ Styrenic part could bring better optical clarity, good resistance to acids and bases, abrasion resistance and good hardness while maintaining better drying time and good chemical resistance as acrylate-alkyd hybrids. Process implied a hydrophobic phase composed of styrene, alkyd and hexadecane; and an aqueous solution of SDS with sodium bicarbonate. Miniemulsion polymerization occurred at $80^{\circ} \mathrm{C}$. Different ratios of styrene (20 to $50 \% \%_{\mathrm{wt}}$ ) were investigated; in all cases conversion reached up to $94 \%$. However polystyrene formation was observed with high ratios of styrene improving the stability of latex that had low droplets size (inferior to $300 \mathrm{~nm}$ ).

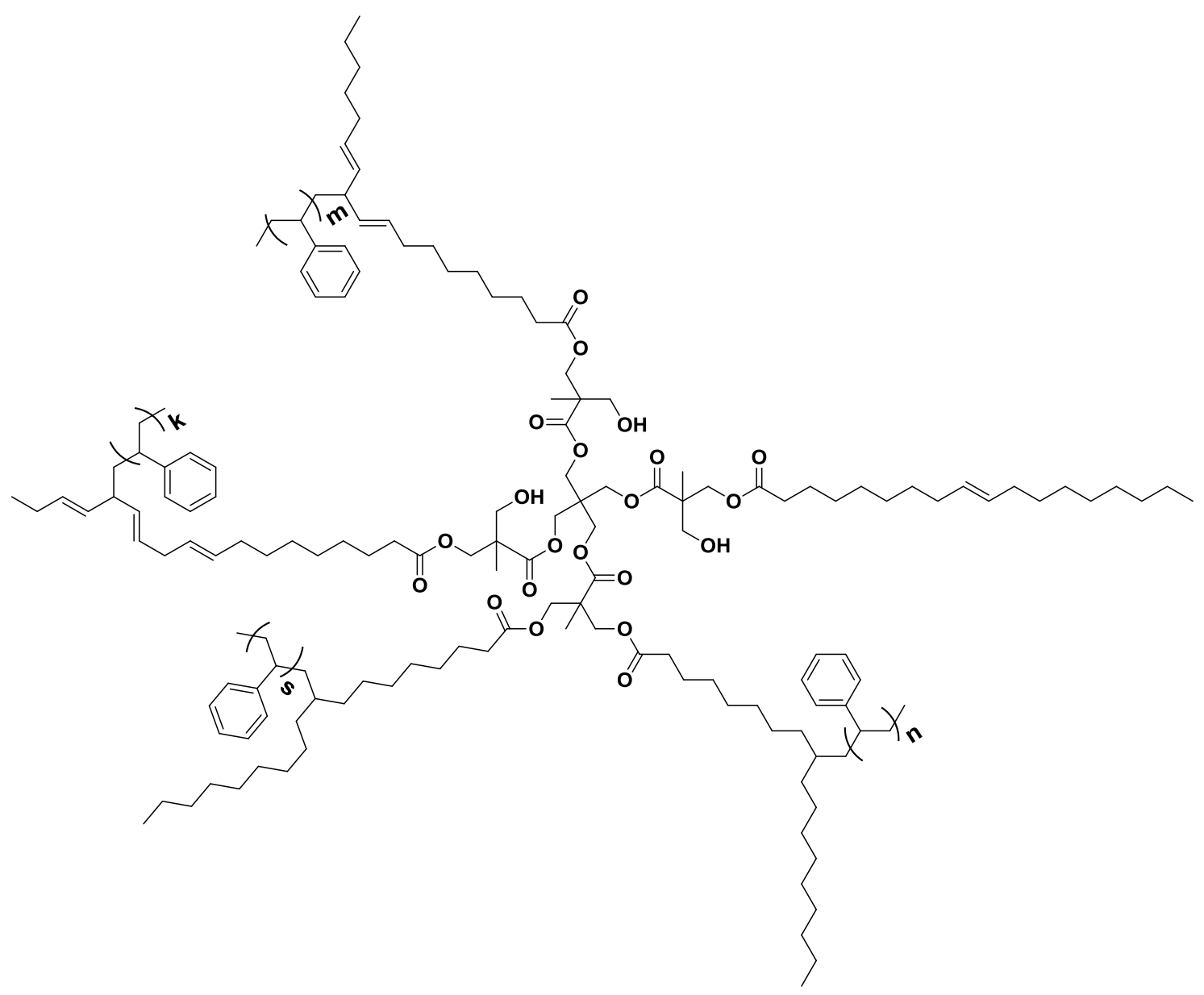

Figure 9: Star shaped alkyd-styrene hybrid resin 


\section{2.b Waterborne silicone-alkyd coatings}

Waterborne alkyd resins can be modified through copolymerization with silicone intermediates to improve their weather resistance, useful in paint coatings for exterior applications. $^{152}$ Generally, synthesis of waterborne silicone-modified alkyds involves a modification of a previously formed silicone-alkyd resin, with an organic intermediate which provides excess carboxylic acid groups in the finished resin. ${ }^{152}$ Then, they are neutralized in order to introduce ionic compounds into the resin, which helps to more easily disperse the resin in water. Nevertheless, waterborne silicone-alkyd coatings could form a gel during dispersion. Several methods have been studied by Easton et al. ${ }^{152}$ to avoid gel formation. One of them consists in controlling the alkyd composition. Indeed, gel formation is high if the molar ratio between dicarboxylic acid or anhydride and polyol used to make the alkyd is greater than 1. The choice of the processing solvent has also an influence on the gel formation. Indeed, stripping out solvent such as xylene, from silicone-alkyd resins can cause gelation. That is why it is preferable to use a non-aromatic solvent having a boiling point similar to xylene and an auto-ignition temperature higher than boiling point, forming an azeotrope with water, being aprotic so as not to participate in the silicone-alkyd reactions and with lowest odor as possible. Moreover, the polar nature of some solvents has a beneficial effect when dispersing the silicone-alkyd in water. The last solution to prevent gel formation is forming silicone intermediates in situ.

\section{2.c Waterborne poly(alkyd-urethane) coatings}

Poly(alkyd-urethane) can be dispersed in water, leading to the formation of waterborne poly(alkyd-urethane) dispersion with superior stability and performances than corresponding alkyds thanks to urethane groups. ${ }^{102}$ Waterborne PAU coatings exhibited flexibility, gloss, good weatherability and excellent adhesion properties. ${ }^{99}$ Hence, a US patent claimed the formation of PAU with soybean oil, pentaerythritol, phthalic anhydride and TDI which was emulsified with an acrylic latex to serve as a binder for corrosion resistant primers. ${ }^{153} \mathrm{~A}$ binder in waterborne coatings for wood was also obtained by emulsifying a PAU in an aqueous dispersion of maleinized polubutadiene. ${ }^{154}$

Numerous studies described the formation of castor oil-based waterborne polyurethane dispersions thanks to the reaction between castor oil as polyol and diisocyanate compound such as IPDI. ${ }^{155}$ Castor oil is composed at $90 \mathrm{wt} \%$ of ricinoleic acid bearing a hydroxyl 
group. $^{99}$ Wei et al. have reacted maleic anhydride and IPDI modified with 2hydroxyethylacrylate to terminal hydroxyl groups of a previously synthetized hyperbranched polyester based on castor oil and 2,2-bis (hydroxymethyl) propionic acid (Scheme 21). ${ }^{155}$

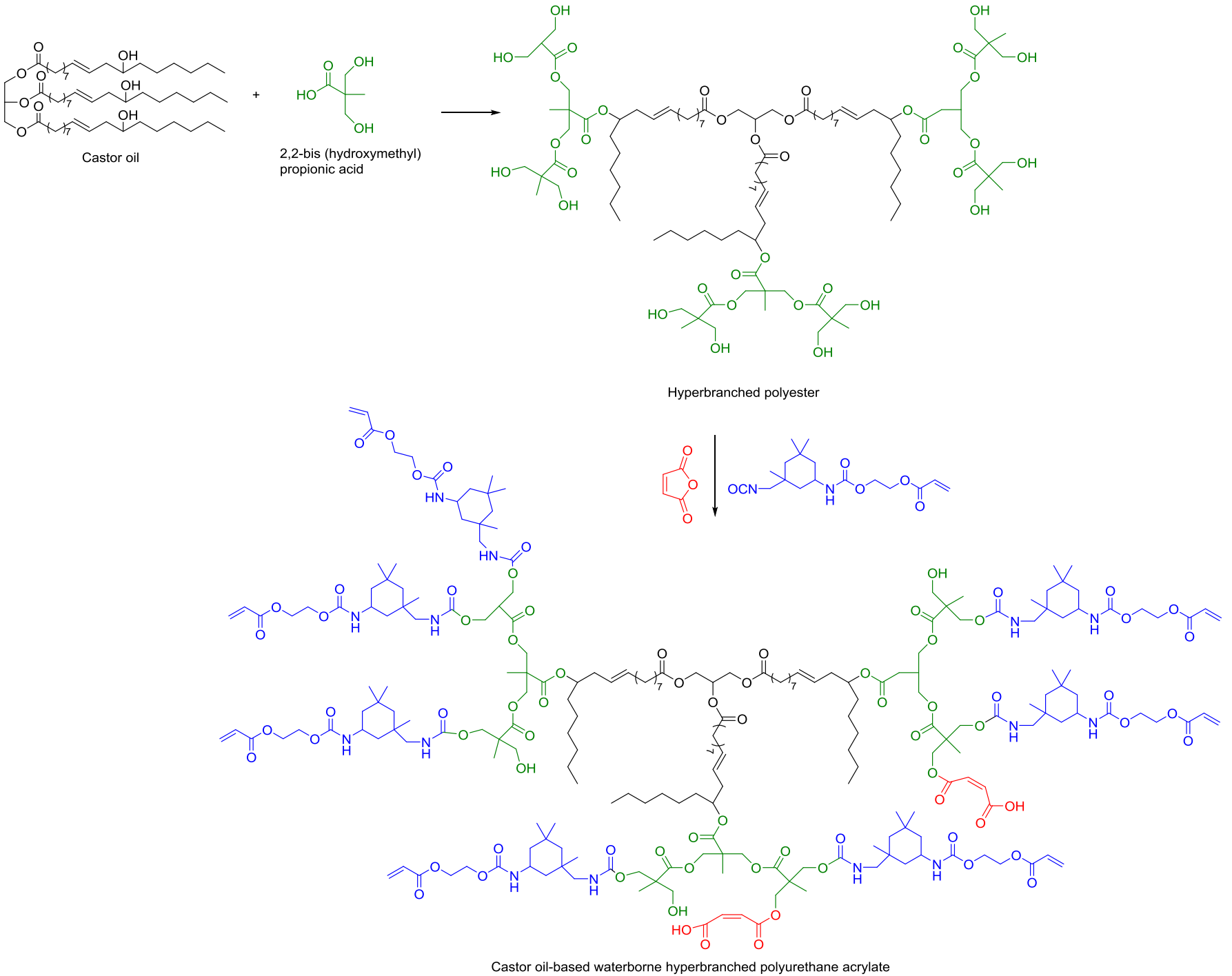

Scheme 21: Castor oil-based waterborne hyperbranched polyurethane acrylate

Finally, the carboxyl groups were neutralized with triethylamine. The resulting castor oilbased waterborne hyperbranched polyurethane acrylate dispersion exhibited UV-curable coating properties thanks to the acrylate compound. The resulting coatings, having a thickness of $100 \mu \mathrm{m}$, exhibited enhancement of tensile strength, elongation at break, flexibility, pencil hardness, and adhesion. The urethane acrylate compounds allowed an increase of crosslinking density of the coating networks after UV-curing, providing an enhancement of mechanicals properties as well as chemical resistance. Moreover, the increase of hydrogen bonds with substrates, due to the large amount of hydrogen bond 
donor groups $(-\mathrm{NH},-\mathrm{COOH},-\mathrm{OH})$, strengthened the interfacial adhesion. Corrosion resistance and antistatic properties have been obtained by Gurunathan et al. thanks to an aqueous cationomeric dispersion made with a castor oil-based waterborne polyurethane which reacted with polyaniline, a conductive polymer. ${ }^{156}$ Thermal stability of the films was improved by increasing the amount of polyaniline incorporated into the castor oil-based waterborne polyurethane.

\section{3) Self-healing properties}

Currently, self-healing polymers are in full development in industry and are particularly promising for coating applications to extend life in use and improve results of Life Cycle Assessment. Indeed, those properties allow to fix coating instead of replace it which is part of a sustainable development approach. In the literature, few articles described alkyd-epoxy hybrid systems with self-healing properties. ${ }^{157-160}$ Nevertheless, those systems are based on an epoxy matrix which contains microencapsulated alkyd resin. Thereby, they become a hybrid coating only once the content of microcapsule is released into the matrix. Hence, Shahabudin et al. demonstrated a successful curing of epoxy with alkyd at room temperature. They interestingly synthesized poly(melamine-urea-formaldehyde) microcapsules containing an alkyd core. The incorporation of these microcapsules into the epoxy matrix did not reduce significantly the engineering properties such as flexural strength and hardness, but allowed self-healing to occur by reaction of the free carboxylic groups of the alkyd with oxirane groups of the epoxy resin. ${ }^{157}$ In another study they scratched the coating and demonstrated that after a curing at $100{ }^{\circ} \mathrm{C}$ for 2 hours, healing had occurred into the scratchs. ${ }^{159}$ Recently, Kurt Çömlekçi et al. proceeded to microencapsulation of linseed oil based alkyd resin in urea-formaldehyde particles. ${ }^{158,160}$ The dispersion in epoxy matrix showed a good homogeneity, which is important for effective self-healing. However, despite they conferred good healing properties, the presence of microcapsules affected the appearance of the coatings that became yellowish. ${ }^{158}$ These first results showed the feasibility of achievement on self-healing concepts in hybrid resins. It would be possible to work on an alkyd resin base and encapsulated epoxy monomers, or isocyanate prepolymers to develop hybrid concepts during healing. Moreover, a new approach focused on the development of an alkyd hybrid matrix with microcapsules containing a healing agent such as trichloroacetic acid and trifluoroacetic acid. ${ }^{161}$ 


\section{4) Impact of ionic monomers' introduction}

The incorporation of ionic monomers into an alkyd hybrid system could lead to improve some properties such as thermal, mechanical and chemical resistances. Otherwise, depending on the ionic molecule introduced, it could lead to bring novel properties such as antimicrobial properties.

Athawale et al. have investigated the influence of an anionic monomer on the properties of a polyalkyd-urethane dispersion. ${ }^{138}$ First of all, an alkyd based on fish and linseed oils was prepared. Then, the anionic monomer, the acrylamido tertiary-butyl sulfonic acid (ATBS) and the isocyanate (IPDI), were added to react with the hydroxyl groups of the alkyd and form urethane linkages. The reduction of number of insaturations in fatty acids chains confirmed grafting of ATBS onto the alkyd compounds. The incorporation of ATBS, with an ionic moiety, displayed high solvent resistance as well as an increase of pencil and scratch hardness values of the coatings with thickness of $50 \mu \mathrm{m}$. This may be due to the branching introduced by grafting APTB on alkyd compound. Moreover, the presence of the acrylate groups reduced the drying time of the coating and provided a higher alkali resistance.

Liang et al. studied antibacterial coatings properties exhibited by the addition of quaternary ammonium into waterborne poly(alkyd-urethane). ${ }^{162}$ Indeed, positively charged groups interacted with negatively charged bacterial cells and/or cytoplasmic membranes. Moreover, castor oil is a typical natural antimicrobial agent (antibacterial, antiviral and antifungal). Those antibacterial coatings can be used in medical instruments, food processing or added into paints for pathogen control. Lu et al. also studied antibacterial properties of a waterborne cationic poly(alkyd-urethane) with soybean oil modified polyol and MDI. ${ }^{136}$ Nowadays, with the global health crisis linked to the SARS-CoV-2, coatings with antiviral properties could experience rapid growth. Indeed, this could prevent the virus from adhering to surfaces and thus limit the number of contaminations. ${ }^{163}$

Much progress has been made in developing of new routes that are more respectful of the environment with, for example, the reduction of VOC emissions or the replacement of harmful constituents. Nevertheless, sometimes, those systems are not as efficient as traditional ones. Therefore studies have to be pursued in order to design even more efficient 
alkyd resins. Moreover, contemporary issues must be taken into account for the development of hybrid coatings with new properties.

\section{Conclusion}

This review focused on different compounds and routes to hybridize alkyd resins in order to alkyd hybrids with combination of improved or specific properties. The use of alkyd resins for coatings has been known for over 100 years but current environmental challenges make alkyds promising polymers for coating industry. Indeed, alkyds are biosourced and exhibit excellent air-drying properties. Nevertheless they suffer from a lack of resistance against external aggressions such as abrasion, leaching and chemicals. The formation of alkyd hybrid systems allow overcoming those limitations and even improving some properties such as thermal and mechanical resistance. However, some polymers such as polyurethane used to be obtained by reacting isocyanate compounds which are harmful for environment and human health. Those compounds have to be replaced and new synthetic routes need to be developed to limit the environmental impact and to form alkyd hybrids as sustainable as possible. With the aim of developing more environmentally friendly coatings, current research is concerned with the formation of water-based coatings to reduce VOC emissions. Coatings with new properties such as self-healing are also in full development and are promising for sustainable future applications.

\section{References}

(1) Hofland, A. Alkyd Resins: From down and out to Alive and Kicking. Progress in Organic Coatings 2012, 73 (4), 274-282. https://doi.org/10.1016/j.porgcoat.2011.01.014.

(2) Elliott, W. T. Alkyd Resins. Surface coatings 1993, 76-109.

(3) Nabuurs, T. Alkyd-Acrylic Composite Emulsions: Polymerization and Morphology; 1997.

(4) Soucek, M. D.; Salata, R. R. Alkyd Resin Synthesis. In Encyclopedia of Polymeric Nanomaterials; Kobayashi, S., Müllen, K., Eds.; Springer Berlin Heidelberg: Berlin, Heidelberg, 2014; pp 1-6. https://doi.org/10.1007/978-3-642-36199-9_278-1. 
(5) Elba, M. E.; Rehim, E. M. A.; Ashery, R. E. Progress in Organic Coating: Synthesis and Characterization Alkyd Resin Based on Soya Bean Oil and Glycerin Using Zirconium Octoate as Catalyst. 13.

(6) La Nasa, J.; Degano, I.; Modugno, F.; Colombini, M. P. Alkyd Paints in Art: Characterization Using Integrated Mass Spectrometry. Analytica Chimica Acta 2013, 797, 64-80. https://doi.org/10.1016/j.aca.2013.08.021.

(7) Murillo, E. A.; Lopez, B. L.; Brostow, W. Synthesis and Characterization of Novel AlkydSilicone Hyperbranched Nanoresins with High Solid Contents. Progress in Organic Coatings 2011, 72 (3), 292-298. https://doi.org/10.1016/j.porgcoat.2011.04.019.

(8) Ren, X.; Soucek, M. Soya-Based Coatings and Adhesives. In Soy-Based Chemicals and Materials; Brentin, R. P., Ed.; American Chemical Society, Series Ed.; ACS Symposium Series; American Chemical Society: Washington, DC, 2014; Vol. 1178, pp 207-254. https://doi.org/10.1021/bk-2014-1178.ch010.

(9) Manning, L.; Moreillon, O.; Hamacek, K. Opportunities for the Alkyd Resin Market. Paint and coatings industry. February 2019.

(10) Ling, J. S.; Ahmed Mohammed, I.; Ghazali, A.; Khairuddean, M. Novel Poly(AlkydUrethane)s from Vegetable Oils: Synthesis and Properties. Industrial Crops and Products 2014, 52, 74-84. https://doi.org/10.1016/j.indcrop.2013.10.002.

(11) Nalawade, P. P.; Soucek, M. D. Modified Soybean Oil as a Reactive Diluent: Coating Performance. J Coat Technol Res 2015, 12 (6), 1005-1021. https://doi.org/10.1007/s11998-015-9691-2.

(12) Overbeek, A. Polymer Heterogeneity in Waterborne Coatings. J Coat Technol Res 2010, 7 (1), 1-21. https://doi.org/10.1007/s11998-009-9201-5.

(13) Journal Officiel de l'Union Européenne. Directive 2004/42/CE Du Parlement Européen et Du Conseil; 2004; $\mathrm{p} 87$.

(14) Saravari, O.; Phapant, P.; Pimpan, V. Synthesis of Water-Reducible Acrylic-Alkyd Resins Based on Modified Palm Oil. J. Appl. Polym. Sci. 2005, 96 (4), 1170-1175. https://doi.org/10.1002/app.21009.

(15) Murillo, E.; López, B. Waterborne Hyperbranched Alkyd-Acrylic Resin Obtained by Miniemulsion Polymerization. Polímeros 2016, 26 (4), 343-351. https://doi.org/10.1590/0104-1428.2344.

(16) Chakraborty, R.; Thatte, M.; Soucek, M. D. A New Approach to Graft Siloxanes to Alkyds. Journal of Coatings Technology and Research 2009, 6 (4), 471-481. https://doi.org/10.1007/s11998-008-9155-z.

(17) Güner, F. S.; Gümüsel, A.; Calica, S.; Erciyes, A. T. Study of Film Properties of Some Urethane Oils. J. Coatings Tech. 2002, 74 (6), 55-59.

https://doi.org/10.1007/BF02698369.

(18) Jowkar-Deriss, M.; Karlsson, O. J. Morphologies and Droplet Sizes of Alkyd-Acrylic Hybrids with High Solids Content. Colloids and Surfaces A: Physicochemical and Engineering Aspects 2004, 245 (1-3), 115-125.

https://doi.org/10.1016/j.colsurfa.2004.07.003.

(19) Minari, R. J.; Goikoetxea, M.; Beristain, I.; Paulis, M.; Barandiaran, M. J.; Asua, J. M. Molecular Characterization of Alkyd/Acrylic Latexes Prepared by Miniemulsion Polymerization. Journal of Applied Polymer Science 2009, 114 (5), 3143-3151. https://doi.org/10.1002/app.30866. 
(20) Shoaf, G. L.; Stockl, R. R. Alkyd/Acrylic Hybrid Latexes with Enhanced Oxidative Curing. Polymer Reaction Engineering 2003, 11 (3), 319-334. https://doi.org/10.1081/PRE120024417.

(21) Jones, F. N. Alkyd Resins. In Ullmann's Encyclopedia of Industrial Chemistry; Wiley-VCH Verlag GmbH \& Co. KGaA, Ed.; Wiley-VCH Verlag GmbH \& Co. KGaA: Weinheim, Germany, 2003; p a01_409. https://doi.org/10.1002/14356007.a01_409.

(22) Mutar, M. A.; Hassan, N. M. A. SYNTHESIS AND CHARACTERIZATION OF NEW ALKYD RESINS (SHORT, MEDIUM AND LONG) BASED ON SUNFLOWER OIL AND LINOLEIC ACID AS BINDER FOR PAINTS. 17.

(23) Kienle, R. H.; Rohlfs, H. C. Flexible Alkyd Resin and Method of Preparation. US1897260A.

(24) Kienle, R. H.; Rohlfs, H. C. Flexible Alkyd Resin. CA347682A.

(25) Grandou, P.; Pastour, P. Peintures et Vernis, Hermann.; 1966.

(26) Patel, V. C.; Varughese, J.; Krishnamoorthy, P. A.; Jain, R. C.; Singh, A. K.; Ramamoorty, M. Synthesis of Alkyd Resin from Jatropha and Rapeseed Oils and Their Applications in Electrical Insulation. J. Appl. Polym. Sci. 2008, 107 (3), 1724-1729. https://doi.org/10.1002/app.27195.

(27) Islam, M. R.; Hosen Beg, M. D.; Jamari, S. S. Alkyd Based Resin from Non-Drying Oil. Procedia Engineering 2014, 90, 78-88. https://doi.org/10.1016/j.proeng.2014.11.818.

(28) Xu, X.; Chen, L.; Guo, J.; Cao, X.; Wang, S. Synthesis and Characteristics of Tung OilBased Acrylated-Alkyd Resin Modified by Isobornyl Acrylate. RSC Advances 2017, 7 (48), 30439-30445. https://doi.org/10.1039/C7RA02189E.

(29) Bora, M. M.; Deka, R.; Ahmed, N.; Kakati, D. K. Karanja (Millettia Pinnata (L.) Panigrahi) Seed Oil as a Renewable Raw Material for the Synthesis of Alkyd Resin. Industrial Crops and Products 2014, 61, 106-114. https://doi.org/10.1016/j.indcrop.2014.06.048.

(30) Rämänen, P.; Maunu, S. L. Structure of Tall Oil Fatty Acid-Based Alkyd Resins and Alkyd-Acrylic Copolymers Studied by NMR Spectroscopy. Progress in Organic Coatings 2014, 77 (2), 361-368. https://doi.org/10.1016/j.porgcoat.2013.10.013.

(31) Formo, M. W. Ester Reactions of Fatty Materials. J Am Oil Chem Soc 1954, 31 (11), 548-559. https://doi.org/10.1007/BF02638571.

(32) Oil and Colour Chemists' Association, Australia. Manufacture of Alkyd Resins. In Surface Coatings; Springer Netherlands: Dordrecht, 1983; pp 65-74. https://doi.org/10.1007/978-94-011-6940-0_6.

(33) Carlston, E. F.; El Cerrito. Preparation of Alkyd Resins Involving the Acidolysis of Triglyceride Oils, Isophthalic and Terephthalic Acids. US2,991,259.

(34) Wang, Q.; Pellegrene, B.; Soucek, M. D. Investigation of Methyl Methacrylate Grafting on Model Single Fatty Acid Alkyds. Ind. Eng. Chem. Res. 2018, 57 (36), 12018-12028. https://doi.org/10.1021/acs.iecr.8b01941.

(35) Uschanov, P.; Heiskanen, N.; Mononen, P.; Maunu, S. L.; Koskimies, S. Synthesis and Characterization of Tall Oil Fatty Acids-Based Alkyd Resins and Alkyd-Acrylate Copolymers. Progress in Organic Coatings 2008, 63 (1), 92-99. https://doi.org/10.1016/j.porgcoat.2008.04.011.

(36) Lee, R.; Gryn'ova, G.; Ingold, K. U.; Coote, M. L. Why Are Sec-Alkylperoxyl Bimolecular Self-Reactions Orders of Magnitude Faster than the Analogous Reactions of TertAlkylperoxyls? The Unanticipated Role of $\mathrm{CH}$ Hydrogen Bond Donation. Phys. Chem. Chem. Phys. 2016, 18 (34), 23673-23679. https://doi.org/10.1039/C6CP04670C. 
(37) Honzíček, J. Curing of Air-Drying Paints: A Critical Review. Ind. Eng. Chem. Res. 2019, 58 (28), 12485-12505. https://doi.org/10.1021/acs.iecr.9b02567.

(38) van Haveren, J.; Oostveen, E. A.; Miccichè, F.; Noordover, B. A. J.; Koning, C. E.; van Benthem, R. A. T. M.; Frissen, A. E.; Weijnen, J. G. J. Resins and Additives for Powder Coatings and Alkyd Paints, Based on Renewable Resources. J Coat Technol Res 2007, 4 (2), 177-186. https://doi.org/10.1007/s11998-007-9020-5.

(39) Bieleman, J. H. Driers. Additives in plastics and paints 2002, 56 (5), 184-190.

(40) Simpson; Maaijen; Roelofsen; Hage. The Evolution of Catalysis for Alkyd Coatings: Responding to Impending Cobalt Reclassification with Very Active Iron and Manganese Catalysts, Using Polydentate Nitrogen Donor Ligands. Catalysts 2019, 9 (10), 825. https://doi.org/10.3390/catal9100825.

(41) Grobelny, Z.; Jurek-Suliga, J.; Golba, S. Ring-Opening Polymerization of Monosubstituted Oxiranes in the Presence of Potassium Hydride: Determination of Initiation Course and Structure of Macromolecules by MALDI-TOF Mass Spectrometry. Journal of Polymer Research 2019, 26 (12). https://doi.org/10.1007/s10965-019-1943$\mathrm{x}$.

(42) Epoxy Resins: Chemistry and Technology, 2nd ed., rev.expanded.; May, C. A., Ed.; M. Dekker: New York, 1988.

(43) Milchert, E.; Malarczyk-Matusiak, K.; Musik, M. Technological Aspects of Vegetable Oils Epoxidation in the Presence of Ion Exchange Resins: A Review. Polish Journal of Chemical Technology 2016, 18 (3), 128-133. https://doi.org/10.1515/pjct-2016-0059.

(44) Bell, J. P. Structure of a Typical Amine-Cured Epoxy Resin. Journal of Polymer Science Part A-2: Polymer Physics 1970, 8 (3), 417-436. https://doi.org/10.1002/pol.1970.160080308.

(45) Smeal, T. W. Epoxy Adhesive Compositions Containing Amine Hardener and Tertiar y Amine Catalyst. US3532653A, October 6, 1970.

(46) Matějka, L.; Lövy, J.; Pokorný, S.; Bouchal, K.; Dušek, K. Curing Epoxy Resins with Anhydrides. Model Reactions and Reaction Mechanism. Journal of Polymer Science: Polymer Chemistry Edition 1983, 21 (10), 2873-2885. https://doi.org/10.1002/pol.1983.170211003.

(47) Massingill, J. L.; Bauer, R. S. EPOXY RESINS. In Applied Polymer Science: 21st Century; Craver, C. D., Carraher, C. E., Eds.; Pergamon: Oxford, 2000; pp 393-424. https://doi.org/10.1016/B978-008043417-9/50023-4.

(48) Abdelkader, A. F.; White, J. R. Water Absorption in Epoxy Resins: The Effects of the Crosslinking Agent and Curing Temperature. Journal of Applied Polymer Science 2005, 98 (6), 2544-2549. https://doi.org/10.1002/app.22400.

(49) González, L.; Ferrando, F.; Ramis, X.; Salla, J. M.; Mantecón, A.; Serra, A. Characterization of New Reworkable Thermosetting Coatings Obtained by Cationic and Anionic Curing of DGEBA and Some Meldrum Acid Derivatives. Progress in Organic Coatings 2009, 65 (2), 175-181. https://doi.org/10.1016/j.porgcoat.2008.10.007.

(50) Dean, K.; Cook, W. D.; Zipper, M. D.; Burchill, P. Curing Behaviour of IPNs Formed from Model VERs and Epoxy Systems I Amine Cured Epoxy. Polymer 2001, 42 (4), 13451359. https://doi.org/10.1016/S0032-3861(00)00486-9.

(51) Assanvo, E. F.; Gogoi, P.; Dolui, S. K.; Baruah, S. D. Synthesis, Characterization, and Performance Characteristics of Alkyd Resins Based on Ricinodendron Heudelotii Oil and Their Blending with Epoxy Resins. Industrial Crops and Products 2015, 65, 293 302. https://doi.org/10.1016/j.indcrop.2014.11.049. 
(52) Das, P.; Sharma, N.; Puzari, A.; Kakati, D. K.; Devi, N. Synthesis and Characterization of Neem (Azadirachta Indica) Seed Oil-Based Alkyd Resins for Efficient Anticorrosive Coating Application. Polymer Bulletin 2020. https://doi.org/10.1007/s00289-02003120-8.

(53) Patel, H. S.; Patel, B. K.; Patel, K. B.; Desai, S. N. Surface Coating Studies of AlkydCastor Oil-Epoxy Resin Condensate-Ketone Resin Blends. International Journal of Polymeric Materials 2009, 59 (1), 25-32. https://doi.org/10.1080/00914030903172882.

(54) Bajpai, M.; Seth, S. Use of Unconventional Oils in Surface Coatings: Blends of Alkyd Resins with Epoxy Esters. Pigment \& Resin Technology 2000, 29 (2), 82-87. https://doi.org/10.1108/03699420010317825.

(55) Issam, A. M.; Khizrien, A. K. N.; Mazlan, I. Physical and Mechanical Properties of Different Ratios of Palm Oil-Based Alkyd/Epoxy Resins. Polymer-Plastics Technology and Engineering 2011, 50 (12), 1256-1261. https://doi.org/10.1080/03602559.2011.578289.

(56) Ma, Y.; Lei, R.; Jiang, Y. Synthesis and Characteristics of Zanthoxylum Bungeanum Seed Oil-Based Alkyd Resin Modified by Epoxy Resin and Their Blends with HMMM. Polymer Bulletin 2019. https://doi.org/10.1007/s00289-019-02980-z.

(57) Cakić, S. M.; Ristić, I. S.; Jašo, V. M.; Radičević, R. Ž.; Ilić, O. Z.; Simendić, J. K. B. Investigation of the Curing Kinetics of Alkyd-Melamine-Epoxy Resin System. Progress in Organic Coatings 2012, 73 (4), 415-424. https://doi.org/10.1016/j.porgcoat.2011.03.016.

(58) Patil, D. M.; Phalak, G. A.; Mhaske, S. T. Design and Synthesis of Bio-Based Epoxidized Alkyd Resin for Anti-Corrosive Coating Application. Iranian Polymer Journal 2018, 27 (10), 709-719. https://doi.org/10.1007/s13726-018-0646-1.

(59) Li, C.; Veldhuis, T.; Reuvers, B.; Sablong, R. J.; Koning, C. E. Fully Renewable Limonene-derived Polycarbonate as a High-performance Alkyd Resin. Polymer International 2019. https://doi.org/10.1002/pi.5929.

(60) Mora, A.-S.; Tayouo, R.; Boutevin, B.; David, G.; Caillol, S. A Perspective Approach on the Amine Reactivity and the Hydrogen Bonds Effect on Epoxy-Amine Systems. European Polymer Journal 2020, 123, 109460. https://doi.org/10.1016/j.eurpolymj.2019.109460.

(61) Müller, B.; Poth, U. Coatings Formulation: An International Textbook; Vincentz Network: Hannover, Germany, 2019. https://doi.org/10.1515/9783748600268.

(62) Akbarinezhad, E.; Ebrahimi, M.; Kassiriha, S. M.; Khorasani, M. Synthesis and Evaluation of Water-Reducible Acrylic-Alkyd Resins with High Hydrolytic Stability. Progress in Organic Coatings 2009, 65 (2), 217-221. https://doi.org/10.1016/j.porgcoat.2008.11.012.

(63) Akgün, N.; Büyükyonga, Ö. N.; Acar, I.; Güçlü, G. Synthesis of Novel Acrylic Modified Water Reducible Alkyd Resin: Investigation of Acrylic Copolymer Ratio Effect on Film Properties and Thermal Behaviors. Polymer Engineering \& Science 2016, 56 (8), 947954. https://doi.org/10.1002/pen.24324.

(64) Büyükyonga, Ö. N.; Akgün, N.; Acar, I.; Güçlü, G. The Usage of Novel Acrylic-Modified Water-Reducible Alkyd Resin Obtained from Post-Consumer PET Bottles in WaterBased Paint Formulation. Journal of Material Cycles and Waste Management 2020, 22 (1), 187-196. https://doi.org/10.1007/s10163-019-00929-y. 
(65) Wang, Q.; Soucek, M. D. The Investigation of Butyl Acrylate Grafting Using Model Alkyds. Journal of Coatings Technology and Research 2019, 16 (1), 221-233. https://doi.org/10.1007/s11998-018-0140-x.

(66) Ataei, S.; Yahya, R.; Gan, S. N. Coating Performances of Copolymers from a Novel Palm Oil-based Macromer and Methyl Methacrylate. Pigment \& Resin Technology 2012, 41 (2), 112-121. https://doi.org/10.1108/03699421211210775.

(67) Dziczkowski, J.; Soucek, M. D. Factors Influencing the Stability and Film Properties of Acrylic/Alkyd Water-Reducible Hybrid Systems Using a Response Surface Technique. Progress in Organic Coatings 2012, 73 (4), 330-343.

https://doi.org/10.1016/j.porgcoat.2011.03.005.

(68) Elrebii, M.; Ben Mabrouk, A.; Boufi, S. Synthesis and Properties of Hybrid Alkyd-Acrylic Dispersions and Their Use in VOC-Free Waterborne Coatings. Progress in Organic Coatings 2014, 77 (4), 757-764. https://doi.org/10.1016/j.porgcoat.2013.12.016.

(69) Elrebii, M.; Kamoun, A.; Boufi, S. Waterborne Hybrid Alkyd-Acrylic Dispersion: Optimization of the Composition Using Mixture Experimental Designs. Progress in Organic Coatings 2015, 87, 222-231. https://doi.org/10.1016/j.porgcoat.2015.06.006.

(70) Nalawade, P. P.; Soucek, M. D. Acrylated Alkyds Synthesized via Quasi-Living Radical Polymerization: ATRP and RAFT. Macromolecular Chemistry and Physics 2017, 218 (22), 1700234. https://doi.org/10.1002/macp.201700234.

(71) Thanamongkollit, N.; Soucek, M. D. Synthesis and Properties of Acrylate Functionalized Alkyds via a Diels-Alder Reaction. Progress in Organic Coatings 2012, 73 (4), 382-391. https://doi.org/10.1016/j.porgcoat.2011.02.004.

(72) Xu, X.; Chen, L.; Guo, J.; Cao, X.; Wang, S. Synthesis and Characteristics of Tung OilBased Acrylated-Alkyd Resin Modified by Isobornyl Acrylate. RSC Adv. 2017, 7 (48), 30439-30445. https://doi.org/10.1039/C7RA02189E.

(73) A. M. Herk, V. Chemistry and Technology of Emulsion Polymerisation; Wiley-Blackwell, 2005. https://doi.org/10.1002/9780470988466.

(74) Chern, C. S. Emulsion Polymerization Mechanisms and Kinetics. Progress in Polymer Science 2006, 31 (5), 443-486. https://doi.org/10.1016/j.progpolymsci.2006.02.001.

(75) Asua, J. M. Emulsion Polymerization: From Fundamental Mechanisms to Process Developments. Journal of Polymer Science Part A: Polymer Chemistry 2004, 42 (5), 1025-1041. https://doi.org/10.1002/pola.11096.

(76) Thickett, S. C.; Gilbert, R. G. Emulsion Polymerization: State of the Art in Kinetics and Mechanisms. Polymer 2007, 48 (24), 6965-6991. https://doi.org/10.1016/j.polymer.2007.09.031.

(77) Li, W. S. J.; Negrell, C.; Ladmiral, V.; Lai-Kee-Him, J.; Bron, P.; Lacroix-Desmazes, P.; Joly-Duhamel, C.; Caillol, S. Cardanol-Based Polymer Latex by Radical Aqueous Miniemulsion Polymerization. Polym. Chem. 2018, 9 (18), 2468-2477. https://doi.org/10.1039/C8PY00167G.

(78) Molina-Gutiérrez, S.; Ladmiral, V.; Bongiovanni, R.; Caillol, S.; Lacroix-Desmazes, P. Emulsion Polymerization of Dihydroeugenol-, Eugenol-, and Isoeugenol-Derived Methacrylates. Ind. Eng. Chem. Res. 2019, 58 (46), 21155-21164. https://doi.org/10.1021/acs.iecr.9b02338.

(79) Li, W. S. J.; Ladmiral, V.; Takeshima, H.; Satoh, K.; Kamigaito, M.; Semsarilar, M.; Negrell, C.; Lacroix-Desmazes, P.; Caillol, S. Ferulic Acid-Based Reactive Core-Shell Latex by Seeded Emulsion Polymerization. Polym. Chem. 2019, 10 (23), 3116-3126. https://doi.org/10.1039/C9PY00079H. 
(80) Molina-Gutiérrez, S.; Li, W. S. J.; Perrin, R.; Ladmiral, V.; Bongiovanni, R.; Caillol, S.; Lacroix-Desmazes, P. Radical Aqueous Emulsion Copolymerization of Eugenol-Derived Monomers for Adhesive Applications. Biomacromolecules 2020, acs.biomac.0c00461. https://doi.org/10.1021/acs.biomac.0c00461.

(81) Molina-Gutiérrez, S.; Ladmiral, V.; Bongiovanni, R.; Caillol, S.; Lacroix-Desmazes, P. Radical Polymerization of Biobased Monomers in Aqueous Dispersed Media. Green Chem. 2019, 21 (1), 36-53. https://doi.org/10.1039/C8GC02277A.

(82) Nabuurs, T.; Baijards, R. A.; German, A. L. Alkyd-Acrylic Hybrid Systems for Use as Binders in Waterborne Paints. Progress in Organic Coatings 1996, 27 (1-4), 163-172. https://doi.org/10.1016/0300-9440(95)00533-1.

(83) Wang, S. T.; Schork, F. J.; Poehlein, G. W.; Gooch, J. W. Emulsion and Miniemulsion Copolymerization of Acrylic Monomers in the Presence of Alkyd Resin. Journal of Applied Polymer Science 1996, 60, 2069-2076.

(84) Heiskanen, N.; Jämsä, S.; Paajanen, L.; Koskimies, S. Synthesis and Performance of Alkyd-Acrylic Hybrid Binders. Progress in Organic Coatings 2010, 67 (3), 329-338. https://doi.org/10.1016/j.porgcoat.2009.10.025.

(85) Rämänen, P.; Pitkänen, P.; Jämsä, S.; Maunu, S. L. Natural Oil-Based Alkyd-Acrylic Copolymers: New Candidates for Barrier Materials. Journal of Polymers and the Environment 2012, 20 (4), 950-958. https://doi.org/10.1007/s10924-012-0492-8.

(86) Rämänen, P.; Maunu, S. L. Structure of Tall Oil Fatty Acid-Based Alkyd Resins and Alkyd-Acrylic Copolymers Studied by NMR Spectroscopy. Progress in Organic Coatings 2014, 77 (2), 361-368. https://doi.org/10.1016/j.porgcoat.2013.10.013.

(87) Van Hamersveld, E. M. S.; Van Es, J. J. G. S.; German, A. L.; Cuperus, F. P.; Weissenborn, P.; Hellgren, A.-C. Oil-Acrylic Hybrid Latexes as Binders for Waterborne Coatings. Progress in Organic Coatings 1999, 35 (1-4), 235-246. https://doi.org/10.1016/S0300-9440(99)00040-5.

(88) Minari, R. J.; Goikoetxea, M.; Beristain, I.; Paulis, M.; Barandiaran, M. J.; Asua, J. M. Post-Polymerization of Waterborne Alkyd/Acrylics. Effect on Polymer Architecture and Particle Morphology. Polymer 2009, 50 (25), 5892-5900. https://doi.org/10.1016/j.polymer.2009.10.042.

(89) Assanvo, E. F.; Baruah, S. D. Synthesis and Properties of Ricinodendron Heudelotii Oil Based Hybrid Alkyd-Acrylate Latexes via Miniemulsion Polymerization. Progress in Organic Coatings 2015, 86, 25-32. https://doi.org/10.1016/j.porgcoat.2015.03.022.

(90) Athawale, V. D.; Nimbalkar, R. V. Thermoset Alkyd-Acrylic Hybrid Emulsions for Coatings. Journal of Dispersion Science and Technology 2011, 32 (5), 646-653. https://doi.org/10.1080/01932691003799985.

(91) Faucheu, J.; Chazeau, L.; Gauthier, C.; Cavaillé, J.-Y.; Goikoetxea, M.; Minari, R.; Asua, J. M. Latex Imaging by Environmental STEM: Application to the Study of the Surfactant Outcome in Hybrid Alkyd/Acrylate Systems. Langmuir 2009, 25 (17), 10251-10258. https://doi.org/10.1021/la901049h.

(92) Limousin, E.; Martinez-Tong, D. E.; Ballard, N.; Asua, J. M. Cure-Dependent Morphology of Acrylic/Alkyd Hybrid Latex Films via Nanomechanical Mapping. ACS Applied Polymer Materials 2019, 1 (8), 2213-2223. https://doi.org/10.1021/acsapm.9b00507.

(93) Goikoetxea, M.; Minari, R. J.; Beristain, I.; Paulis, M.; Barandiaran, M. J.; Asua, J. M. A New Strategy to Improve Alkyd/Acrylic Compatibilization in Waterborne Hybrid 
Dispersions. Polymer 2010, 51 (23), 5313-5317.

https://doi.org/10.1016/j.polymer.2010.09.052.

(94) Wang, T.; de las Heras Alarcón, C.; Goikoetxea, M.; Beristain, I.; Paulis, M.; Barandiaran, M. J.; Asua, J. M.; Keddie, J. L. Cross-Linked Network Development in Compatibilized Alkyd/Acrylic Hybrid Latex Films for the Creation of Hard Coatings. Langmuir 2010, 26 (17), 14323-14333. https://doi.org/10.1021/la102392x.

(95) Murillo, E. A.; Percino, J.; López, B. L. Colloidal, Morphological, Thermal, Rheological, and Film Properties of Waterborne Hyperbranched Alkyd-Acrylic Resins. Journal of Coatings Technology and Research 2019, 16 (5), 1223-1232. https://doi.org/10.1007/s11998-019-00205-6.

(96) Zhong, S.; Li, J.; Yi, L.; Cai, Y.; Zhou, W. Cross-Linked Waterborne Alkyd Hybrid Resin Coatings Modified by Fluorinated Acrylate-Siloxane with High Waterproof and Anticorrosive Performance. Polymers for Advanced Technologies 2019, 30 (2), 292303. https://doi.org/10.1002/pat.4464.

(97) Deriss, M. J.; Karlsson, O. J. Suspension Structures and Film Morphologies of HighSolids Acrylic-Alkyd Hybrid Binders. Surface Coatings International Part B: Coatings Transactions 2005, 88 (4), 251-256. https://doi.org/10.1007/BF02699580.

(98) Geyer, R.; Jambeck, J. R.; Law, K. L. Production, Use, and Fate of All Plastics Ever Made. Sci. Adv. 2017, 3 (7), e1700782. https://doi.org/10.1126/sciadv.1700782.

(99) Zafar, F.; Ghosal, A.; Sharmin, E.; Chaturvedi, R.; Nishat, N. A Review on Cleaner Production of Polymeric and Nanocomposite Coatings Based on Waterborne Polyurethane Dispersions from Seed Oils. Progress in Organic Coatings 2019, 131, 259-275. https://doi.org/10.1016/j.porgcoat.2019.02.014.

(100) Bode, D.; DeGraaf, H. J. High Solids Coatings Using Unsaturated Monoisocyanate Adducts of Alkyd Resins. US4,609,706.

(101) Harris, R. R.; Pollack, W. J. Polyuréthane Modified Alkyd Resin. 4116902.

(102) Wicks, D. A.; Wicks, Z. W. Autoxidizable Urethane Resins. Progress in Organic Coatings 2005, 54 (3), 141-149. https://doi.org/10.1016/j.porgcoat.2004.12.006.

(103) Backman, A. C.; Lindberg, K. A. H. Interaction between Wood and Polyurethane-Alkyd Lacquer Resulting in a Decrease in the Glass Transition Temperature. J. Appl. Polym. Sci. 2002, 85 (3), 595-605. https://doi.org/10.1002/app.10498.

(104) Athawale, V.; Kolekar, S. Uralkyd and Poly (Butyl Methacrylate) Interpenetrating Polymer Networks. Journal of Applied Polymer Science 2000, 75, 825-832.

(105) Saravari, O.; Praditvatanakit, S. Preparation and Properties of Urethane Alkyd Based on a Castor Oil/Jatropha Oil Mixture. Progress in Organic Coatings 2013, 76 (4), 698704. https://doi.org/10.1016/j.porgcoat.2012.12.012.

(106) Liang, H.; Feng, Y.; Lu, J.; Liu, L.; Yang, Z.; Luo, Y.; Zhang, Y.; Zhang, C. Bio-Based Cationic Waterborne Polyurethanes Dispersions Prepared from Different Vegetable Oils. Industrial Crops and Products 2018, 122, 448-455. https://doi.org/10.1016/j.indcrop.2018.06.006.

(107) McMillan, C. From Alkyds to Polysiloxanes: A Review of Bridge Coatings. Te c h n o lo g y 2011, 5.

(108) Ratajczak, I.; Woźniak, M.; Szentner, K.; Babicka, M.; Jenczyk, J.; Mazela, B. Aminosilane Binding to Wood Substance through an Alkyd Resin. Journal of Wood Chemistry and Technology 2020, 40 (1), 73-79. https://doi.org/10.1080/02773813.2019.1697292. 
(109) Mejía, M. C.; Palacio, J.; Murillo, E. A. Comb-Shaped Silicone-Alkyd Resins with High Solid Content. Progress in Organic Coatings 2017, 105, 336-341.

https://doi.org/10.1016/j.porgcoat.2017.02.002.

(110) Zhong, S.; Li, J.; Cai, Y.; Yi, L. Novel Surfactant-Free Waterborne Acrylic-Silicone Modified Alkyd Hybrid Resin Coatings Containing Nano-Silica for the Corrosion Protection of Carbon Steel. Polymer-Plastics Technology and Materials 2019, 58 (8), 866-878. https://doi.org/10.1080/03602559.2018.1542711.

(111) Liu, C.; Liu, Z.; Tisserat, B. H.; Wang, R.; Schuman, T. P.; Zhou, Y.; Hu, L. MicrowaveAssisted Maleation of Tung Oil for Bio-Based Products with Versatile Applications. Industrial Crops and Products 2015, 71, 185-196. https://doi.org/10.1016/j.indcrop.2015.02.066.

(112) Dhoke, S. K.; Bhandari, R.; Khanna, A. S. Effect of Nano-ZnO Addition on the SiliconeModified Alkyd-Based Waterborne Coatings on Its Mechanical and Heat-Resistance Properties. Progress in Organic Coatings 2009, 64 (1), 39-46. https://doi.org/10.1016/j.porgcoat.2008.07.007.

(113) Kanai, T.; Mahato, T. K.; Kumar, D. Synthesis and Characterization of Novel Silicone Acrylate-Soya Alkyd Resin as Binder for Long Life Exterior Coatings. Progress in Organic Coatings 2007, 58 (4), 259-264. https://doi.org/10.1016/j.porgcoat.2006.11.002.

(114) Szabó, A.; Hencsei, P. The Effect of Modified Silicone Copolymers on Surface Tension. Surface Coatings International 1998, 81 (3), 135-142. https://doi.org/10.1007/BF02693854.

(115) Hiles, C. R.; Golding, B.; Shreve, R. N. Copolymerization of Alkyd Silicones for Coatings. Industrial \& Engineering Chemistry 1955, 47 (7), 1418-1424. https://doi.org/10.1021/ie50547a046.

(116) Murillo, E. A.; López, B. L.; Brostow, W. Thermal, Hydrolytic, Anticorrosive, and Tribological Properties of Alkyd-Silicone Hyperbranched Resins with High Solid Content. Journal of Applied Polymer Science 2012, 124 (5), 3591-3599. https://doi.org/10.1002/app.34611.

(117) Murillo, E. A.; Vallejo, P. P.; López, B. L. Synthesis and Characterization of Hyperbranched Alkyd Resins Based on Tall Oil Fatty Acids. Progress in Organic Coatings 2010, 69 (3), 235-240. https://doi.org/10.1016/j.porgcoat.2010.04.018.

(118) Nguyen, T. H. N.; Balligand, F.; Bormann, A.; Bennevault, V.; Guégan, P. Synthesis of New Biobased Linear Poly(Ester Amide)s. European Polymer Journal 2019, 121, 109314. https://doi.org/10.1016/j.eurpolymj.2019.109314.

(119) Marchildon, K. Polyamides - Still Strong After Seventy Years: Polyamides - Still Strong After Seventy Years. Macromolecular Reaction Engineering 2011, 5 (1), 22-54. https://doi.org/10.1002/mren.201000017.

(120) Winnacker, M.; Rieger, B. Biobased Polyamides: Recent Advances in Basic and Applied Research. Macromol. Rapid Commun. 2016, 37 (17), 1391-1413. https://doi.org/10.1002/marc.201600181.

(121) Mewis, J.; Wagner, N. J. Thixotropy. Advances in Colloid and Interface Science 2009, 147-148, 214-227. https://doi.org/10.1016/j.cis.2008.09.005.

(122) Rao, M.; Youn, H.-C.; Toussaint, A. F.; DeCapite, M. G. Thixotropic Alkyd Resins and the Use Thereof in Coating Compositions. US5,591,793.

(123) Glaser, D.; Wittcoff, H. Thixotropic Coating Vehicle Containing a Short Oil Alkyd Resin and a Copolymer Polyamide Resin. US2,932,623. 
(124) Anamika, J. A STUDY OF THIXOTROPIC ALKYDS BASED ON "ARAMIDE CHEMISTRY." 2011, 1, 3.

(125) Anyaogu, I. D.; Ejikeme, P. M.; Ibemesi, J. A. Development of Thixotropic Coatings Using Dimerized Soybean Oil Fatty Acids: The Case of Polyamide of 1,2-Phenylene Diamine. J Polym Environ 2010, 18 (2), 104-115. https://doi.org/10.1007/s10924-0100160-9.

(126) Ikyenge, B. A.; Bello, K. A.; Adamu, H. M.; Jauro, A. Performance Evaluation And Physicochemical Properties Of Unmodified And Fatty Polyamide Modified. 7.

(127) Shende Pradeep; Dabhade Shrikant; Kulkarni Milind. Soybean Oil Modified Polyesteramide Resins. Pigment \& Resin Technology 2003, 32 (1), 4-9. https://doi.org/10.1108/03699420310454875.

(128) Gogoi, P.; Boruah, R.; Dolui, S. K. Jatropha Curcas Oil Based Alkyd/Epoxy/Graphene Oxide (GO) Bionanocomposites: Effect of GO on Curing, Mechanical and Thermal Properties. Progress in Organic Coatings 2015, 84, 128-135. https://doi.org/10.1016/j.porgcoat.2014.09.022.

(129) Zhu, K.; li, X.; Wang, H.; Li, J.; Fei, G. Electrochemical and Anti-Corrosion Behaviors of Water Dispersible Graphene/Acrylic Modified Alkyd Resin Latex Composites Coated Carbon Steel. Journal of Applied Polymer Science 2017, 134 (11). https://doi.org/10.1002/app.44445.

(130) Gogoi, P.; Boruah, M.; Bora, C.; Dolui, S. K. Jatropha Curcas Oil Based Alkyd/Epoxy Resin/Expanded Graphite (EG) Reinforced Bio-Composite: Evaluation of the Thermal, Mechanical and Flame Retardancy Properties. Progress in Organic Coatings 2014, 77 (1), 87-93. https://doi.org/10.1016/j.porgcoat.2013.08.006.

(131) Gogoi, P.; Saikia, B. J.; Dolui, S. K. Effects of Nickel Oxide (NiO) Nanoparticles on the Performance Characteristics of the Jatropha Oil Based Alkyd and Epoxy Blends. J. Appl. Polym. Sci. 2015, 132 (8), n/a-n/a. https://doi.org/10.1002/app.41490.

(132) Ong, H. R.; Rahman Khan, Md. M.; Ramli, R.; Yunus, R. M. Effect of CuO Nanoparticle on Mechanical and Thermal Properties of Palm Oil Based Alkyd/Epoxy Resin Blend. Procedia Chemistry 2015, 16, 623-631. https://doi.org/10.1016/j.proche.2015.12.101.

(133) Huo, L.; Wu, X.; Tian, C.; Gao, J. Thermal, Mechanical, and Electrical Properties of Alkyd-Epoxy Resin Nanocomposites Modified with 3-Glycidyloxypropyl-POSS. PolymerPlastics Technology and Engineering 2018, 57 (5), 371-379. https://doi.org/10.1080/03602559.2016.1185619.

(134) Cakić, S. M.; Ristić, I. S.; Stojiljković, D. T.; Nikolić, N. N.; Todorović, B. Ž.; RadosavljevićStevanović, N. V. Effect of the Silica Nanofiller on the Properties of Castor Oil-Based Waterborne Polyurethane Hybrid Dispersions Based on Recycled PET Waste. Polym. Bull. 2019, 76 (3), 1217-1238. https://doi.org/10.1007/s00289-018-2429-4.

(135) Pawar, S. S.; Baloji Naik, R.; Rath, S. K.; Mahato, T. K.; Kandasubramanian, B. Photoinduced Hydrophilicity and Self-Cleaning Characteristics of Silicone-Modified Soya Alkyd/TiO2 Nanocomposite Coating. Journal of Coatings Technology and Research 2019. https://doi.org/10.1007/s11998-019-00253-y.

(136) Lu, Y.; Larock, R. C. Soybean Oil-Based, Aqueous Cationic Polyurethane Dispersions: Synthesis and Properties. Progress in Organic Coatings 2010, 69 (1), 31-37. https://doi.org/10.1016/j.porgcoat.2010.04.024.

(137) Gurunathan, T.; Mohanty, S.; Nayak, S. K. Effect of Reactive Organoclay on Physicochemical Properties of Vegetable Oil-Based Waterborne Polyurethane 
Nanocomposites. RSC Adv. 2015, 5 (15), 11524-11533.

https://doi.org/10.1039/C4RA14601H.

(138) Athawale, V. D.; Nimbalkar, R. V. Emulsifyable Air Drying Urethane Alkyds. Progress in Organic Coatings 2010, 67 (1), 66-71.

https://doi.org/10.1016/j.porgcoat.2009.09.017.

(139) Règlement (CE) No 1907/2006 Du Parlement Européen et Du Conseil Du 18 Décembre 2006; Journal officiel de I'Union européenne, 2006; $p$ Annexe XVII.

(140) Haniffa, Mhd. Abd. C. M.; Ching, Y. C.; Chuah, C. H.; Kuan, Y. C.; Liu, D.-S.; Liou, N.-S. Synthesis, Characterization and the Solvent Effects on Interfacial Phenomena of Jatropha Curcas Oil Based Non-Isocyanate Polyurethane. Polymers 2017, 9 (12), 162. https://doi.org/10.3390/polym9050162.

(141) Shen, Z.; Zheng, L.; Li, C.; Liu, G.; Xiao, Y.; Wu, S.; Liu, J.; Zhang, B. A Comparison of Non-Isocyanate and HDI-Based Poly(Ether Urethane): Structure and Properties. Polymer 2019, 175, 186-194. https://doi.org/10.1016/j.polymer.2019.05.010.

(142) Kébir, N.; Nouigues, S.; Moranne, P.; Burel, F. Nonisocyanate Thermoplastic Polyurethane Elastomers Based on Poly(Ethylene Glycol) Prepared through the Transurethanization Approach. J. Appl. Polym. Sci. 2017, 134 (45), 44991. https://doi.org/10.1002/app.44991.

(143) Duval, C.; Kébir, N.; Charvet, A.; Martin, A.; Burel, F. Synthesis and Properties of Renewable Nonisocyanate Polyurethanes (NIPUs) from Dimethylcarbonate. J. Polym. Sci. Part A: Polym. Chem. 2015, 53 (11), 1351-1359. https://doi.org/10.1002/pola.27568.

(144) Blattmann, H.; Fleischer, M.; Bähr, M.; Mülhaupt, R. Isocyanate- and Phosgene-Free Routes to Polyfunctional Cyclic Carbonates and Green Polyurethanes by Fixation of Carbon Dioxide. Macromol. Rapid Commun. 2014, 35 (14), 1238-1254. https://doi.org/10.1002/marc.201400209.

(145) Liu, G.; Wu, G.; Chen, J.; Kong, Z. Synthesis, Modification and Properties of RosinBased Non-Isocyanate Polyurethanes Coatings. Progress in Organic Coatings 2016, 101, 461-467. https://doi.org/10.1016/j.porgcoat.2016.09.019.

(146) Maisonneuve, L.; Lamarzelle, O.; Rix, E.; Grau, E.; Cramail, H. Isocyanate-Free Routes to Polyurethanes and Poly(Hydroxy Urethane)s. Chem. Rev. 2015, 115 (22), 1240712439. https://doi.org/10.1021/acs.chemrev.5b00355.

(147) Cornille, A.; Auvergne, R.; Figovsky, O.; Boutevin, B.; Caillol, S. A Perspective Approach to Sustainable Routes for Non-Isocyanate Polyurethanes. European Polymer Journal 2017, 87, 535-552. https://doi.org/10.1016/j.eurpolymj.2016.11.027.

(148) Carré, C.; Ecochard, Y.; Caillol, S.; Avérous, L. From the Synthesis of Biobased Cyclic Carbonate to Polyhydroxyurethanes: A Promising Route towards Renewable Non-Isocyanate Polyurethanes. ChemSusChem 2019, 12 (15), 3410-3430. https://doi.org/10.1002/cssc.201900737.

(149) Silbert, S. D.; Serum, E. M.; LaScala, J.; Sibi, M. P.; Webster, D. C. Biobased, Nonisocyanate, 2K Polyurethane Coatings Produced from Polycarbamate and Dialdehyde Cross-Linking. ACS Sustainable Chemistry \& Engineering 2019, 7 (24), 19621-19630. https://doi.org/10.1021/acssuschemeng.9b04713.

(150) Anderson, J. R.; Argyropoulos, J. N.; Bhattacharjee, D.; Foley, P.; Spilman, G. E.; Zhang, H. AMIBIENT TEMPERATURE CURABLE ISOCYANATE-FREE COMPOSITIONS FOR PREPARING CROSSLINKED POLYURETHANES. US8,653,174. 
(151) Murillo, E. A. Waterborne Star-shaped Styrene-alkyd Resins. Journal of Applied Polymer Science 2019, 48386. https://doi.org/10.1002/app.48386.

(152) Easton, T.; Poultney, S. Waterborne Silicone-Organic Hybrid Coatings for Exterior Applications. Journal of Coatings Technology and Research 2007, 4 (2), 187-190. https://doi.org/10.1007/s11998-007-9018-z.

(153) Eckhoff, P. S. COMPOSITION PROCESS FOR AQUEOUS BASE COATINGS FOR CORRODIBLE METALS. US4,108,811.

(154) Fong, J. J. WATERBORNEMALEINIZED POLYBUTADENE EMULSION COATING COMPOSITION. US5,552,228.

(155) Wei, D.; Liao, B.; Yong, Q.; Wang, H.; Li, T.; Huang, J.; Pang, H. Castor Oil-Based Waterborne Hyperbranched Polyurethane Acrylate Emulsion for UV-Curable Coatings with Excellent Chemical Resistance and High Hardness. J Coat Technol Res 2019, 16 (2), 415-428. https://doi.org/10.1007/s11998-018-0120-1.

(156) Gurunathan, T.; Arukula, R.; Suk Chung, J.; Rao, C. R. K. Development of Environmental Friendly Castor Oil-Based Waterborne Polyurethane Dispersions with Polyaniline: Castor Oil-Based Waterborne Polyurethane Dispersions with Polyaniline. Polym. Adv. Technol. 2016, 27 (11), 1535-1540. https://doi.org/10.1002/pat.3797.

(157) Shahabudin, N.; Yahya, R.; Gan, S. Microcapsules Filled with a Palm Oil-Based Alkyd as Healing Agent for Epoxy Matrix. Polymers 2016, 8 (4), 125. https://doi.org/10.3390/polym8040125.

(158) Kurt Çömlekçi, G.; Ulutan, S. Encapsulation of Linseed Oil and Linseed Oil Based Alkyd Resin by Urea Formaldehyde Shell for Self-Healing Systems. Progress in Organic Coatings 2018, 121, 190-200. https://doi.org/10.1016/j.porgcoat.2018.04.027.

(159) Shahabudin, N.; Yahya, R.; Gan, S. N.; Sonsudin, F. Curing of Epoxy/Alkyd Blends in Self-Healing Coating. High Performance Polymers 2018, 30 (8), 1009-1015. https://doi.org/10.1177/0954008318784635.

(160) Kurt Çömlekçi, G.; Ulutan, S. Acquired Self-Healing Ability of an Epoxy Coating through Microcapsules Having Linseed Oil and Its Alkyd. Progress in Organic Coatings 2019, 129, 292-299. https://doi.org/10.1016/j.porgcoat.2019.01.022.

(161) Tezel, Ö.; Beyler Çiğil, A.; Kahraman, M. V. Encapsulation of Trichloroacetic Acid and Trifluoroacetic Acid for Autonomous Self Healing Coatings. Polymer-Plastics Technology and Materials 2020, 1-10. https://doi.org/10.1080/25740881.2020.1784219.

(162) Liang, H.; Liu, L.; Lu, J.; Chen, M.; Zhang, C. Castor Oil-Based Cationic Waterborne Polyurethane Dispersions: Storage Stability, Thermo-Physical Properties and Antibacterial Properties. Industrial Crops and Products 2018, 117, 169-178. https://doi.org/10.1016/j.indcrop.2018.02.084.

(163) Carraturo, F.; Del Giudice, C.; Morelli, M.; Cerullo, V.; Libralato, G.; Galdiero, E.; Guida, M. Persistence of SARS-CoV-2 in the Environment and COVID-19 Transmission Risk from Environmental Matrices and Surfaces. Environmental Pollution 2020, 265, 115010. https://doi.org/10.1016/j.envpol.2020.115010. 